IN -1443

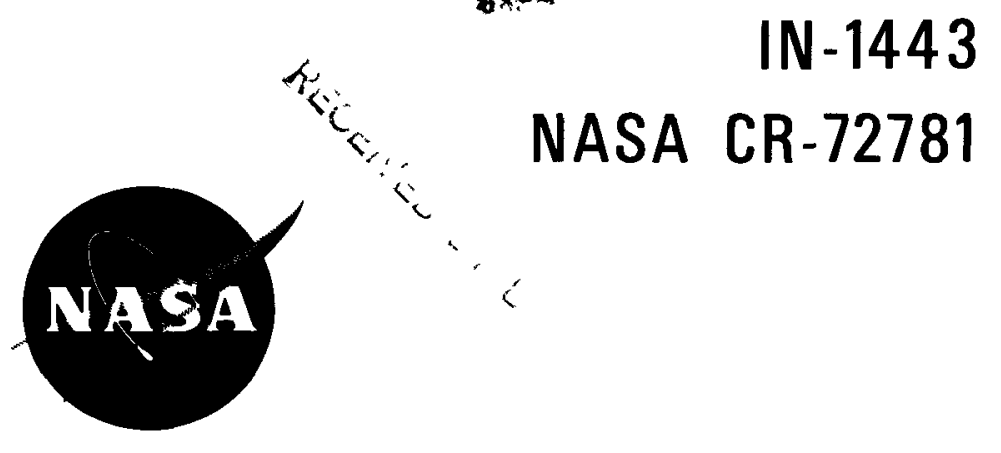

\title{
SPHERICAL GAS CORE REACTOR CRITICAL EXPERIMENT
}

J. H. Lofthouse and J. F. Kunze

Prepared for

NATIONAL AERONAUTICS AND SPACE ADMINISTRATION

Contract C-67747-A

Date Published-February 1971

\section{IDAHO NUCLEAR CORPORATION}

National Reactor Testing Station

Idaho Falls, Idaho 


\section{DISCLAIMER}

This report was prepared as an account of work sponsored by an agency of the United States Government. Neither the United States Government nor any agency Thereof, nor any of their employees, makes any warranty, express or implied, or assumes any legal liability or responsibility for the accuracy, completeness, or usefulness of any information, apparatus, product, or process disclosed, or represents that its use would not infringe privately owned rights. Reference herein to any specific commercial product, process, or service by trade name, trademark, manufacturer, or otherwise does not necessarily constitute or imply its endorsement, recommendation, or favoring by the United States Government or any agency thereof. The views and opinions of authors expressed herein do not necessarily state or reflect those of the United States Government or any agency thereof. 


\section{DISCLAIMER}

Portions of this document may be illegible in electronic image products. Images are produced from the best available original document. 


\section{LEGAL NOTICE}

This report was prepared as an account of work sponsored by the United States Government. Neither the United States nor the United States Atomic Energy Commission, nor any of their employess, nor any of their contractors. subcontractors, or their employees, makes any warranty, express or implied, or assumes any legal liability or responsibility for the accuracy, completeness or usefulness of any information, apparatus, product or process disclosed, or represents that its use would not infinge privately owned rights. 
$S P H E R I C A I$ G A S COREREACTOR

C R I T I A I EXPERIMEN T

by

J. H. Iofthouse and J. F. Kunze

Prepared for

NATIONAI AERONAUTICS AND SPACE ADMINISTRATION

Contract $\mathrm{C}-67747-\mathrm{A}$

Technical Management

INASA-Lewis Research Center

Cleveland, Ohio

Nuclear Systems Division

Robert E. Hyland, Project Manager

Space Nuclear Propulsion Office

Capt. C. E. Franklin, USAF

\section{IDAHO NUCLEAR CORPORATION}

A Jointly Owned Subsidiary of

AEROIET GENERAL CORPORATION

ALLIEO CHEMICAL CORPORATION

PHILLIPS PETROLEUM COMPANY

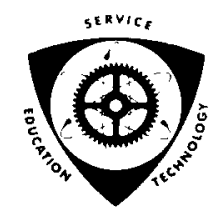

Date Published - February 1971

PREPARED FOR THE U.S. ATOMIC ENERGY COMMISSION

IDAHO OPERATIONS OFFICE

UNDER CONTRACT NO. AT $(10-1)-1230$ 


\section{ADDENDA TO IN-1443 (NASA CR-72781) \\ SPHERICAL GAS CORE REACTOR CRITICAL EXPERIMENT}

Page 71 - The following references should be included:

18. Persona1 Communication - Dale A. Pearson, Idaho Nuclear Corporation, 1970.

19. Greer, C. R., Halble1b, J. A., and Wal.ker, J. V. "A Technique for Unfolding Neutron Spectra from Activation Measurements" SC-RR-67-746, December 1967. 
Criticality experiments using gaseous fuel are reported on. The experiments were relatively "clean" and should serve as benchmarks for calculational purposes. The inner spherical gaseous fuel region ( $127 \mathrm{~cm}$ dia) was located in a $183 \mathrm{~cm}$ diameter cavity surrounded by $91 \mathrm{~cm}$ of commercial grade heavy water. The critical mass was $8.4 \mathrm{~kg}$ of uranium in gaseous $\mathrm{UF}_{6}$ form. The second configuration had hydrogen added between the fuel and the cavity wall. The third added structural material to the cavity wall. The critical mass increased to $12.86 \mathrm{~kg}$ and $29.2 \mathrm{~kg}$ of uranium, respectively. Four methods of controlling reactivity were examined. Results were favorable, with total control system worths as high as 18 dollars.

\section{ACKNOWLEDGEMENTS}

The authors wish to acknowledge the efforts of C. G. Cooper, R. R. Jones, and D. H. Suckling in the operation of the experiment, and of Mrs. P. I. Chase in assisting with data reduction and report preparation. Also, credit is given to D. A. Pearson for his contribution of the neutron spectrum measurements. 


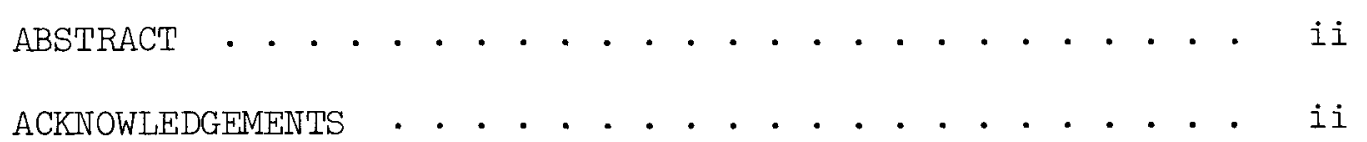

I.0 SUMMARY . . . . . . . . . . . . . . . . . . . 1

2.0 INTRODUCTION . . . . . . . . . . . . . . . 2

3.0 DESCRIPTION OF THE TEST ASSEMBLY AND TEST PROCEDURES 3

3.1 Test Assembly . . . . . . . . . . . 3

3.2 Fuel Transfer and Core Heating System . . . 4

3.3 Test Procedures . . . . . . . . . . . 4

4.0 CONFIGURATION \#I (Initial Configuration) . . . . . 12

4.1 Initial Fuel Loading . . . . . . . . . 12

4.2 Reactivity Measurements . . . . . . . . . 12

4.2.1 Control Rod Worth Measurements . . . . . . 12

4.2.2 Material Reactivity Worth Measurements . . . 13

4.3 Power and Flux Distribution Measurements . . 14

4.3.1 Catcher Foil Data . . . . . . . . . 14

4.3.2 Resonance Foil Detector Data - Gold, Indium

and Manganese . . . . . . . . . . 15

5.0 Configuration \#2 (Hydrogen Propellent Mockup in
Cavity Region) . . . . . . . . . . . 28

5.1 Fuel and Coolant Mockup Reactivity Worths . . 28

5.2 Power and Flux Distribution Measurements . . 29

6.0 CONFIGURATION \#3 (Stainless Steel Cavity Liner) . . 35

6.I Reactivity and Material Worth Measurements. . . 35

6.2 Power and Flux Distribution Measurements . . . 36

6.2.1 Catcher Foil Data ............. . 36

6.2.2 Resonance Foil Detector Data - Gold,

Indium and Manganese . . . . . . . 36 
7.0 CONTROL SYSTEMS EVALUATIONS . . . . . . . . . 47

7.1 Designs . . . . . . . . . . . 47

7.2 Measurement Method . . . . . . . 47

7.3 Results of Pulsed Neutron Data . . . . . 48

8.0 ANALYTICAL CALCULATIONS . . . . . . . . . 54

9.0 DISUCSSION OF EXPERIMENT AND RESULTS . • • • • • 57

10.0 CONCLUSIONS AND RECOMMENDATIONS . . . . . . . 67

APPENDIX A ....................... 68

REFERENCES . . . . . . . . . . . . . . . . . . 70

INDEX .. . . . . . . . . . . . . . 72 
3.1 Spherical Cavity Reactor Configuration Code . . . . . 6

3.2 Reactor Component Description. . . . . . . . . 7

3.3 Effective Delayed Neutron Parameters . . . . . . 9

4.1 Nuclear Model of Gas Core Experiment . . . . . . . . 16

4.2 Initial Loading - Inverse Multiplication . . . . . . 17

4.3 Control Rod Worth Measurements . . . . . . . . . 19

4.4 Catcher Foil Cadmium Ratio - Configuration \#I . . . . 20

4.5 Infinitely Dilute Gold Foil Cadmium Ratios and

Thermal Flux - Configuration \#1 . . . . . . . . 21

4.6 Infinitely Dilute Indium Foil Cadmium Ratios and

Thermal Flux - Configuration \#1 . . . . . . . . . 22

4.7 Infinitely Dilute Manganese Foil Cadmium Ratios and

Thermal Flux - Configuration \#1 . . . . . . . . . 22

5.1 Catcher Foil Cadmium Ratio - Configuration \#2 . . . . 30

5.2 Infinitely Dilute Gold Foil Cadmium Ratios and

Thermal Flux - Configuration \#2 . . . . . . . . . 31

6.1 Catcher Foil Cadmium Ratio - Configuration \#3 ..... 38

6.2 Infinitely Dilute Gold Foil Cadmium Ratios and Thermal Flux - Configuration \#3 ......... . 39

6.3 Infinitely Dilute Indium Foil Cadmium Ratios and Thermal Flux - Configuration $\# 3$. . . . . . . . . 40

6.4 Infinitely Dilute Manganese Foil Cadmium Ratios and Thermal Flux - Configuration \#3 .......... . 41

7.1 Decay Constants for Control Systems . . . . . . . 50

8.1 Cross Sections - 19-Energy Group Format . . . . . . . 56

8.2 Calculated Eigenvalues for Three Configurations . . . . 56

9.1 Summary of Critical Masses and Fuel Worth for Three Configurations . . . . . . . . . . . 59 
3.1 Overall diagram of the Spherical Cavity

Reactor Configuration .. . . . . . . . . 10

3.2 Horizontal cross section showing location of sheet metal shrouds . . . . . . . . . . . . . . 11

4.1 Inverse multiplication for initial fuel loading of Configuration \#l . . . . . . . . . . . . . 23

4.2 Control system rod worth curves . . . . . . . . 24

4.3 Relative specific power (U-235 fission rate)

in Configuration \#l . . . . . . . . . . . . . 25

4.4 Radial bare gold activity (d/m/gm-watt)

in Configuration \#l . . . . . . . . . . . . 26

4.5 Radial gold determined thermal flux-Configuration \#1 . 27

5.1 Relative specific power (U-235 fission rate)

in Configuration \#2 . . . . . . . . . . . . 32

5.2 Radial bare gold activity ( $d / m$-gm-watt)

in Configuration \#2 . . . . . . . . . . . . . . 33

5.3 Radial gold determined thermal flux-Configuration \#2 . 34

6.1 Fuel worth vs core loading . . . . . . . . . 42

6.2 Relative specific power (U-235 fission rate)

in Configuration $\# 3$. . . . . . . . . . . . 43

6.3 Radial bare gold activity (d/m-gm-watt)

in Configuration \#3 . . . . . . . . . . . . 44

6.4 Radial gold determined thermal flux

in Configuration \#3 . . . . . . . . . . . . 45

6.5 Neutron spectrum determined from multiple

foils activation ............. . 46

7.1 Control Schemes . . . . . . . . . . . . 51

7.2 Typical detector response plot (all control rods in) . 52

7.3 Control worth shape curves . . . . . . . . . 53 
9.1 Reactivity changes during heatup and cooldown . . . 60

9.2 Comparison of fuel worth vs fuel loading for two configurations ............. 61

9.3 Comparison of relative radial fission rate for three spherical cavity reactor configurations . . . 62

9.4 Thermal neutron flux determined from bare and cadmium covered gold foils in the sensor well for three configurations ............. 63

9.5 Comparison of neutron spectra calculated from multiple foil exposure and calculated with $\mathrm{S}_{4}$, 19 energy group transport theory (SCAMP code) at a radial distance of $0.0 \mathrm{~cm}$. ................ 64

9.6 Comparison of neutron spectra calculated from multiple foil exposure and calculated with $\mathrm{S}_{4}, 19$ energy group, transport theory (SCAMP code) at a radial distance of $61.0 \mathrm{~cm}$. ............... 65

9.7 Comparison of neutron spectra calculated from multiple foil exposure and calculated with $S_{4}, 19$ energy group transport theory (SCAMP code) at a radial distance of $105.0 \mathrm{~cm}$. . . . . . . . . . . . . 66 
A spherical gas core critical experiment was conducted in order to provide benchmark results for the cold conditions of a typical nuclear rocket concept. This experiment had a significant advantage over previously measured configurations -- it was a relatively clean spherical geometry, and thus could be analyzed by one dimensional reactor physics codes. In fact, the perturbations to perfect spherical geometry were experimentally evaluated as being worth less than $3 / 4 \% \Delta \mathrm{k}$, and thus this experiment can serve as a convenient and "simple" benchmark.

The basic reactor dimensions were a core region $127 \mathrm{~cm}$ diameter in a cavity $183 \mathrm{~cm}$ in diameter and reflected by $91.4 \mathrm{~cm}$ of $\mathrm{D}_{2} \mathrm{O}$. Three configurations were measured. The first, with the bare minimum of structure and no hydrogen in the cavity region, had a critical mass of $8.434 \mathrm{~kg}$ of uranium (in the form of $12.52 \mathrm{~kg}$ of $\mathrm{UF}_{6}$ ). When $1 \times 10^{21}$ atoms $/ \mathrm{cc}$ of hydrogen were added to the cavity region between the core and reflector, the critical mass increased to $12.86 \mathrm{~kg}$ of $\mathrm{U}$. When the cavity wall was made nuclearly thicker by adding 0.019 mean free paths of thermal absorber as $0.076 \mathrm{~cm}$ of stainless steel, the critical mass increased to $29.2 \mathrm{~kg}$ of $\mathrm{U}$.

Efforts were made to correlate these clean (without control systems) spherical experiments using $S_{4}$ transport theory with 19 energy groups (seven of which were thermal). In these initial efforts, the absolute multiplication factor was calculated to be approximately 1.04 , $3 \% \Delta \mathrm{k}$ higher than the corrected experimental value. The worth of the added stainless steel absorber on the cavity wall was predicted to within approximately 3\%. However, the worth of adding hydrogen to the cavity was underpredicted by approximately 50\%. The reason for this discrepancy and of the $3 \% \Delta \mathrm{k}$ over prediction of the basic eigenvalue has not been resolved.

The commonly proposed methods of controlling this type of reactor is to have movable poison absorber devices in the reflector. Four such control schemes were measured using the pulsed neutron generator technique. Rotating drums, caps that fit against the cavity wall, and a sleeve that slides down over the cavity wall all yielded very large swings in reactivity. These three methods all were worth more than the 23 control rods of the operating control system of the critical experiment. Total control system worths exceeding $10 \% \Delta \mathrm{k}$ can easily be designed for a gas core system of this type.

$\begin{array}{lr}23 \text { Control Rods } & \text { Total Worth } \% \Delta \mathrm{k} / \mathrm{k} \\ 1 \text { Control Drum } & (3.8 \pm 0.4) \\ 1 \text { Cap } & (3.9 \pm 0.3) \\ \text { I Sleeve } & (17 \pm 4.5) \\ \text { (Note: One dollar }=0.788 \% \Delta \mathrm{k})\end{array}$

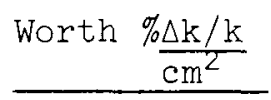

$1.44 \times 10^{-3}$

$1.58 \times 10^{-3}$

$.96 \times 10^{-3}$

The concluding reactor run for this series of tests was made at a power of 500 watts for 2 hours duration. IJuclear heating was sufficient to maintain the core temperature above $210^{\circ} \mathrm{F}$ and the external electrical heaters normally used to maintain the UF6 core in the vapor state could be turned off. 
Over the past several years a continuing series of reactor critical experiments have been performed on a nuclear mockup of a Gas Core Cavity Reactor ( $r e f .1,2,3,4,5$ ) that shows promise for space propulsion applications. The work is sponsored by the National Aeronautics and Space Administration, Lewis Research Center and was performed at the Low Power Test Facility at the National Reactor Testing Station in Idaho. All of the initial work in the above references was done on a cylindrical configuration. Analytical correlation of the test results was difficult and not very extensive because of the exceedingly long convergence time (ref. 6) required for either transport or Monte Carlo solutions in two dimensions. This, together with the results from recent flowing gas tests (ref. 7) showing that a spherical shaped cavity can give large fluid dynamic containment of the gaseous fuel, provided the basis for the spherically shaped experiments.

During the latter half of 1969 a spherical geometry Cavity Reactor Mockup was constructed and nuclear testing with a highly enriched ${ }^{23}{ }^{\mathrm{UF}} 6$ core commenced. This document contains the test data and summarizes the results from the experiment.

Following the initial fuel loading to criticality three configurations were tested.

Configuration \#I - clean spherical geometry (except for necessary structural material)

Configuration $\# 2-1 \times 10^{21}$ atoms/ce hydrogen in the form of styrafoam added to the cavity propellant region, (region between the UF6 sphere wall and the cavity wall).

Configuration \#3 - same as Configuration \#2 except 0.019 mean free paths of thermal absorber material in the form of stainless steel added to the cavity wall.

Throughout this report these three configurations will be referred to as the bare, hydrogen, and stainless steel configurations, respectively. 
3.0 DESCRIPTION OF THE TEST ASSEMBLY AND TEST PROCEDURES

3.1 Test Assembly

Figure 3.1 and Table 3.1 show the arrangement of the reactor system. The salient components are labeled and Table 3.2 lists the important component dimensions, weights when known, and construction materials.

Concentric spheres, $127.6 \mathrm{~cm} 0$. . and $183.1 \mathrm{~cm}$ o.d., respectively with $0.635 \mathrm{~cm}$ thick walls nominal, form the core tank and cavity wall. The cavity wall sphere composed of two halves is held together with a stainless steel V-band and O-ring seal arrangement. Removal of the top hemisphere allows access to the cavity region for installation of test material. The cavity wall is also the inner containment for the surrounding heavy water reflector-moderator of the system.

The outer containment wall of the reflector-moderator is a tank which provides a minimum $\mathrm{D}_{2} \mathrm{O}$ thickness of $91.41 \mathrm{~cm}$ ( 3 feet). This tank consists of a cylindrical section, $365.8 \mathrm{~cm}$ (12 feet) in diameter by $152.4 \mathrm{~cm}$ ( 5 feet) in height. Truncated conical top and bottom sections are $106.7 \mathrm{~cm}$ ( 3.5 feet) in height and the top and bottom plates forming the ends are $152.4 \mathrm{~cm}$ ( 5 feet) in diameter. The tank would thus appear as an octagon in an elevation view and circular in the plan view. A portion of the top conical section is a removable lid of sufficient diameter to allow installation and maintenance of the cavity and core spheres. Control rod guide tubes (3/4-inch schedule 40 pipe) extend into the $\mathrm{D}_{2} \mathrm{O}$ a distance of $86.5 \mathrm{~cm}$ from reinforcing plates welded to the side of the tank. In addition, a 2-inch schedule 40 pipe extends up from the cavity sphere and serves as a sensor access well to the cavity region and core.

The cavity sphere is supported on an 8-inch schedule 40 pipe $(0 . \mathrm{d} .=21.91 \mathrm{~cm})$. The core sphere is on a concentric 5-inch schedule 40 pipe with a series of holes through the wall near the core tank. The annuli formed by these two columns along with two concentric sheet metal shrouds surrounding the core sphere provide inlet and outlet channels for a forced air heating system to maintain the $\mathrm{UF}_{6}$ fuel in the gaseous state. Figure 3.2 shows a horizontal cross section diagram across the core and cavity with nominal dimensions and shroud spacing. A l-inch schedule 40 pipe leading from the fuel transfer and heating system up through the core support column to the core tank provides a means of transferring fuel into and out of the reactor.

Control is achieved with eight shim scram actuators, located and equally spaced circumferentially, at the reactor midplane. Each actuator, with the exception of one, drives a gang of three poison tips in the control rod guide tubes. One guide tube was used as an additional sensor well during power and flux measurements. Thus the regular control system consisted of 23 poison tips. 
3.2 Fuel Transfer and Core Heating System

At the start of a normal operation the core tank containing UF6 is heated to vaporize the fuel by drawing air over electrical heaters, through a metal "hot box" and associated ducting leading to the core support column. The hot air then passes up the support column, through some holes through the wall near the top, and out into an annulus formed by the core tank and a thin aluminum shroud open at the top as shown in Figure 3.1. A second, outer, concentric shroud guides the outlet air back to an annulus formed by the core support column and the cavity sphere support column hence out through the exit ducting, which is concentric with the inlet ducting part of the way, to a filter and blower which exhausts the air.

Fuel is transferred to the core tank, from a UF6 shipping cylinder heated by the hot air in the "hot box" through a l-inch schedule 40 pipe which is concentric with the inlet air ducting and core support column. A sleeve type valve on the core support column near the top can be adjusted so that the hot air bypasses the core. Thus the core tank can be maintained at a temperature sufficiently low to allow condensation of the UF 6 vapor being fed into it from the heated cylinder and transfer line with their associated valving.

\subsection{Test Procedures}

The principal measurements made on these critical experiments were reactivity, power distributions and flux distribution. The achieving of criticality is considered to be only an intermediate step, and though subcritical data can yield information on reactivity, those results are usually less reliable than the measurements made from the critical configuration. When feasible, the measurements were made with the control rods nearly fully withdrawn so as to limit the amount of perturbation of the reflector flux caused by the control rods.

Reactivity measurements were made using the delayed neutron parameters, either by means of asymptotic positive period measurements and the inhour equation or by means of the inverse kinetics method of computing reactivity from a flux trace. Base conditions were established by measuring the asymptotic period rather than by establishing a level power position. The long-lived $(\gamma-n)$ reactions in the $\mathrm{D}_{2} \mathrm{O}$ created a strong enough spurious neutron source that level power conditions were always subcritical, and by differing amounts depending on the past operating history and hence the strength of the source. Period measurements could be made over several decades, thus making possible a reliable extrapolation to the asymptotic, no-source value. The relatively small integrated power of a period measurement also minimized the spurious $(\gamma-n)$ source buildup. The delayed neutron parameters used for this reactor are given in Table 3.3, and include eight groups of neutrons from $(\gamma-n)$ reactiors in the heavy water. The total delayed fraction (one dollar) was $0.788 \%^{*}$.

* This value of $0.788 \%$ includes corrections for differences in importance of the delayed and prompt neutrons. Commonly called the effective $\beta$, this value is slightly higher than the direct $\beta$ because the delayed neutrons are born at a much lower energy. 
All results are reported in $\% \mathrm{k}$ instead of dollars and cents. Without considering uncertainties in the delayed neutron fraction, most period measurements of reactivity have associated with them an uncertainty of approximately $\pm 0.0005 \% \Delta \mathrm{k}$. Day-to-day reactivity measurements (at the same average core temperature and constant $\mathrm{D}_{2} \mathrm{O}$ reflector temperature) were reproducible to within $\pm 0.0015 \% \mathrm{k}$. Reactivity coefficient measurements made all in the same day (sample vs base) have an approximate uncertainty of no more than $\pm 0.001 \% \mathrm{dk}$.

The temperature coefficient of the core, once all the fuel was vaporized, was too small to be measured over a span of approximately $7^{\circ} \mathrm{F}$ in the neighborhood of $210^{\circ} \mathrm{F}$ - i.e. the temperature coefficient was probably less than $0.0015 \% \mathrm{k}$ per $7^{\circ} \mathrm{F}$. The reflector temperature coefficient was not measured in this experiment because there was no provision for heating or controlling the temperature of the $\mathrm{D}_{2} \mathrm{O}$. However, on an earlier cylindrical configuration (Ref. I, p.172 and 181), the temperature coefficient of the $\mathrm{D}_{2} \mathrm{O}$ reflector-moderator was found to be quite significant, approximately $-0.014 \% \mathrm{\Delta k} /{ }^{\circ} \mathrm{C}$ in the region of $30^{\circ} \mathrm{C}$. Similar values would be expected for this spherical configuration. Day-to-day variations of $\mathrm{D}_{2} \mathrm{O}$ temperature were less than $1 / 2^{\circ} \mathrm{F}$. From winter to summer the $\mathrm{D}_{2} \mathrm{O}$ temperature did vary by $11^{\circ} \mathrm{F}$, and thus absolute $\mathrm{k}$-excess values drifted by perhaps as much as $0.08 \% \Delta \mathrm{k}$ between the critical condition measurements on Configuration 1 and 3 , bare and stainless steel, respectively.

In the heating and cooling of the reactor, some unusual effects were observed in reactivity as the fuel was passing to or from the vaporization state. These results are discussed in Section 9.

Power distribution measurements were routinely made using aluminum fission-product-catcher foils on cleaned uranium metal sheet. Reproducibility of results is better than $\pm 2 \%$, and there is no detectable spectral dependence of this technique in the thermal or near thermal range. Decay of the foils was automatically included by counting aII foils vs a normalizer foil from the same exposure. Absolute power levels were determined with a $2 \pi$ beta counter $(3.8 \mathrm{~cm}$ radius chamber) precalibrated with absolute fission chambers and gold foils. This counter (an NMC type PC-3) gives $56 \mathrm{fiss} / \mathrm{gm}$ of U-235 per count per minute 50 minutes after shutdown from a constant 20 minute exposure. Absolute power levels are believed to be accurate to $\pm 3 \%$ standard deviation.

Thermal fluxes are reported as equivalent $2200 \mathrm{~m} / \mathrm{sec}$ fluxes, not as Maxwell-Boltzmann average fluxes. The fluxes were determined by use of bare and cadmium covered gold foils. The gold was nominally $0.0012 \mathrm{~cm}$ thick, with an effective resonance integral of 680 barns (vs 1555 barns infinitely dilute). In computing cadmium ratios, each foil was corrected for its effective resonance integral (ref. 8) by its mass to give the infinitely dilute value. Thermal flux perturbation was negligible, nominally $2 \%$ (ref. 9). The cadmium covers employed were $0.05 \mathrm{~cm}$ thick, giving an effective cadmiuil cutoff energy of 0.55 ev (ref. 10). 
TABLE 3.1

Spherical Cavity Reactor Configuration Code

Code No.

Description

1

2

3

4

5

6

7

8

9

Core sphere tank

Air flow guide baffles

Cavity sphere tank

Stainless steel V-band connector

$\mathrm{D}_{2} \mathrm{O}$ tank

Sensor well

Removable $\mathrm{D}_{2} \mathrm{O}$ tank lid

$\mathrm{D}_{2} \mathrm{O}$ level sensing and fill level limit switches

Typical of 8 symmetrical control rod actuators and support

Control rod poison tip (cluster of three per actuator)

Control rod guide tube

Core tank support column

Cavity tank support column

UF6 fuel line

Cavity tank hold down rod (typical of 8 symmetrical)

Core tank valve

Air operated $\mathrm{D}_{2} \mathrm{O}$ quick durnp valve

Motor operated $\mathrm{D}_{2} \mathrm{O}$ inlet control valve

$\mathrm{D}_{2} \mathrm{O}$ fill line

$\mathrm{D}_{2} \mathrm{O}$ pump

$\mathrm{D}_{2} \mathrm{O}$ overflow and cover gas return line

Main support column

Valve bellows and valve actuating mechanism

$\mathrm{D}_{2} \mathrm{O}$ tank support column

Emergency $\mathrm{D}_{2} \mathrm{O}$ catch tank

Work platform

Fand rail

UF 6 transfer and core heating system

$\mathrm{D}_{2} \mathrm{O}$ storage tank 
TABLE 3.2

Reactor Component Description

\begin{tabular}{|c|c|c|c|c|}
\hline Component & General Description & $\begin{array}{l}\text { Weight } \\
\text { kg }\end{array}$ & Dimensions & Material \\
\hline Core $\operatorname{tank}$ & $\begin{array}{l}\text { Two spun hemispheres welded } \\
\text { together. Designed for } \\
\text { internal pressure of } 50 \text { psig } \\
\text { at } 230^{\circ} \mathrm{F} \text {. }\end{array}$ & 90.72 & $\begin{array}{l}127.55 \mathrm{~cm} \mathrm{O.D.} \\
\times 0.635 \mathrm{~cm} \text { wall } \\
\text { nominal }\end{array}$ & $5052 \mathrm{Al}$ \\
\hline $\begin{array}{l}\text { Core tank sensor } \\
\text { well flange }\end{array}$ & $\begin{array}{l}\text { 2-inch pipe flange and neck } \\
\text { extends above core tank } 12.86 \mathrm{~cm}\end{array}$ & 2 (calc.) & & $6061 \mathrm{Al}$ \\
\hline $\mathrm{UF}_{6}$ inlet line & 1-inch schedule 40 pipe & & $\begin{array}{l}3.34 \mathrm{~cm} \mathrm{O.D.} \\
\times 0.338 \mathrm{~cm} \text { wall }\end{array}$ & $5052 \mathrm{Al}$ \\
\hline $\begin{array}{l}\text { Core tank support } \\
\text { column }\end{array}$ & 5-inch schedule 40 pipe & & $\begin{array}{l}14.12 \mathrm{~cm} \text { wall } \\
\times 0.655 \mathrm{~cm} \text { wall }\end{array}$ & $5052 \mathrm{Al}$ \\
\hline Cavity $\operatorname{tank}$ wall & $\begin{array}{l}\text { Two spun hemispheres held to- } \\
\text { gether with a SS V-band clamp } \\
\text { and sealed with a butyl rubber } \\
\text { o-ring }\end{array}$ & 170.1 & $\begin{array}{l}183.10 \mathrm{~cm} \mathrm{O.D.} \\
x 0.635 \mathrm{~cm} \text { wall } \\
\text { nominal }\end{array}$ & $5052 \mathrm{Al}$ \\
\hline $\begin{array}{l}\text { Cavity tank } \\
\text { support column }\end{array}$ & 8-inch schedule 40 pipe & & $\begin{array}{l}21.9 \mathrm{~cm} \text { O.D. } \\
\times 0.818 \mathrm{~cm} \text { wall }\end{array}$ & $5052 \mathrm{Al}$ \\
\hline $\begin{array}{l}\mathrm{V} \text { band connecter } \\
\text { and bolts }\end{array}$ & Marmon V-band clamp & 8.62 & & 301 SS \\
\hline $\begin{array}{l}\text { Sensor well } \\
\text { guide tube }\end{array}$ & 2-inch schedule 40 pipe & & & $1100 \mathrm{Al}$ \\
\hline
\end{tabular}


TABLE 3.2

(Continued)

\begin{tabular}{|c|c|c|c|c|}
\hline Component & General Description & $\begin{array}{l}\text { Weight } \\
\mathrm{kg}\end{array}$ & Dimensions & Material \\
\hline $\begin{array}{l}\text { Control rod } \\
\text { guide tubes }\end{array}$ & $\begin{array}{l}3 / 4-\text { inch schedule } 40 \text { pipe } \\
\text { sealed at one end with welded } \\
\text { flat plate }\end{array}$ & & & $5086 \mathrm{Al}$ \\
\hline $\begin{array}{l}\text { Control rod guide } \\
\text { tube end spacers }\end{array}$ & $\begin{array}{l}\text { Triangular piece - one on the end } \\
\text { of each gang of } 3 \text { guide tubes }\end{array}$ & .325 ea. & & $1100 \mathrm{Al}$ \\
\hline $\begin{array}{l}\text { Startup neutron } \\
\text { source guide tube }\end{array}$ & $\begin{array}{l}\text { I } 1 / 2 \text {-inch schedule } 40 \text { pipe - } \\
\text { penetrates reflector-moderator } \\
\text { tank above midplane and extends } \\
\text { downward at } 30^{\circ} \text { angle to cavity } \\
\text { tank wall near midplane }\end{array}$ & & & $5052 \mathrm{Al}$ \\
\hline $\begin{array}{l}\text { Cavity tank hold } \\
\text { down rods }\end{array}$ & $\begin{array}{l}8-9 / 16-\text { inch diam. rods equally } \\
\text { spaced around periphery of cavity } \\
\text { tank and extending downward to } \\
\text { the floor of the reflector mod- } \\
\text { erator tank }\end{array}$ & & & 6061 Al \\
\hline $\begin{array}{l}\text { Air flow circulation } \\
\text { baffles }\end{array}$ & $\begin{array}{l}2 \text { concentric octagonal spheres with } \\
\text { a transition to cylindrical at the } \\
\text { bottom- constructed from } 20 \text { gauge } \\
\text { aluminum sheet }\end{array}$ & 29.94 & & $1100 \mathrm{Al}$ \\
\hline $\begin{array}{l}\text { Core tank valve } \\
\text { push rod. }\end{array}$ & I/2-inch diameter rod & & & $1100 \mathrm{Al}$ \\
\hline
\end{tabular}

sealed at one end with welded

Triangular piece - one on the end .325 ea.

1 1/2-inch schedule 40 pipe -

penetrates reflector-moderator

tank above midplane and extends

downward at $30^{\circ}$ angle to cavity

tank wall near midplane

spaced around periphery of cavity

the floor of the reflector mod

the reflector mod-

2 concentric octagonal spheres with

transition to cylindrical at the

bottom- constructed from 20 gauge

minum sheet

Weight 
TABLE 3.3

Effective Delayed Neutron Parameters

\begin{tabular}{|c|c|c|}
\hline Group & $\beta_{i}$ & $\lambda_{i}$ \\
\hline 1 & 0.000217 & 0.012400 \\
\hline 2 & 0.001460 & 0.030500 \\
\hline 3 & 0.001315 & 0.111000 \\
\hline 4 & 0.002640 & 0.301000 \\
\hline 5 & 0.000766 & 1.100000 \\
\hline 6 & 0.000280 & 3.000000 \\
\hline 7 & 0.000780 & 0.277000 \\
\hline 8 & 0.000240 & 0.016900 \\
\hline 9 & 0.000084 & 0.004810 \\
\hline 10 & 0.000040 & 0.001500 \\
\hline 11 & 0.000025 & 0.000428 \\
\hline 12 & 0.000028 & 0.000117 \\
\hline 13 & 0.000004 & 0.000044 \\
\hline 14 & 0.000001 & 0.000004 \\
\hline & 0.007652 & \\
\hline
\end{tabular}




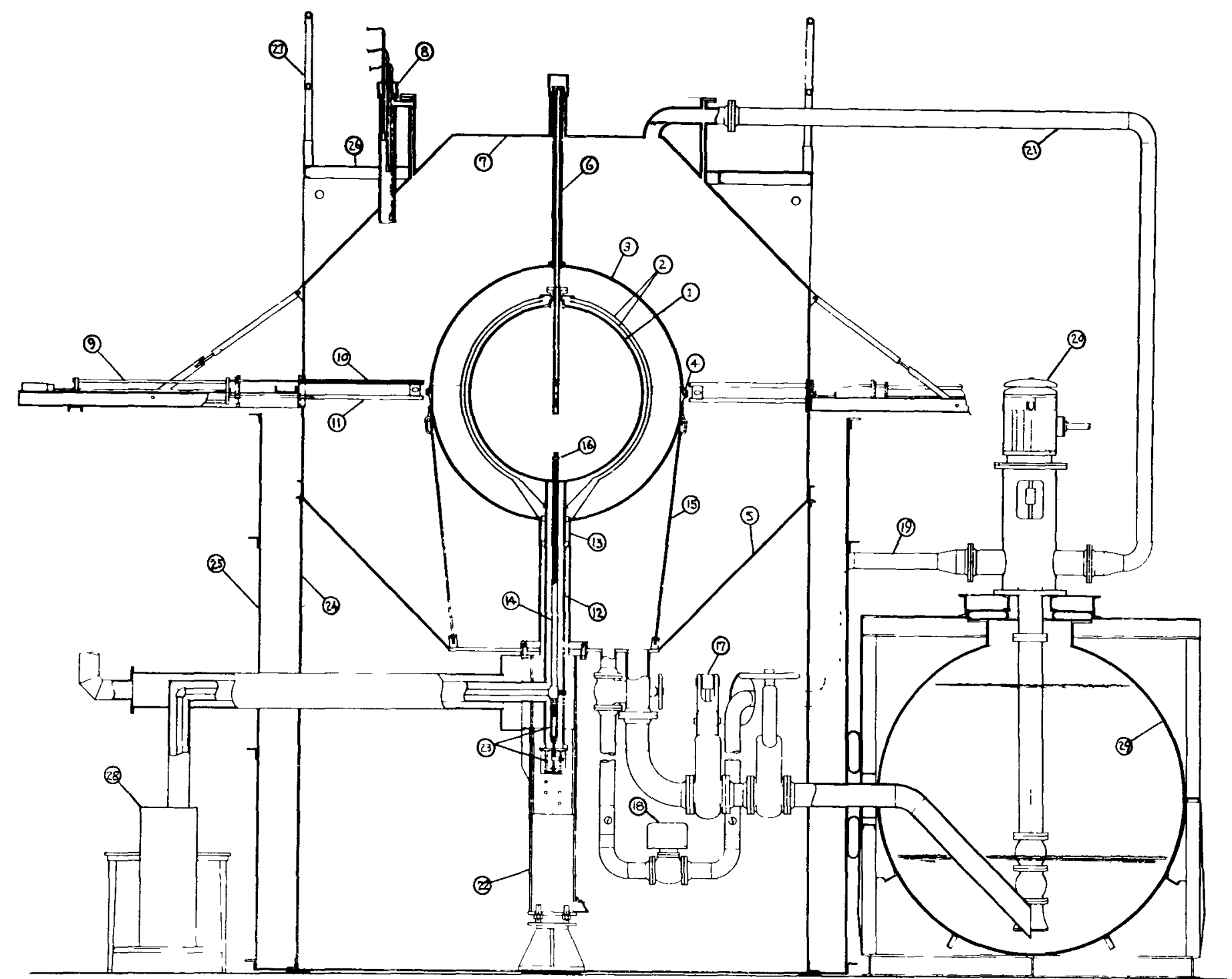

Fig. 3.1 Overall diagram of the Spherical Cavity Reactor Configuration 


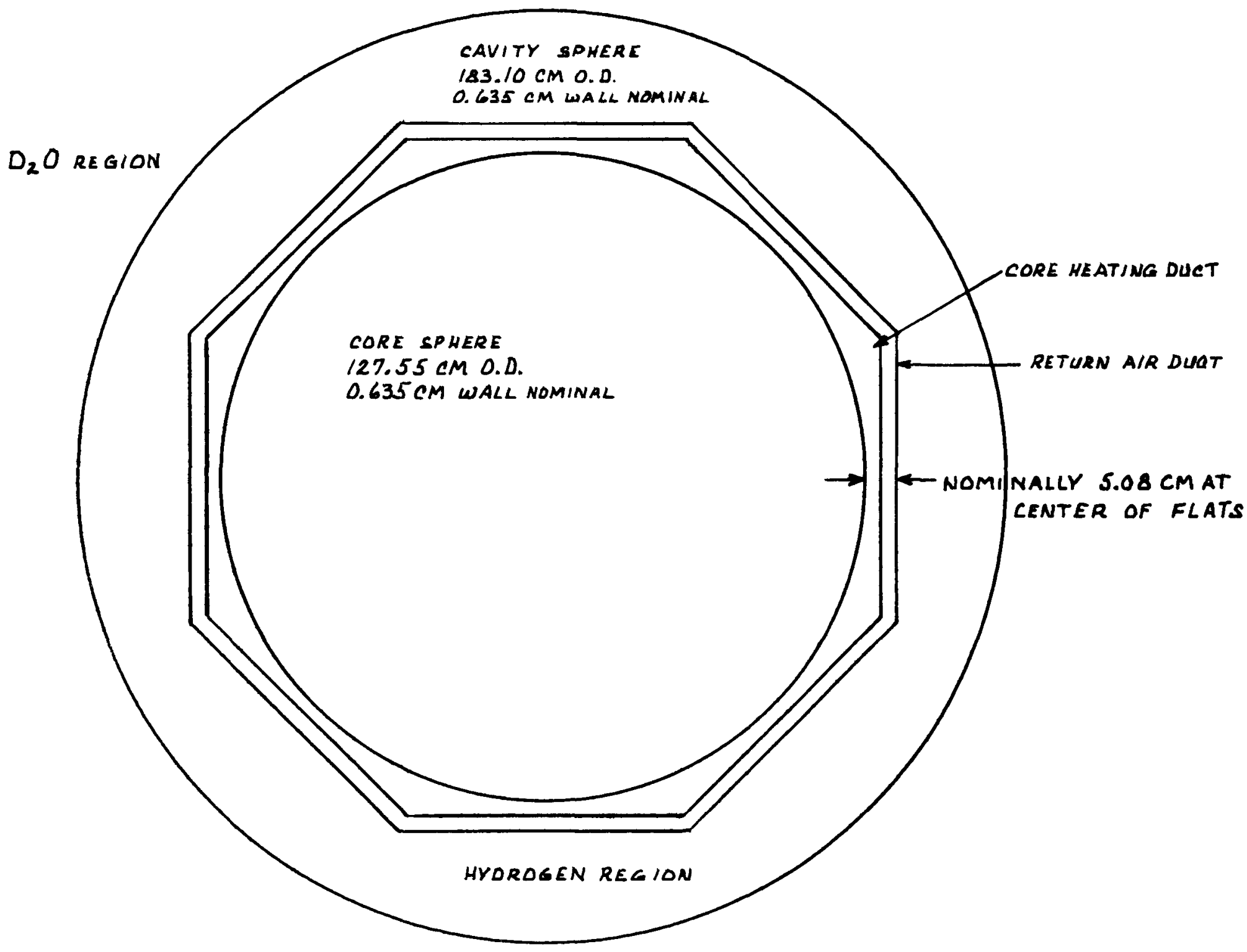

Fig. 3.2 Horizontal cross section showing location of sheet metal shrouds 


\subsection{CONFIGURATION \#1 (Initial Configuration) \\ 4.1 Initial Fuel Ioading}

Initial $\mathrm{UF}_{6}$ transfer to the core tank and the taking of inverse multiplication data began on December 4, 1969. Prior to any actual fuel loading a 19-group transport calculation was performed with the SCAMP (ref. II) Code to estimate the critical mass. The calculation with a slight adjustment from fuel worth measurements made on previous configurations (Figure 3.3, Ref. 3) resulted in calculated critical uranium mass of 8.4 kilograms. The actual adjusted critical loading completed on December 10, 1969, was 8.434 kilograms uranium. The mathematical spherical model used for the calculation is given in Table 4.1.

A normal incremental loading procedure was followed. Three counting channels were used to monitor multiplication. After the tenth increment with a fuel loading of 8.673 kilograms of uranium (12.880 kilograms UF6) the reactor was critical with a k-excess of $0.2404 \% \mathrm{dk} / \mathrm{k}$. Ioading and counting data is given in Table 4.2 and the average inverse multiplication from the three counting channels is plotted in Figure 4.1.

4.2 Reactivity Measurements

4.2.1 Control Rod Worth Measurements

The reactivity worth of two of the eight control rods (actuators 4 and 8 ) was measured by period measurements and the data are tabulated in Table 4.3. In addition, a single rod (actuator 4) and an all rods insertion flux trace was obtained from the critical position, from which the rod worth shape curve was obtained by an inverse kinetics calculation. The rod shape from these calculations along with the points obtained by the period measurements are shown in Figure 4.2. The total rod worth of actuator \#4 by inverse kinetics was $(0.62 \pm 0.04) \% \mathrm{k}$. By period measurement of incremental sections, actuator \#4 is worth $0.585 \% \mathrm{\Delta k} / \mathrm{k}$ and actuator \#8 is worth $0.534 \% \mathrm{\Delta k} / \mathrm{k}$. Actuators 4 and 8 are $180^{\circ}$ apart around the $\mathrm{D}_{2} \mathrm{O}$ tank. When the worth difference was observed from the measurements an inspection of geometry revealed that the cavity sphere is slightly off center (by $\sim 1 \mathrm{~cm}$ ) with respect to the ring of actuators and that the tips of actuator \#4 in the inserted position are slightly closer to the cavity wall than those of actuator \#8, which accounts for the difference in worth.

Fortuitously, these two actuators are located at the points of greatest offset of the cavity sphere, therefore the total control system worth was estimated to be eight times the average worths of actuators \#4 and $\# 8$ or $4.289 \% \mathrm{k} / \mathrm{k}$ (adjusted for one poison tip missing from actuator \#5 where the guide tube was used as a sensor well into the $D_{2} O$ ). This total control system worth is probably slightly high, since it assumes no "shadowing-interaction" of actuator worths. This effect is at most 2 to $3 \%$ of the total summed worth, which was the limiting accuracy of the measurements that attempted to evaluate the interaction effects. 


\subsubsection{Material Reactivity Worth Measurements}

Fuel worth in the core was determined by adding a $197.67 \mathrm{gm}$ increment of $\mathrm{UF}_{6}$ to the initial fuel loading. $\mathrm{UF}_{6}$ worth is $1.99 \% \mathrm{k} / \mathrm{k}$ per kilogram of the hexafluoride or $2.96 \% \mathrm{dk} / \mathrm{k}$ per kilogram of highly enriched uranium $\left(93.2 \% \mathrm{U}^{2} 35\right)$ metal.

The functional loss of a valve isolating the core tank from the fuel transfer line made it necessary to make all measurements with fuel in the transfer line. To evaluate the worth of fuel in the line, a mockup of the line, through the $\mathrm{D}_{2} \mathrm{O}$ and cavity, was constructed by wrapping sheet fuel on an aluminum wand and measuring the worth of the mockup in the sensor well. The 27.5 grams of sheet fuel (oralloy), at evenly spaced intervals along the wand to simulate a uniform radial distribution, was worth $3.833 \% \mathrm{dk} / \mathrm{k}$ on a per kilogram basis.

The results of the two foregoing measurements were used to correct the initial loading for comparison to the clean calculated critical mass value spoken of in 4.1 above.

One additional fuel worth measurement was made in the sensor well with sheet fuel by placing 6.94 grams of oralloy, evenly distributed on a wand over a $22.8 \mathrm{~cm}$ length of the core radius from the center. This fuel was worth $1.50 \% \mathrm{k} / \mathrm{k}$ on a per kilogram basis, and is approxmately a core-center fuel worth.

Stainless steel worth on the cavity wall was evaluated by placing 934 grams ( 4 strips) of type 304 on the $\mathrm{D}_{2} \mathrm{O}$ side of the wall. This measurement yielded a value of $-0.2547 \% \Delta \mathrm{k} / \mathrm{k}$ per kilogram. If this worth is applied to the stainless steel V-band connector holding the two hemispheres of the cavity tank together to create the seal then the reactivity worth of the $V$ band $(8.62 \mathrm{~kg})$ is $-2.20 \% \mathrm{dk} / \mathrm{k}$.

One additional stainless steel measurement was made to evaluate the worth of four stainless steel bolts used to fasten the flange containing the sensor well to the top flange of the core tank. This measurement was made by placing an identical bolt ( 142.2 grams) in the sensor well at the same radial position as the flange bolts. From the measurement the four flange bolts were calculated to be worth $-0.105 \% \mathrm{k} / \mathrm{k}$.

To evaluate the worth of the aluminum in the support columns to the core and cavity tanks and of the void they create through the $\mathrm{D}_{2} \mathrm{O}$ an aluminum mockup tank was constructed. It was installed at the top of the reactor around the sensor well tube through the $\mathrm{D}_{2} \mathrm{O}$. The reactivity worth of this tank was $-0.541 \% \mathrm{dk} / \mathrm{k}$. The worth of a $21.6 \mathrm{~cm}$ (8.5 inches) length of aluminum pipe (5-inch schedule 40) in the void between cavity wall and the outer air baffle around the core tank was worth $-0.0637 \% \mathrm{kk} / \mathrm{k}$. If a linear extrapolation of this worth to a pipe $30.5 \mathrm{~cm}$ in length is made and added to the worth of the mockup in the $\mathrm{D}_{2} \mathrm{O}$ then the worth of the support pipes and the void created in the $\mathrm{D}_{2} \mathrm{O}$ is worth $-0.631 \% \mathrm{dk} / \mathrm{k}$. 
The worth of aluminum on the core tank wall was measured as $-0.0410 \% \Delta \mathrm{k} / \mathrm{k}$ per kilogram by placing 3.36 kilograms of type 1100 aluminum strips between the tank wall and the inner air baffle shroud. This is about double the worth in the cylindrical geometry at edge of core (ref. 3, p. 45).

Using the applicable material worths above applied to the mass of the structural material in the assembly the following reactivity worths were calculated:

$\begin{array}{ll}\text { Al Core wall } & \frac{}{-3.72} \\ \text { Air guide shrouds } & -1.23 \\ \text { * Support columns \& void } & -0.631 \\ \text { *Fuel in transfer line } & +0.033 \\ \text { * SS bolts in core flange } & -0.105 \\ \text { SS V-band connector } & -2.20 \\ \text { Al core flange } & -0.344 \\ \text { Al cavity wall } & -8.36\end{array}$

Those items with an asterisk in front perturb the spherical one-dimensional uniformity of the system and therefore cannot be correctly (and easily) incorporated into a spherical reactor model. The other items in the above list have essentially spherical symmetry and can be included in a calculational model.

In preparation for going to a new configuration with $\mathrm{CH}$ and $\mathrm{CH}_{2}$ in the cavity region to mock up a hydrogen propellent, a cylindrical lump of $193 \mathrm{gms}$ of polyethelene (rolled sheet to form a cylinder $5.1 \mathrm{~cm}$ diameter by $15.24 \mathrm{~cm}$ long) was installed in the sensor well so that it extended from the cavity wall to the core sphere sensor well flange $(0.56$ of the distance between the cavity wall and the outside of the core sphere). The reactivity worth was measured as $-0.140 \% \Delta \mathrm{k} / \mathrm{k}$ per kilogram.

4.3 Power and Flux Distribution Measurements

Power and flux distributions over the radius of the reactor were determined in both the sensor well and a rod guide tube by exposing both bare and cadmium covered catcher foils, gold foils, indium foils and manganese foils. In addition, cadmium ratios and thermal flux were calculated from the data taken at selected points. All cadmium covered foils were enclosed in $0.051 \mathrm{~cm}$ (20 mil) thick buckets. The method used to calculate the infinitely dilute cadmium ratios and thermal flux are given in Appendix 1.

4.3.1 Catcher Foil Data

Catcher foil data are plotted as a fine radial power distribution relative to the power at the core center in Figure 4.3 and the cadmium ratio, which is the ratio of the normalized counts from bare and cadmium covered foils exposed at selected radial positions, are given in Table 4.4. Because of the short range of the fission products in the uranium metal foils, these cadmium ratios are essentially infinitely dilute values. Therefore, they represent the ratio of total to epithermal fission rate. 
4.3.2 Resonance Foil Detector Data - Gold, Indium and Manganese

Figure 4.4 is a plot of radial bare gold activity distribution, of $1.2 \times 10^{-3} \mathrm{~cm}$ thick gold. The actual response of foils of this thickness to thermal and epithermal neutrons can be determined by comparing columns 2 and 4 of Table 4.5. However, for general usefulness, the infinitely dilute response of total to epithermal neutrons is preferred, and this is given in column 6 of that table. Bare and cadmium covered gold, indium and manganese foils were exposed at selected radial locations in both the sensor well and a rod guide tube. The calculated infinitely dilute cadmium ratios and the thermal flux data are shown in Tables 4.5, 4.6 and 4.7. In addition the thermal flux determined from the gold foil activity is plotted in Figure 4.5 . All of the data are normalized to a power of one watt as determined from volume weighted catcher foil activity within the spherical core. 
TABLE 4.1

Nuclear Model of Gas Core Experiment

\begin{tabular}{|c|c|c|c|c|}
\hline Region & $\begin{array}{l}\text { Inner } \\
\text { Radius } \\
(\mathrm{cm})\end{array}$ & $\begin{array}{l}\text { Outer } \\
\text { Radius } \\
(\mathrm{cm})\end{array}$ & Materials & $\begin{array}{r}\text { Mass } \\
(\mathrm{kg}) \\
\end{array}$ \\
\hline Core & 0.0 & 63.138 & $\begin{array}{l}\mathrm{UF} \sigma^{*} \\
\mathrm{Al} \\
\text { (type } 1100 \text { ) }\end{array}$ & $\begin{array}{c}\text { to be determined } \\
0.546\end{array}$ \\
\hline Core tank wall & 63.138 & 63.773 & $\begin{array}{r}\text { AI } \\
\text { (type 5052) }\end{array}$ & 90.72 \\
\hline $\begin{array}{l}\text { "Void" between } \\
\text { core \& reflector }\end{array}$ & 63.773 & 90.92 & $\begin{array}{l}\text { AI } \\
\text { (type 1100) } \\
\text { AI } \\
\text { (type 5052) } \\
\text { SS } \\
\text { (type } 301 \text { ) } \\
\text { UF } 6\end{array}$ & $\begin{array}{l}29.9 \\
8.38 \\
.661 \\
0.17 \% \text { core mass }\end{array}$ \\
\hline Cavity tank wall & 90.92 & 91.555 & $\begin{array}{c}\text { Al } \\
\text { (type 5052) }\end{array}$ & 170.1 \\
\hline $\begin{array}{l}\text { Moderator } \\
\text { Region A } \\
\text { (with V-band } \\
\text { connector) }\end{array}$ & 91.55 & 94.095 & $\begin{array}{l}\text { Al } \\
\text { (type 5052) } \\
\text { SS } \\
\text { (type 301) } \\
\text { Heavy water }\end{array}$ & $\begin{array}{l}1.5 \\
8.6 \\
\text { remainder of volume }\end{array}$ \\
\hline $\begin{array}{l}\text { Moderator } \\
\text { Region B }\end{array}$ & 94.095 & 122.035 & 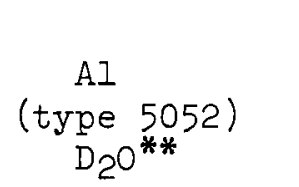 & $\begin{array}{l}\quad 7.71 \\
\text { remainder of volume }\end{array}$ \\
\hline $\begin{array}{l}\text { Moderator } \\
\text { Region C }\end{array}$ & 122.035 & 152.515 & $\begin{array}{l}\mathrm{Al} \\
(\text { type } 5052) \\
\mathrm{D}_{2} \mathrm{O}^{* *}\end{array}$ & $\begin{array}{l}5.11 \\
\text { remainder of volume }\end{array}$ \\
\hline $\begin{array}{l}\text { Moderator } \\
\text { Region D }\end{array}$ & 152.515 & $188.14^{* * *}$ & $\frac{\mathrm{Al}}{\left(\operatorname{type}_{\mathrm{D}_{2}} \mathrm{O}^{* * 52}\right)}$ & $\begin{array}{l}5.11 \\
\text { remainder of volume }\end{array}$ \\
\hline
\end{tabular}

* Isotopic composition is $93.2 \% \mathrm{U}^{235}$

** (Volume fraction of light water $\left(\mathrm{H}_{2} \mathrm{O}\right)$ was $0.0028 \pm 0.0002$ )

*** Equivalent spherical inside radius to match the volume of the outer tank which consists of a cylinder $152.5 \mathrm{~cm}$ high by $366 \mathrm{~cm}$ dia. and two truncated cones, each approximately $117 \mathrm{~cm}$ high by $152 \mathrm{~cm}$ dia. on the small end. 
TABLE 4.2

Initial Ioading

Inverse Multiplication

\begin{tabular}{|c|c|c|c|c|c|c|c|c|c|}
\hline Increment & $\begin{array}{l}\text { Total Fuel } \\
\text { in Core (kg U) }\end{array}$ & $\begin{array}{l}\text { Channe } \\
\text { CPM }\end{array}$ & $\begin{array}{r}\text { I No. I } \\
\text { CRo/CR }\end{array}$ & $\begin{array}{l}\text { Chan } \\
\text { CPM }\end{array}$ & $\begin{array}{r}1 \mathrm{No} \cdot 2 \\
\mathrm{CR}_{0} / \mathrm{CR} \\
\end{array}$ & $\begin{array}{l}\text { Chann } \\
\text { CPM }\end{array}$ & $\begin{array}{r}\text { No. } 3 \\
\mathrm{CR}_{0} / \mathrm{CR} \\
\end{array}$ & Average & $\begin{array}{c}\text { Rod } \\
\text { Positions } \\
\end{array}$ \\
\hline$\left(\begin{array}{c}0 \\
\left(\mathrm{CR}_{0}\right.\end{array}\right)$ & $\begin{array}{l}0 \\
0\end{array}$ & $\begin{array}{l}625 \\
814\end{array}$ & $\begin{array}{l}1.000 \\
1.000\end{array}$ & $\begin{array}{l}661 \\
904\end{array}$ & $\begin{array}{l}1.000 \\
1.000\end{array}$ & $\begin{array}{l}681 \\
889\end{array}$ & $\begin{array}{l}1.000 \\
1.000\end{array}$ & $\begin{array}{l}1.000 \\
1.000\end{array}$ & $\begin{array}{l}\text { In } \\
\text { Out }\end{array}$ \\
\hline $\begin{array}{l}1 \\
1\end{array}$ & $\begin{array}{l}1.50 \\
1.50\end{array}$ & $\begin{array}{l}1140 \\
1561\end{array}$ & $\begin{array}{l}0.548 \\
0.521\end{array}$ & $\begin{array}{l}1171 \\
1700\end{array}$ & $\begin{array}{l}0.565 \\
0.532\end{array}$ & $\begin{array}{r}905 \\
1233\end{array}$ & $\begin{array}{l}0.752 \\
0.721\end{array}$ & $\begin{array}{l}0.622 \\
0.591\end{array}$ & $\begin{array}{l}\text { In } \\
\text { Out }\end{array}$ \\
\hline $\begin{array}{l}2 \\
2\end{array}$ & $\begin{array}{l}2.17 \\
2.17\end{array}$ & $\begin{array}{l}1430 \\
1979\end{array}$ & $\begin{array}{l}0.437 \\
0.411\end{array}$ & $\begin{array}{l}1425 \\
2100\end{array}$ & $\begin{array}{l}0.464 \\
0.430\end{array}$ & $\begin{array}{l}1323 \\
1988\end{array}$ & $\begin{array}{l}0.515 \\
0.447\end{array}$ & $\begin{array}{l}0.472 \\
0.429\end{array}$ & $\begin{array}{l}\text { In } \\
\text { Out }\end{array}$ \\
\hline $\begin{array}{l}3 \\
3\end{array}$ & $\begin{array}{l}3.05 \\
3.05\end{array}$ & $\begin{array}{l}1847 \\
2682\end{array}$ & $\begin{array}{l}0.338 \\
0.304\end{array}$ & $\begin{array}{l}1860 \\
2820\end{array}$ & $\begin{array}{l}0.355 \\
0.321\end{array}$ & $\begin{array}{l}1871 \\
2552\end{array}$ & $\begin{array}{l}0.364 \\
0.348\end{array}$ & $\begin{array}{l}0.352 \\
0.324\end{array}$ & $\begin{array}{l}\text { In } \\
\text { Out }\end{array}$ \\
\hline $\begin{array}{l}4 \\
4\end{array}$ & $\begin{array}{l}4.31 \\
4.31\end{array}$ & $\begin{array}{l}2472 \\
3881\end{array}$ & $\begin{array}{l}0.253 \\
0.210\end{array}$ & $\begin{array}{l}2481 \\
4106\end{array}$ & $\begin{array}{l}0.266 \\
0.220\end{array}$ & $\begin{array}{l}2485 \\
3740\end{array}$ & $\begin{array}{l}0.274 \\
0.238\end{array}$ & $\begin{array}{l}0.264 \\
0.223\end{array}$ & $\begin{array}{l}\text { In } \\
\text { Out }\end{array}$ \\
\hline $\begin{array}{l}5 \\
5\end{array}$ & $\begin{array}{l}5.83 \\
5.83\end{array}$ & $\begin{array}{l}3994 \\
7431\end{array}$ & $\begin{array}{l}0.156 \\
0.110\end{array}$ & $\begin{array}{l}3988 \\
7782\end{array}$ & $\begin{array}{l}0.166 \\
0.166\end{array}$ & $\begin{array}{l}3752 \\
6514\end{array}$ & $\begin{array}{l}0.182 \\
0.136\end{array}$ & $\begin{array}{l}0.168 \\
0.121\end{array}$ & $\begin{array}{l}\text { In } \\
\text { Out }\end{array}$ \\
\hline $\begin{array}{l}6 \\
6\end{array}$ & $\begin{array}{l}6.66 \\
6.66\end{array}$ & $\begin{array}{r}5248 \\
11626\end{array}$ & $\begin{array}{l}0.119 \\
0.070\end{array}$ & $\begin{array}{r}5338 \\
12274\end{array}$ & $\begin{array}{l}0.124 \\
0.074\end{array}$ & $\begin{array}{l}4746 \\
9886\end{array}$ & $\begin{array}{l}0.143 \\
0.090\end{array}$ & $\begin{array}{l}0.127 \\
0.078\end{array}$ & $\begin{array}{l}\text { In } \\
\text { Out }\end{array}$ \\
\hline $\begin{array}{l}7 \\
7\end{array}$ & $\begin{array}{l}7.06 \\
7.06\end{array}$ & $\begin{array}{r}6218 \\
15873\end{array}$ & $\begin{array}{l}0.101 \\
0.051\end{array}$ & $\begin{array}{r}6296 \\
16794\end{array}$ & $\begin{array}{l}0.105 \\
0.054\end{array}$ & $\begin{array}{r}5544 \\
13271\end{array}$ & $\begin{array}{l}0.123 \\
0.067\end{array}$ & $\begin{array}{l}0.110 \\
0.057\end{array}$ & $\begin{array}{l}\text { In } \\
\text { Out }\end{array}$ \\
\hline $\begin{array}{l}8 \\
8\end{array}$ & $\begin{array}{l}8.06 \\
8.06\end{array}$ & $\begin{array}{l}10569 \\
96096\end{array}$ & $\begin{array}{l}0.059 \\
0.0085\end{array}$ & $\begin{array}{r}10573 \\
104749\end{array}$ & $\begin{array}{l}0.063 \\
0.0086\end{array}$ & $\begin{array}{r}9300 \\
76467\end{array}$ & $\begin{array}{l}0.073 \\
0.0116\end{array}$ & $\begin{array}{l}0.065 \\
0.0096\end{array}$ & $\begin{array}{l}\text { In } \\
\text { Out }\end{array}$ \\
\hline
\end{tabular}


TABLE 4.2

\section{(Continued)}

Inverse Multiplication

\begin{tabular}{|c|c|c|c|c|c|c|c|c|c|}
\hline Increment & $\begin{array}{l}\text { Total Fuel } \\
\text { in Core (kg U) }\end{array}$ & $\begin{array}{l}\text { Chann } \\
\text { CPM }\end{array}$ & $\begin{array}{l}1 \mathrm{No} \cdot 1 \\
\mathrm{CR}_{0} / \mathrm{CR} \\
\end{array}$ & $\begin{array}{l}\text { Channe } \\
\text { CPM }\end{array}$ & $\begin{array}{r}\text { No. } 2 \\
\mathrm{CR}_{\mathrm{O}} / \mathrm{CR} \\
\end{array}$ & $\begin{array}{l}\text { Channe] } \\
\text { CPM }\end{array}$ & $\begin{array}{r}\text { No. } 3 \\
\mathrm{CR}_{\mathrm{O}} / \mathrm{CR} \\
\end{array}$ & Average & $\begin{array}{c}\text { Rod } \\
\text { Positions } \\
\end{array}$ \\
\hline $\begin{array}{l}9 \\
9\end{array}$ & $\begin{array}{l}8.16 \\
8.16\end{array}$ & $\begin{array}{r}17128 \\
139936\end{array}$ & $\begin{array}{l}0.0562 \\
0.00582\end{array}$ & $\begin{array}{r}11190 \\
153866\end{array}$ & $\begin{array}{l}0.0591 \\
0.00588\end{array}$ & $\begin{array}{r}9603 \\
110736\end{array}$ & $\begin{array}{l}0.0710 \\
0.00803\end{array}$ & $\begin{array}{l}0.0621 \\
0.00658\end{array}$ & $\begin{array}{l}\text { In } \\
\text { Out }\end{array}$ \\
\hline 10 & 8.40 & 13185 & 0.0474 & 13166 & 0.0502 & 11316 & 0.0602 & 0.0526 & In \\
\hline
\end{tabular}


TABIE 4.3

Control Rod Worth Measurements

\begin{tabular}{|c|c|c|c|}
\hline $\begin{array}{c}\text { Run } \\
\text { Number } \\
\end{array}$ & $\begin{array}{l}\text { Actuator } \\
\text { Positions } \\
\end{array}$ & $\begin{array}{l}\text { Actuator \#8 } \\
\text { Position } \\
\end{array}$ & $\begin{array}{l}\text { Reactivity Worth } \\
\text { of Increment } \% \Delta \mathrm{k} / \mathrm{k}\end{array}$ \\
\hline 10 & $\begin{array}{l}1,2,3,5,6,7 \text { out } \\
4 \text { at } 3813\end{array}$ & in(173) to 1062 & .1631 \\
\hline 9 & $\begin{array}{l}1,2,3,5,6,7 \text { out } \\
4 \text { at } 2000\end{array}$ & 1063 to 2500 & .1834 \\
\hline 11 & $\begin{array}{l}1,2,3,5,6,7 \text { out } \\
4 \text { at } 818\end{array}$ & 2500 to 5500 & .1574 \\
\hline 12 & $\begin{array}{l}1,2,3,5,6,7 \text { out } \\
4 \text { at } 818\end{array}$ & 2500 to 6513 & .1751 \\
\hline 13 & $\begin{array}{l}1,2,3,5,6,7 \text { out } \\
4 \text { at } 393\end{array}$ & 3500 to 6513 & .0919 \\
\hline \multirow[t]{2}{*}{14} & $\begin{array}{l}1,2,3,5,6,7 \text { out } \\
4 \text { at } 393\end{array}$ & 3500 to out (9613) & .1040 \\
\hline & & $\begin{array}{l}\text { Actuator \#4 } \\
\text { Position }\end{array}$ & \\
\hline 29 & $\begin{array}{l}1,2,3,5,6,7 \text { out } \\
8 \text { at } 5382\end{array}$ & in $(134)$ to 700 & .1217 \\
\hline $26 \mathrm{~B}^{*}$ & $\begin{array}{l}1,2,3,5,6,7 \text { out } \\
8 \text { at } 6259\end{array}$ & 700 to 1500 & .1352 \\
\hline $28 \mathrm{~B}^{*}$ & $\begin{array}{l}1,2,3,5,6,7 \text { out } \\
8 \text { at } 4570\end{array}$ & 1500 to 3000 & .1727 \\
\hline $28 C^{*}$ & $\begin{array}{l}1,2,3,5,6,7 \text { out } \\
8 \text { at } 2032\end{array}$ & 3000 to out (9553) & .1558 \\
\hline \multicolumn{4}{|c|}{$\begin{array}{l}\text { These measurements were made with a different core } \\
\text { configuration }\end{array}$} \\
\hline
\end{tabular}


TABLE 4.4

Catcher Foil Cadmium Ratio

Configuration \#1

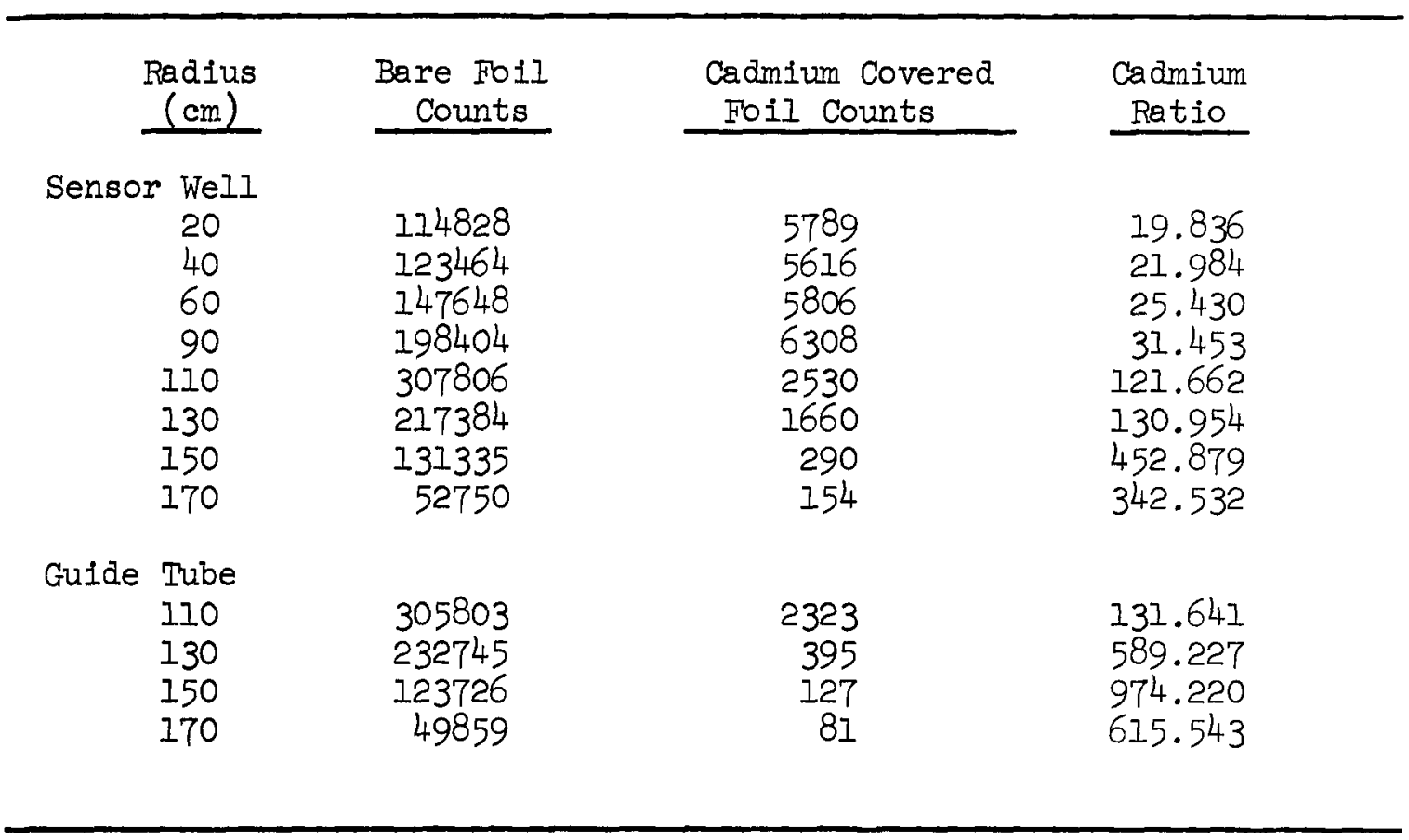


TABLE 4.5

Infinitely Dilute

Fold Foil Cadmium Ratios and Thermal Flux

Configuration \#I

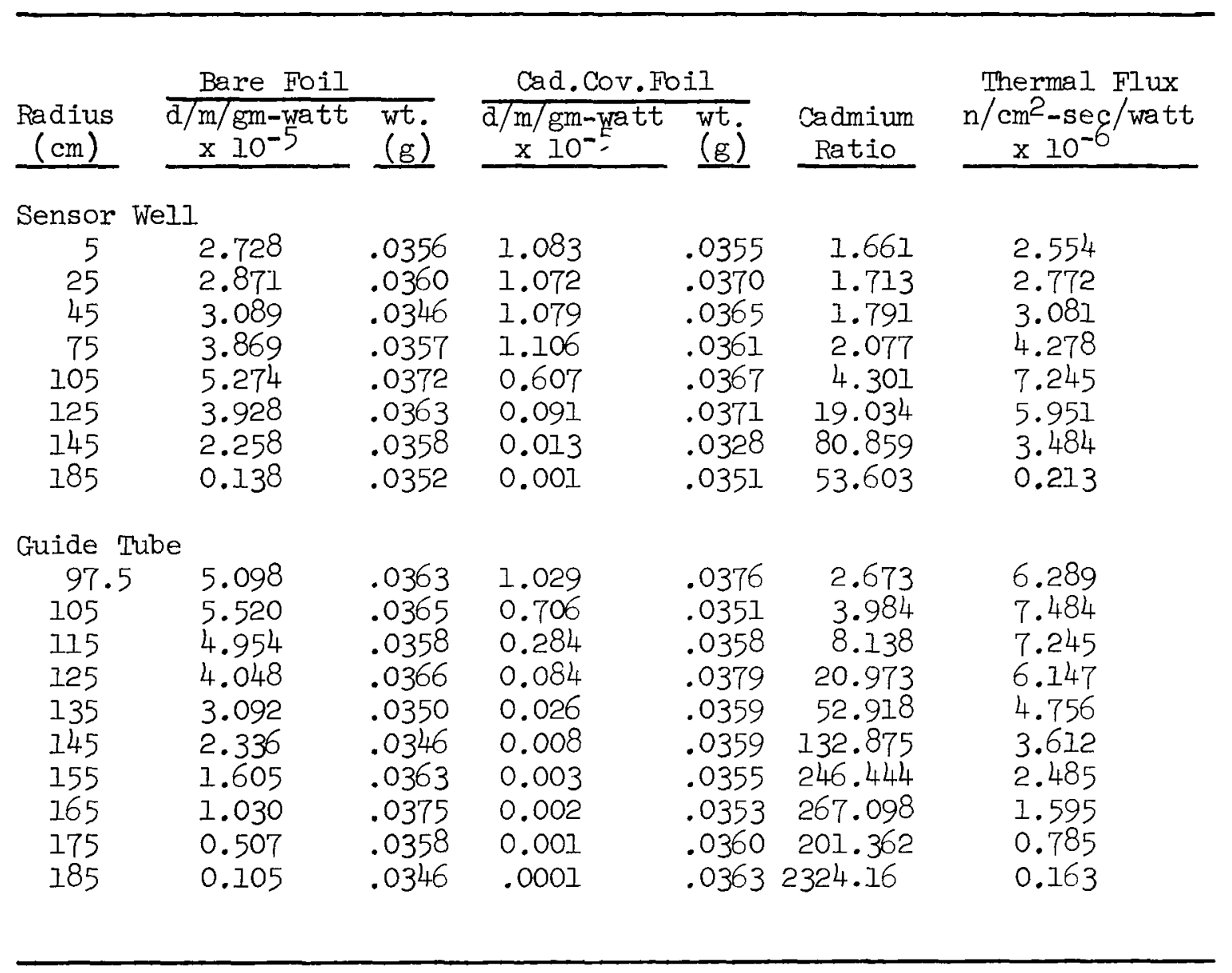




\section{TABLE 4.6}

\section{Infinitely Dilute}

Indium Foil Cadmium Ratios and Thermal Flux

Configuration \#I

\begin{tabular}{|c|c|c|c|c|c|c|}
\hline \multirow[b]{2}{*}{$\begin{array}{c}\text { Radius } \\
(\mathrm{cm}) \\
\end{array}$} & \multicolumn{2}{|c|}{ Bare Foil } & \multicolumn{2}{|c|}{ Cad. Cov.Foil } & \multirow[b]{2}{*}{$\begin{array}{l}\text { Cadmium } \\
\text { Ratio } \\
\end{array}$} & \multirow{2}{*}{$\begin{array}{l}\text { Thermal Flux } \\
\mathrm{n} / \mathrm{cm}^{2}-\mathrm{sec} / \text { watt } \\
\times 10^{-6}\end{array}$} \\
\hline & $\begin{array}{l}\mathrm{d} / \mathrm{m} / \mathrm{gm}-\mathrm{watt} \\
\mathrm{x} 10^{-7} \\
\end{array}$ & (g) & $\begin{array}{c}\mathrm{d} / \mathrm{m} / \mathrm{gm}-\mathrm{watt} \\
\times 10^{-7} \\
\end{array}$ & $\begin{array}{l}\text { wt. } \\
\text { (g) }\end{array}$ & & \\
\hline \multicolumn{7}{|c|}{ Sensor Well } \\
\hline 5 & 5.733 & .00584 & 2.725 & .00515 & 1.808 & 2.569 \\
\hline 60 & 5.217 & .00510 & 2.807 & .00584 & 1.568 & 1.920 \\
\hline 90 & 8.755 & .00518 & 2.522 & .00740 & 2.531 & 4.967 \\
\hline 120 & 8.568 & .00518 & 0.851 & .00519 & 7.442 & 6.409 \\
\hline 170 & 0.403 & .00512 & 0.003 & .00679 & 77.552 & 0.332 \\
\hline 185 & 0.260 & .00649 & 0.0008 & .00562 & 227.497 & 0.215 \\
\hline \multicolumn{7}{|c|}{ Guide Tube } \\
\hline 120 & 9.244 & .00515 & 0.515 & .00512 & 13.073 & 7.251 \\
\hline 185 & 2.061 & .00516 & 0.0003 & .00510 & 408.227 & 0.171 \\
\hline
\end{tabular}

Bare Foil

Radius $\overline{\mathrm{d} / \mathrm{m} / \mathrm{gm} \text {-watt wt. }}$

(cm) $\times 10^{-6} \quad(\mathrm{~g})$

Sensor Well

$\begin{array}{rll}5 & 2.022 & .0426 \\ 60 & 2.654 & .0415 \\ 90 & 3.652 & .0427 \\ 120 & 4.639 & .0430 \\ 145 & 2.590 & .0456 \\ 170 & 0.878 & .0459\end{array}$

TABLE 4.7

\section{Infinitely Dilute}

Manganese Foil Cadmium Ratios and Thermal Flux

Configuration \#1
Thermal Flux

$\begin{array}{r}\mathrm{n} / \mathrm{cm}^{2}-\mathrm{seq} / \text { watt } \\ \times 10^{-6} \\ \hline\end{array}$

2.569

1.920

4.967

6.409

0.332

0.215

0.171

Thermal Flux d/m/gm-wat wt. $\times 10^{-5} \quad(\mathrm{~g})$ Cadmium Ratio $\mathrm{n} / \mathrm{cm}^{2}-\mathrm{seg} /$ watt $\times 10^{-6}$

$\begin{array}{lrrr}1.559 & .0407 & 6.924 & 4.208 \\ 1.548 & .0480 & 8.511 & 5.611 \\ 1.513 & .0459 & 11.958 & 7.876 \\ 0.214 & .0415 & 107.153 & 10.400 \\ 0.024 & .0426 & 534.093 & 5.828 \\ 0.007 & .0467 & 567.595 & 1.975\end{array}$

Guide Tube

$\begin{array}{rrrrrrr}97.5 & 4.724 & .0432 & 1.440 & .0430 & 16.422 & 10.320 \\ 170 & 0.913 & .0433 & 0.004 & .0424 & 1075.464 & 2.055\end{array}$




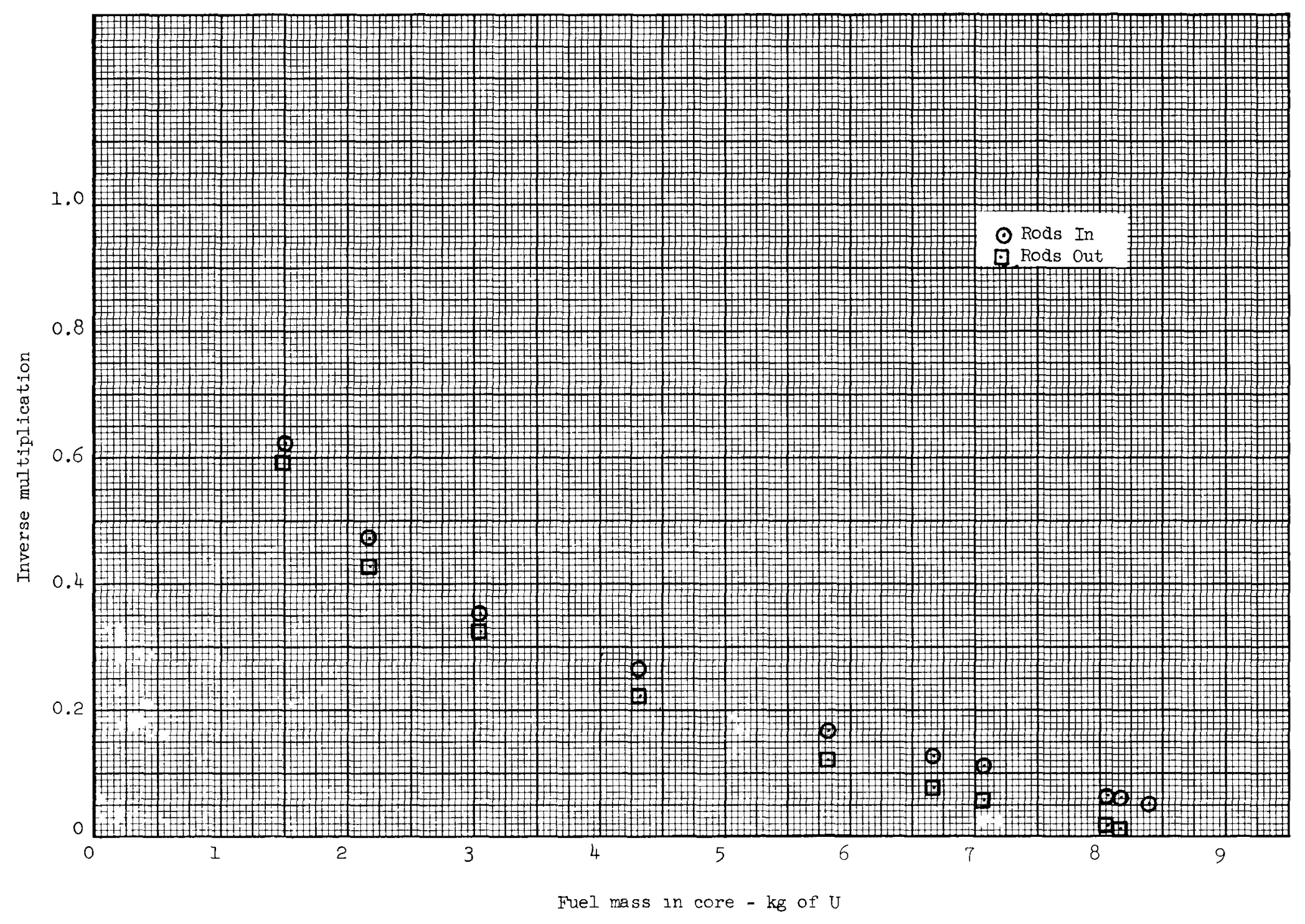

Fig. 4.I Inverse multiplication for initial fuel loading of Configuration \#l 


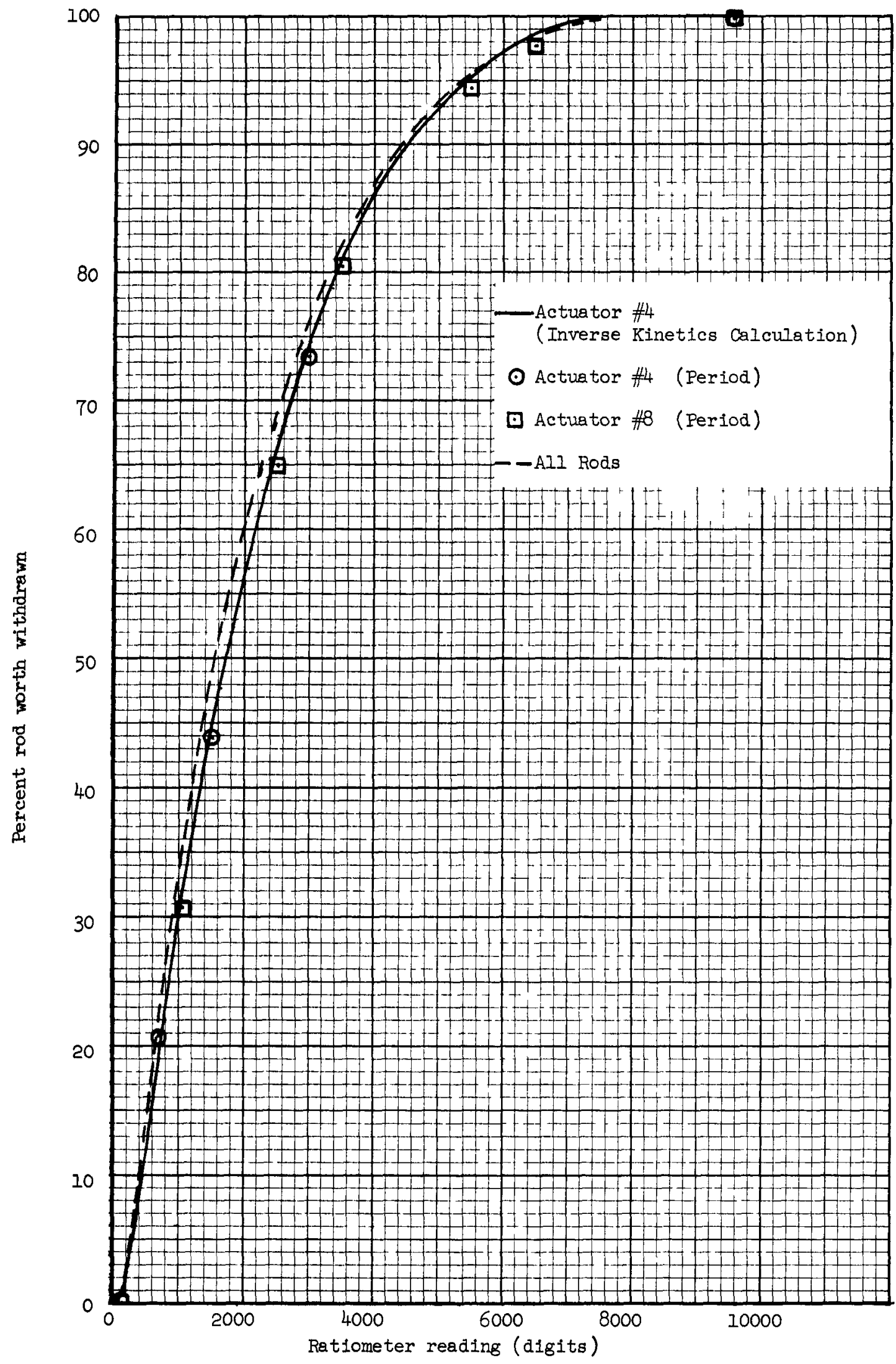

Fig. 4.2 Control system rod worth curves 


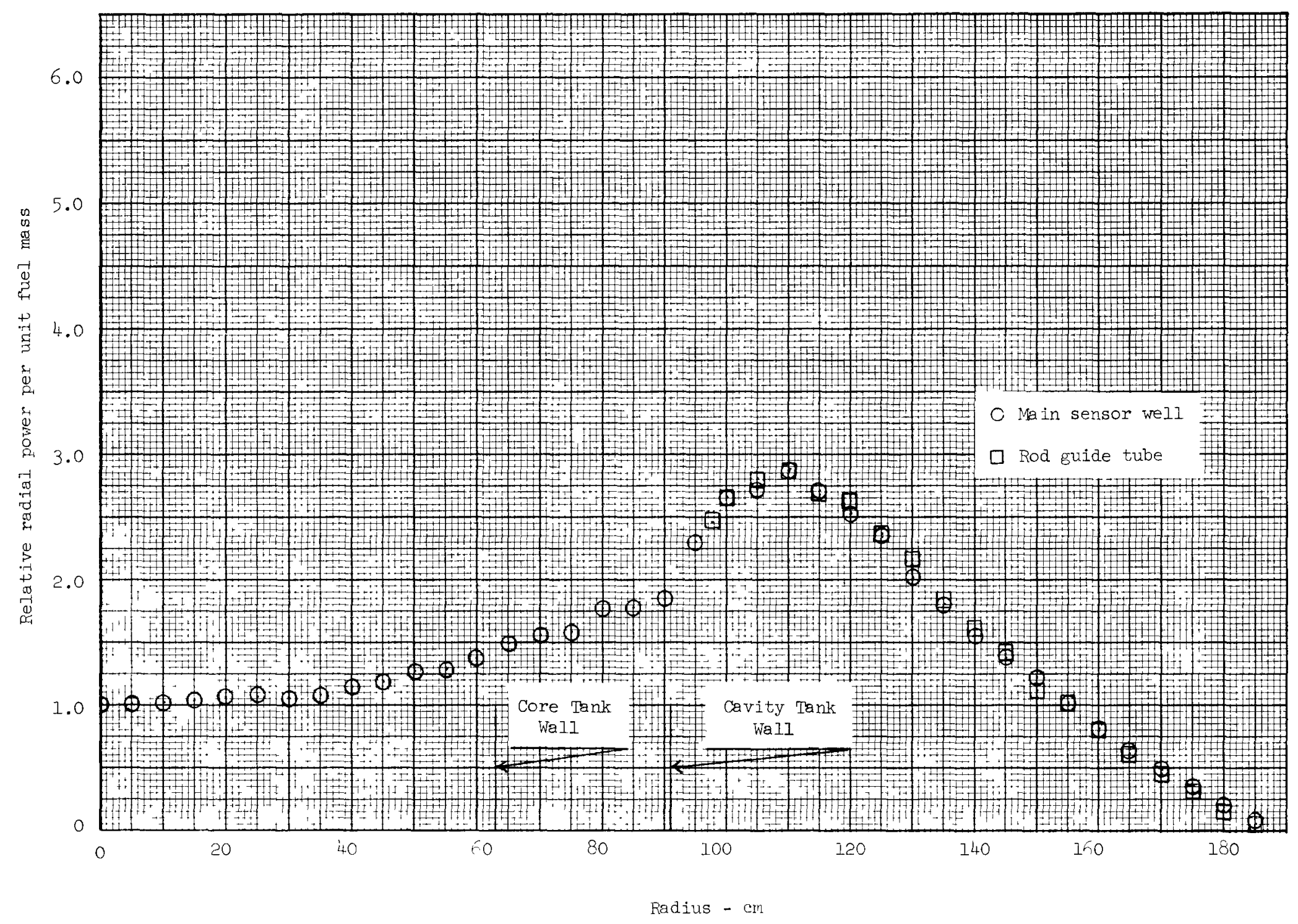

Fig. 4.3 Relative specific power (U-235 fission rate) in Configuration \#I 


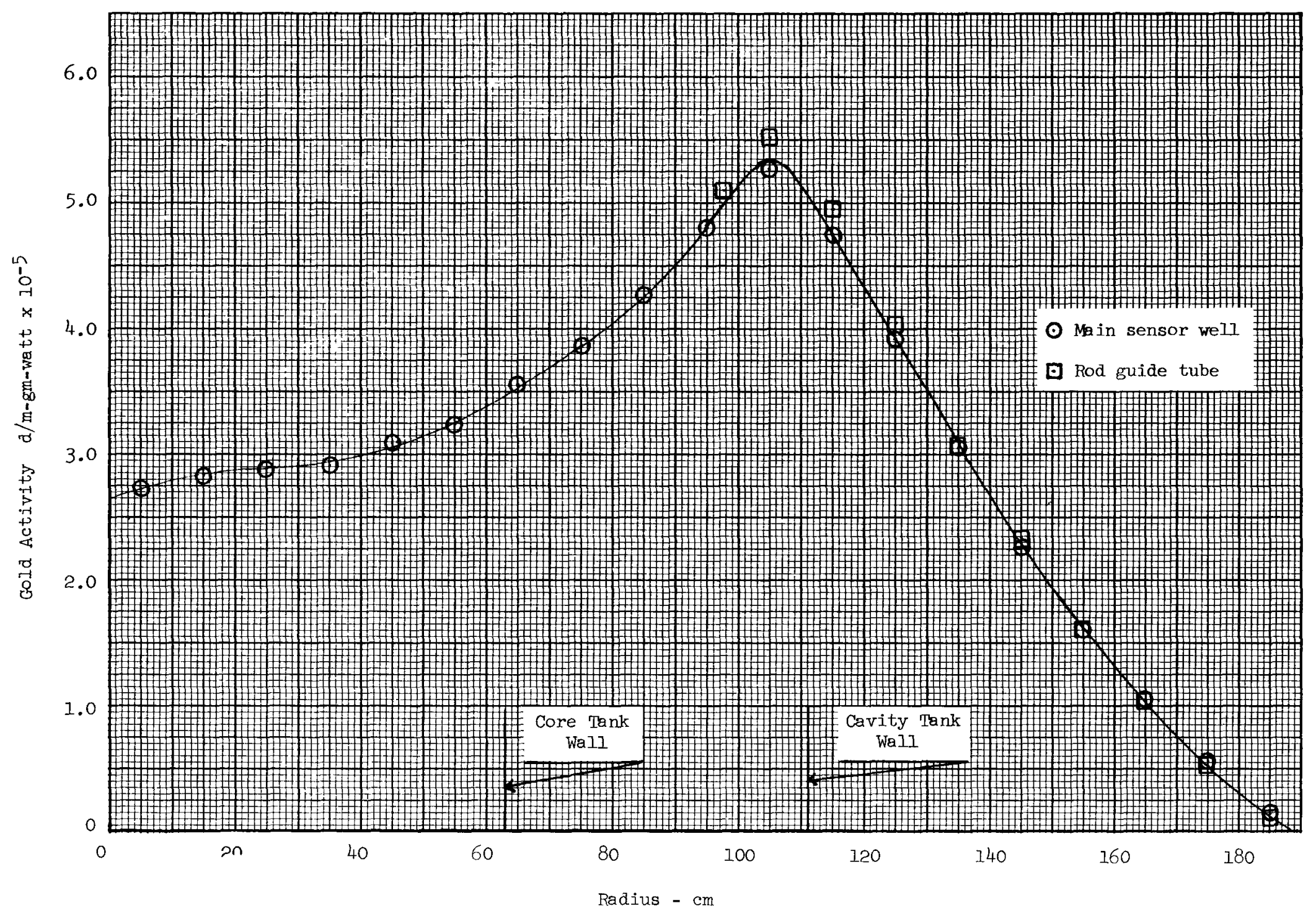

Fig. 4.4 Radial bare gold activity (d/m-gm-watt)

Configuration \#1 


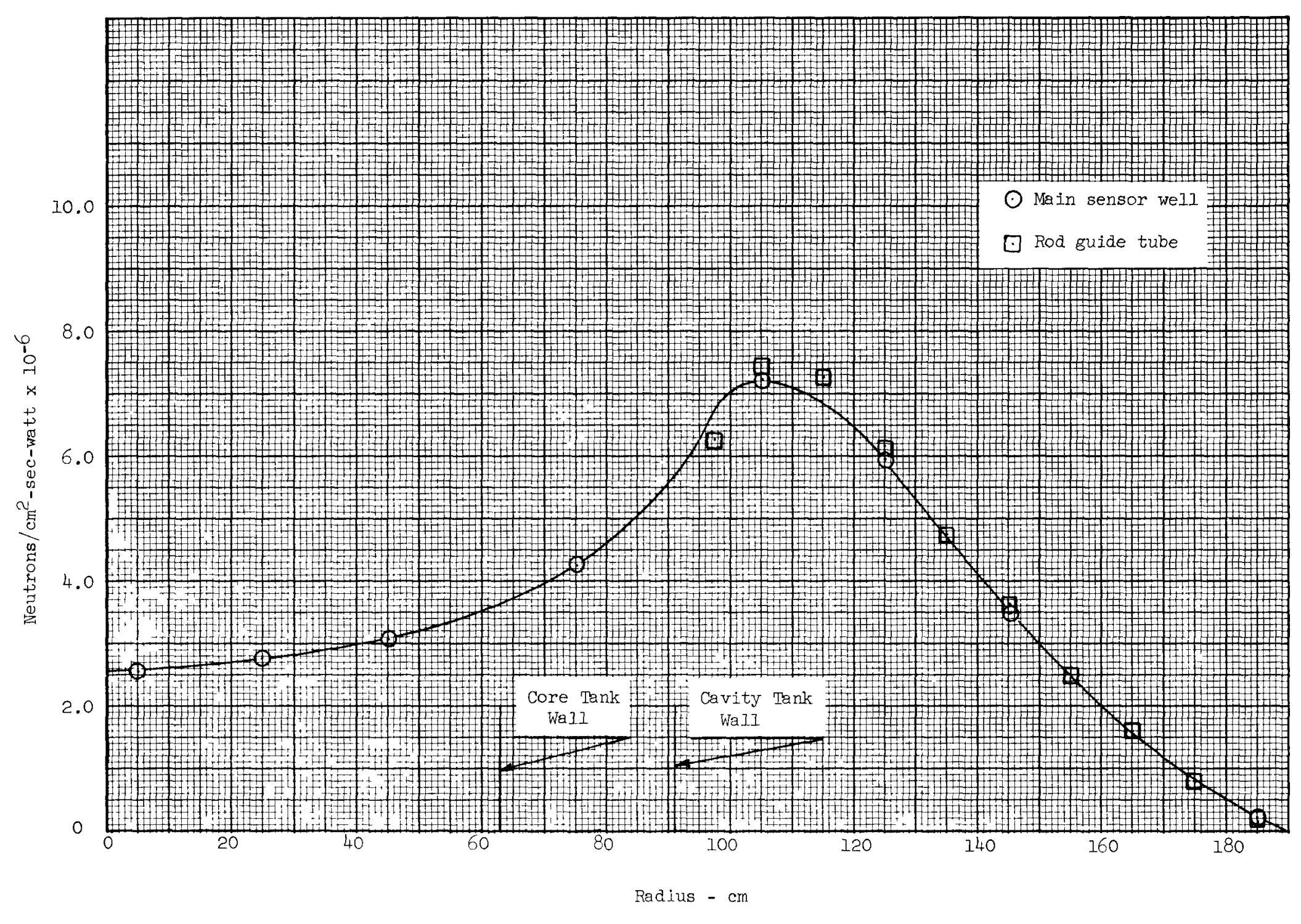

Fig. 4.5 Radial gold determined thermal flux Configuration \#l 
Configuration \#2 aiffered from Configuration \#1 in that

$1 \times 10^{21}$ atoms/cc hydrogen in the form of foamed polystyrene and polyethelene sheet was installed in the cavity region between the heating air shrouds and the cavity wall. The polyethelene $\left(\mathrm{CH}_{2}\right)$ was in the form of $0.064 \mathrm{~cm}$ thick sheet cut and evenly disbursed throughout the volume while the polystyrene foam (CH) was in the form of both cut sheets $\left(2.54 \mathrm{~cm}\right.$ thick) and small cubes nominally $16.4 \mathrm{~cm}^{3}$ for a total mass of $14.23 \mathrm{~kg}$ of $\mathrm{CH}_{2}$ and $22.33 \mathrm{~kg}$ of $\mathrm{CH}$.

The system $\mathrm{k}$-excess before the hydrogen was added to create Configuration $\# 2$ was $0.634 \% \mathrm{dk} / \mathrm{k}$ with $12.880 \mathrm{~kg} \mathrm{UF} 6$ fuel loading. After adding the $\mathrm{CH}$ and $\mathrm{CH}_{2}$, UF6 was added to bring the total to $19.505 \mathrm{~kg}$ of $\mathrm{UF}_{6}$. A k-excess of $0.454 \% \Delta \mathrm{k} / \mathrm{k}$ was measured.

\subsection{Fuel and Coolant Mockup Reactivity Worths}

Fuel worth was evaluated by adding a 306.0 gram increment of $\mathrm{UF}_{6}$ to the core raising the $\mathrm{k}$-excess to $0.890 \% \mathrm{dk} / \mathrm{k}$, from which a fuel worth of $7,36 \% \mathrm{k} / \mathrm{k}$ per kilogram of $\mathrm{UF}_{6}$ or $2.02 \% \Delta \mathrm{k} / \mathrm{k}$ per $\mathrm{kilogram}$ uranium (93.2\% U $\mathrm{u}^{2} \overline{5}$ enriched) was calculated. This compares to $2.96 \% \mathrm{k} / \mathrm{k}$ per kilogram uranium for Configuration \#1. Assuming a linear worth per kilogram for fuel over the range of fuel loaded (adjusted to $k_{e f f}=1$ for both configuration \#I and \#2, $8.46 \mathrm{~kg} U$ to $12.91 \mathrm{~kg} U$ ) the hydrogen mockup propellent was worth $-11.0 \% \mathrm{Nk} / \mathrm{k}$. The assumption of linear worth in this range of fuel densities appears to be justified based on experience with other cavity reactor configurations tested, as show graphically in Figure 3.3 of reference 3 .

The reactivity penalty of the coolant mockup material was somewhat larger than expected from calculations and from the measurement of a lump of $\mathrm{CH}_{2}$ on Configuration \#1. This measurement indicated a total reactivity change of $3.57 \% \mathrm{dk} / \mathrm{k}$ for the mockup while a measurement on the same lump of material in the same position in the reactor (Iump positioned in the sensor well between the cavity wall and the core sensor well flange) after installation of the mockup extrapolated to $5.50 \% \mathrm{kk} / \mathrm{k}$ change, neither of which explained the large $11.0 \% \Delta \mathrm{k}$ change determined from the fuel worth measurements and the fuel increment added. A subsequent measurement was made with the lump in the same position but the void above the lump into the $\mathrm{D}_{2} \mathrm{O}$ region was plugged with $545 \mathrm{gms}$ of $\mathrm{CH}_{2}$ in an effort to minimize neutron streaming in the sensor well, however the result was nominally the same, i.e. a calculated penalty of $5.29 \% \mathrm{dk} / \mathrm{k}$ for the coolant mockup. However, subsequent measurements of the worth of hydrogen made on the stainless configuration (\#3) and reported in section 6 showed a strong effect of spatial dependence and/or effect of flux depression of the core flange on the measurement results. This strong spatial dependence has been observed on other configurations (Reference $1, p .251$ and 252 and Reference 3, p. 97). In general, these previous experiments showed that hydrogen was worth most when adjacent to the core, least when against the cavity. For this experiment, all of the hydrogen (as $\mathrm{CH}$ and $\mathrm{CH}_{2}$ ) was installed between the outer air-flow shroud and the cavity wall 
and thus there was no hydrogen within approximately $5 \mathrm{~cm}$ of the UF6 core wall. However, the amount of hydrogen installed was equivalent to

$1 \times 10^{21} \mathrm{H} / \mathrm{cc}$ average over the entire region from core to cavity wall.

Further difficulties have been encountered with hydrogen in attempts to calculate its worth (See Section 8) and in measured differences in hydrogen worth in $\mathrm{CH}$ and $\mathrm{CH}_{2}$ (Ref. 3, p. 88). Molecular binding differences between these two molecules could well have a significant effect. The carbon atom contribution to the worth of $\mathrm{CH}$ and $\mathrm{CH}_{2}$ is quite small, having been measured previously on a number of other configurations to be between 1 and $8 \%$ of the measured worth of the organic molecule. (Ref. I, p. 255; Ref. 3, p. 88; and Ref. 5, p. 38).

\subsection{Power and Flux Distribution Measurements}

Only catcher foils and gold foils were exposed on this configuration. The radial power distribution in the sensor well and a rod guide tube is shown in Figure 5.1. Data from the $1.2 \times 10^{-3} \mathrm{~cm}$ thick gold foils are shown as a plot of the bare gold activity in Figure 5.2 and a plot of the thermal flux in Figure 5.3. Catcher foil cadmium ratios (essentially infinitely dilute) are tabulated in Table 5.1 and the infinitely dilute gold cadmium ratios at selected radial positions are given in Table 5.2. All cadmium covered foils were exposed in $0.051 \mathrm{~cm}(20 \mathrm{mil})$ thick buckets. 


\section{TABLE 5.1}

Catcher Foil Cadmium Ratio

Configuration \#2

\begin{tabular}{cccc}
$\begin{array}{c}\text { Radius } \\
(\mathrm{cm})\end{array}$ & $\begin{array}{c}\text { Bare Foil } \\
\text { Counts }\end{array}$ & $\begin{array}{c}\text { Cadmium Covered } \\
\text { Foil Counts }\end{array}$ & $\begin{array}{c}\text { Cadmium } \\
\text { Ratio }\end{array}$ \\
\cline { 2 - 3 } Sensor Well & & & \\
20 & 121029 & 1548 & 78.1 \\
40 & 140206 & 1557 & 90.0 \\
60 & 172999 & 1639 & 106.0 \\
90 & 344540 & 1845 & 187.0 \\
110 & 488949 & 814 & 601.0 \\
130 & 362919 & 214 & 1690.0 \\
150 & 190954 & 434 & 440.0 \\
170 & 81196 & 237 & 343.0 \\
& & & \\
Tube & & 5877 & 180.1 \\
105 & 492323 & 2225 & 187.9 \\
125 & 400736 & 1241 & 355.5 \\
145 & 233182 & 300 & 269.1 \\
165 & 106701 & 42 & \\
185 & 11194 & & \\
& & & \\
\hline
\end{tabular}




\section{TABLE 5.2 \\ Infinitely Dilute}

Gold Foil Cadmium Ratios and Thermal Flux

Configuration \#2

\begin{tabular}{|c|c|c|c|c|c|c|}
\hline \multirow[b]{3}{*}{$\begin{array}{l}\text { Radius } \\
(\mathrm{cm})\end{array}$} & \multirow{2}{*}{\multicolumn{2}{|c|}{ Bare Foil }} & \multicolumn{4}{|c|}{ Infinitely } \\
\hline & & & \multicolumn{2}{|c|}{ Cad.Cov.Foil } & \multirow{2}{*}{$\begin{array}{l}\text { Dilute } \\
\text { Cadmium } \\
\text { Ratio } \\
\end{array}$} & \multirow{2}{*}{$\begin{array}{r}\text { Thermal Flux } \\
\mathrm{n} / \mathrm{cm}^{2}-\mathrm{sec} / \text { watt } \\
\mathrm{x} 10^{-6}\end{array}$} \\
\hline & $\begin{array}{l}\mathrm{d} / \mathrm{m} / \mathrm{gm}-\mathrm{watt} \\
\times 10^{-5} \\
\end{array}$ & $\begin{array}{l}\text { wt. } \\
\text { (g) }\end{array}$ & $\begin{array}{c}\mathrm{d} / \mathrm{m} / \mathrm{gm} \text {-watt } \\
\mathrm{x} 10^{-5} \\
\end{array}$ & $\begin{array}{l}\text { wt } \\
\text { (g) }\end{array}$ & & \\
\hline \multicolumn{7}{|c|}{ Sensor WeII } \\
\hline 20 & 2.065 & .0356 & 1.039 & .0368 & 1.42 & 1.570 \\
\hline 40 & 2.281 & .0348 & 1.020 & .0376 & 1.51 & 1.906 \\
\hline 60 & 2.640 & .0367 & 1.092 & .0351 & 1.63 & 2.432 \\
\hline 90 & 4.240 & .0359 & 1.032 & .0358 & 2.35 & 4.978 \\
\hline 110 & 5.001 & .0359 & 0.387 & .0366 & 6.12 & 7.153 \\
\hline 130 & 3.307 & .0361 & 0.050 & .0359 & 29.40 & 5.053 \\
\hline 150 & 1.878 & .0364 & 0.007 & .0364 & 112.50 & 2.902 \\
\hline 170 & 0.754 & .0370 & 0.002 & .0375 & 163.90 & 1.166 \\
\hline \multicolumn{7}{|c|}{ Guide Tube } \\
\hline 105 & 5.395 & .0359 & 0.646 & .0348 & 4.23 & 7.379 \\
\hline 125 & 3.908 & .0363 & 0.087 & .0344 & 20.29 & 5.930 \\
\hline 145 & 2.224 & .0354 & 0.007 & .0361 & 131.50 & 3.438 \\
\hline 165 & 0.988 & .0363 & 0.002 & .0369 & 218.90 & 1.530 \\
\hline 185 & 0.108 & .0356 & 0.001 & .0364 & 45.50 & 0.166 \\
\hline
\end{tabular}




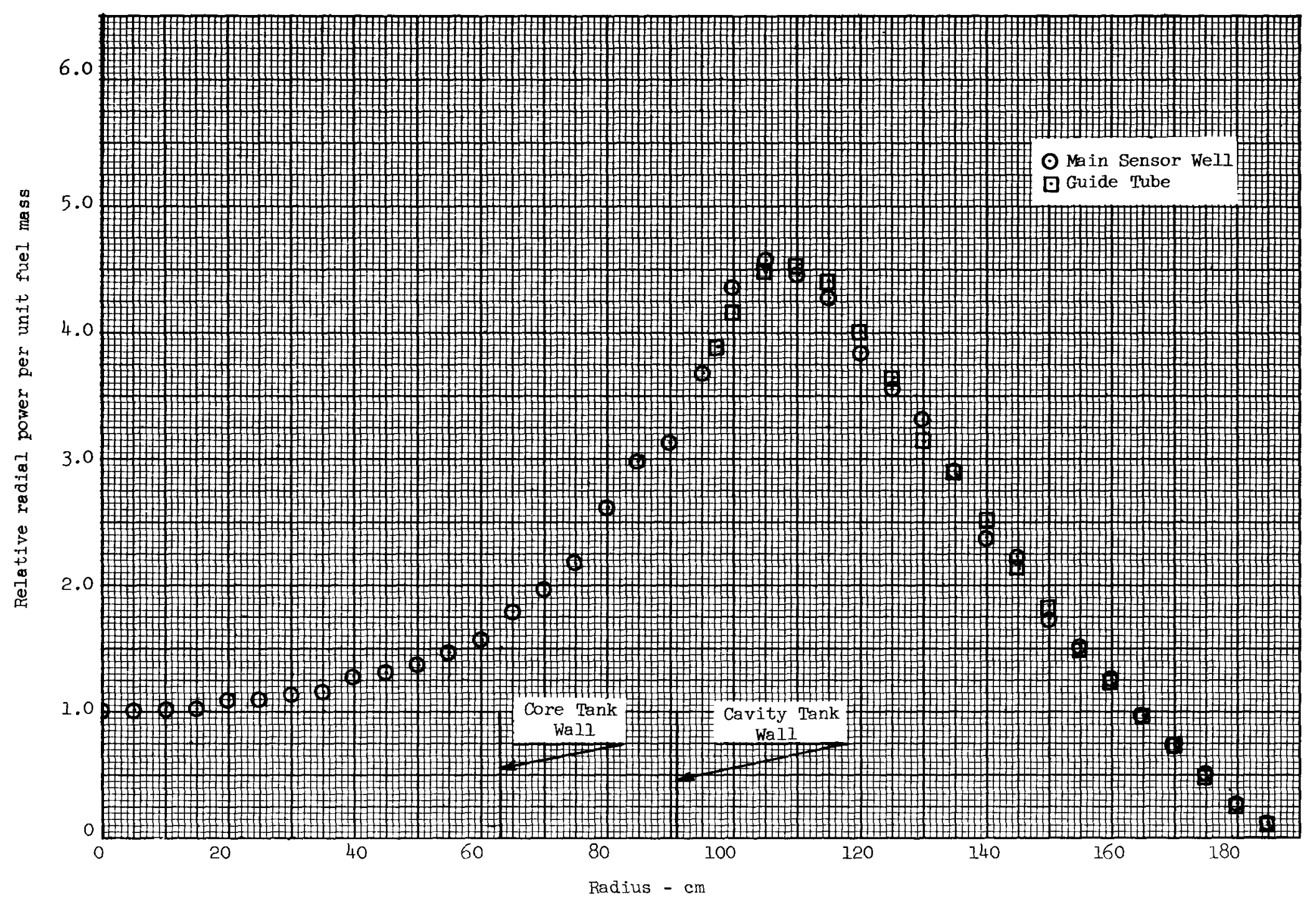

Fig. 5.1 Relative Specific Power (U-235 fission rate) Configuration \#2 


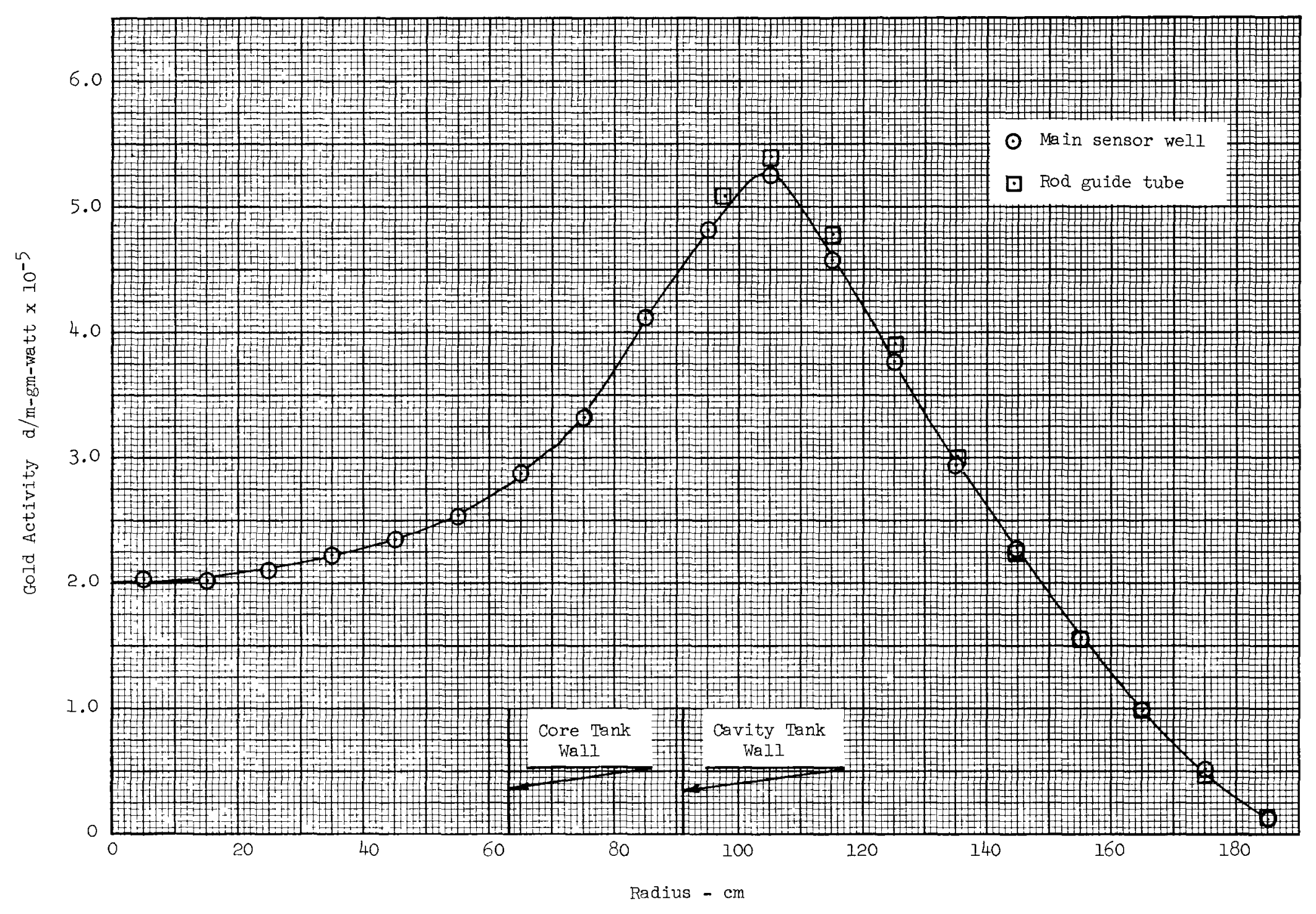

Fig. 5.2 Radial bare gold activity (d/m-gm-watt) Configuration \#2 


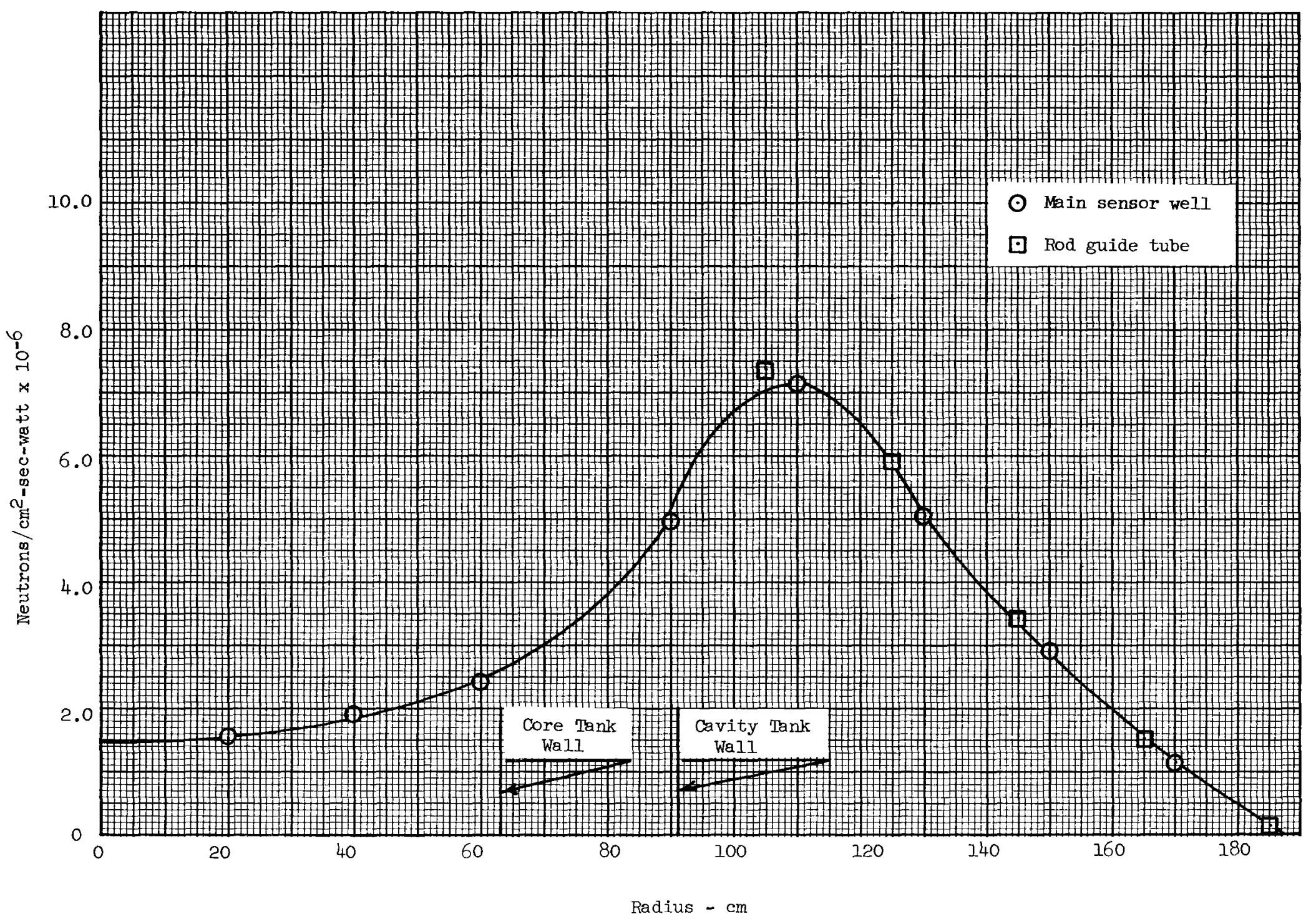

Fig. 5.3 Radial gold determined thermal flux - Configuration \#2 
Transformation from Configuration \#t (hydrogen) to Configuration \#3 (hydrogen plus stainless steel) was accomplished by installing 62.2 kilograms of type 321 stainless steel sheet to the cavity wall to give a nominal SS thickness of $0.0762 \mathrm{~cm}$ (30 mils), equivalent to 0.019 mean free absorption paths. The steel, cut to shape from $0.0254 \mathrm{~cm}$ thick ( $10 \mathrm{mil}$ ) stock, was installed between the $\mathrm{CH}_{2}$ - $\mathrm{CH}$ hydrogen propellent mockup and the outer wall of the cavity.

The system $\mathrm{k}$-excess just prior to changing to Configuration \#3 was $0.200 \% / \mathrm{kk} / \mathrm{k}$ with a fuel loading of $19.811 \mathrm{~kg} \mathrm{UF} 6$ ( $13.340 \mathrm{~kg} \mathrm{U})$. After adding $23.843 \mathrm{~kg}$ of $\mathrm{UF}_{6}$ to pay the stainless steel penalty (43.655 $\mathrm{kg} \mathrm{UF} 6$ or $29.395 \mathrm{~kg} \mathrm{U}$ total in the reactor) the reactor was critical with $0.0654 \% \Delta \mathrm{k} / \mathrm{k}$ k-excess. The critical loading corrected for fuel in the transfer line and the k-excess is $43.626 \mathrm{~kg} \mathrm{UF} 6$ or 29.376 $\mathrm{kg} \mathrm{U}$.

\subsection{Reactivity and Material Worth Measurements}

Fuel worth was evaluated by adding a 429.7 gram increment of UF/ to the core which resulted in a worth of $0.294 \% \mathrm{sk} / \mathrm{k}$ per $\mathrm{kg} \mathrm{UF}$ or $0.437 \% \Delta \mathrm{k} / \mathrm{k}$ per $\mathrm{kg} \mathrm{U}-235$. This value compares to $2.02 \% \Delta \mathrm{k} / \mathrm{k}$ per $\mathrm{kg}$ uranium for configuration \#2 with a $13.17 \mathrm{~kg} U$ loading and $2.96 \% \mathrm{dk} / \mathrm{k}$ per $\mathrm{kg}$ UF6 for Configuration \#I with a $8.54 \mathrm{~kg} U$ loading. Using these three fuel worth values, at their respective core loading, and with the aid of Figure 3.3 of Reference 3, a fuel worth vs core loading curve, Fig. 6.1, was constructed and the area under the curve between the appropriate limits was integrated to yield a stainless steel worth of $-15.3 \% \Delta \mathrm{k} / \mathrm{k}$.

Direct measurement of stainless steel worth was made by placing narrow strips of $0.091 \mathrm{~cm}$ thick ( $36 \mathrm{mil}$ ) stock against the outside of the cavity wall (on the $\mathrm{D}_{2} \mathrm{O}$ side). After the stainless steel was installed, a 234 gram sample was measured as a period difference of $-0.0285 \% \Delta \mathrm{k} / \mathrm{k}$ or $-0.122 \% \mathrm{kk} / \mathrm{k}$ per $\mathrm{kg}$ which would extrapolate to $-7.6 \% \mathrm{dk}$ for the entire 62.2 kilogram stainless steel liner. A subsequent measurement with a larger 911 gram sample gave a value of $-0.161 \% \mathrm{dk} / \mathrm{k}$ per $\mathrm{kg}$ which extrapolates to $-10.0 \% \mathrm{k}$ worth for the liner. These values can be compared to $-0.255 \% \Delta \mathrm{k} / \mathrm{k}$ per $\mathrm{kg}$ measured on Configuration \#l which extrapolates to $-15.8 \% \mathrm{dk} / \mathrm{k}$ for the $67.2 \mathrm{~kg}$ liner and is in very good agreement with that value deduced from the fuel worth measurements cited above. The steel worth should decrease as the loading becomes heavier, and this was observed. However, the average measured worth is still about $15 \%$ less than that deduced from the fuel loading differences. The latter method involved interpolation between three fuel worth points, and conceivably could be in error by this amount.

The hydrogen worth between the core and reflector was carefully remeasured. The previous results of the reactivity coefficient showed considerable variance (factor of two) from the gross result of the loading change required when $10^{21}$ atoms/ce of hydrogen were added to the cavity. (See Section 5.1) A small 3-inch long sample of $\mathrm{CH}_{2}$ weighing 
$101 \mathrm{gm}$ was measured near the middle of the annular cavity void within the sensor well. The sample in this case was three inches from the core top flange and was essentially not influenced by its flux depressing properties. The measured worth of polyethylene was $-0.60 \% \Delta \mathrm{k} / \mathrm{kg}, 2$ to 4 times the previous results (Section 4.2 and 5.1). This latter result, however, extrapolates to a total hydrogen penalty of $15 \%$, compared to the 11\% observed between the first two configurations. Since the worth varies with fuel loading and other configuration properties, these later results imply consistency, and indicate that the earlier reactivity coefficient results were adversely affected by the presence of the top core flange. Note, the carbon worth, less than $10 \%$ of the hydrogen worth in $\mathrm{CH}_{2}$, has been ignored.

\subsection{Power and Flux Distribution Measurements}

Power and flux distributions over the radius of the reactor were determined in both the sensor well and a rod guide tube by exposing both bare and cadmium covered catcher foils, gold foils, indium foils and manganese foils. In addition, cadmium ratios and thermal flux were calculated from the data taken at selected points. All cadmium covered foils were enclosed in $0.051 \mathrm{~cm}$ (20 mil) thick buckets. The method used to calculate the infinitely dilute cadmium ratios and thermal flux are given in Appendix 1.

\subsubsection{Catcher Foil Data}

Catcher foil data are plotted as a fine radial power distribution relative to the power at the core center in Figure 6.2 and the cadmium ratio, which is the ratio of the normalized counts from bare and cadmium covered foils exposed at selected radial positions, are given in Table 6.1. Because of the short range of the fission products in the uranium metal foils, these cadmium ratios are essentially infinitely dilute values. Therefore they represent the ratio of total to epithermal fission rate.

6.2.2 Resonance Foil Detector Data - Gold, Indium and Manganese

Figure 6.3 is a plot of radial bare gold activity distribution, of $1.2 \times 10^{-3} \mathrm{~cm}$ thick gold. The actual response of foils of this thickness to thermal and epithermal neutrons can be determined by comparing columns 2 and 4 of Table 6.2. However, for general usefulness, the infinitely dilute response of total to epithermal neutrons is preferred, and this is given in column 6 of that table. Bare and cadmium covered gold, indium and manganese foils were exposed at selected radial locations in both the sensor well and a rod guide tube. The calculated infinitely dilute cadmium ratios and the thermal flux data are shown in Tables $6.2,6.3$, and 6.4. In addition the thermal flux determined from the gold foil activity is plotted in Figure 6.4 All of the data are normalized to a power of one watt as determined from volume weighted catcher foil activity within the spherical core. 
A final power run at 500 watts and two hour duration was made with special foil packets located at three locations in the sensor well for additional neutron spectrum determination. The positions were core center and $61 \mathrm{~cm}$ and $105 \mathrm{~cm}$ from core center. In each location ${ }^{5}{ }^{5} \mathrm{Mn}(\mathrm{n}, \gamma)^{56} \mathrm{Mn},{ }^{127} \mathrm{I}(\mathrm{n}, \gamma)^{128} \mathrm{I},{ }^{63} \mathrm{Cu}(\mathrm{n}, \gamma)^{64} \mathrm{Cu},{ }^{11}{ }^{5} \mathrm{In}(\mathrm{n}, \mathrm{n}){ }^{11} \mathrm{~m}_{\mathrm{In}},{ }^{56} \mathrm{Fe}(\mathrm{n}, \mathrm{p})$ ${ }^{56} \mathrm{Mn},{ }^{64} \mathrm{Zn}(\mathrm{n}, \mathrm{p}){ }^{64} \mathrm{Cu},{ }^{24} \mathrm{Mg}(\mathrm{n}, \mathrm{p}){ }^{24} \mathrm{Na}$, and ${ }^{27} \mathrm{Al}(\mathrm{n}, \alpha){ }^{24} \mathrm{Na}$ were used.

A multiple foil activation technique (ref. 18) employing the SPECTRA ( ref. 19) code was used to determine the neutron spectrum from the reaction products. The thermal flux results (equivalent $2200 \mathrm{~m} / \mathrm{sec}$ flux) are shown in Fig. 6.4, in which the multiple foil results using $\mathrm{Cu}, \mathrm{I}$, and $\mathrm{Mn}$ are compared with the standard gold foil results. The spectrum at several different locations, from Mev energies to thermal, are shown in Figure 6.5, as relative flux per unit energy. Section 8 describes a comparison of these results with the spectrum calculated with a 19-energy group transport code. 
TABLE 6.1

Catcher Foil Cadmium Ratio

Configuration \#3

\begin{tabular}{cccc}
\hline $\begin{array}{c}\text { Radius } \\
(\mathrm{cm})\end{array}$ & $\begin{array}{c}\text { Bare Foil } \\
\text { Counts }\end{array}$ & $\begin{array}{c}\text { Cadmium Covered } \\
\text { Foil Counts }\end{array}$ & $\begin{array}{r}\text { Cadmium } \\
\text { Ratio }\end{array}$ \\
\cline { 2 - 3 } Sensor Wel1 & & & \\
20 & 56371 & 20802 & 2.710 \\
40 & 76736 & 22197 & 3.457 \\
60 & 143159 & 24025 & 5.959 \\
90 & 403425 & 29319 & 13.760 \\
110 & 641731 & 12599 & 50.935 \\
130 & 462736 & 3836 & 120.630 \\
150 & 251824 & 1455 & 173.075 \\
170 & 107514 & 659 & 163.147 \\
185 & 16314 & 244 & 66.861 \\
& & & \\
Guide & & 12400 & \\
110 & 685136 & 4405 & 117.186 \\
130 & 516206 & 2240 & 102.424 \\
150 & 229437 & 1649 & 64.025 \\
170 & 105577 & 111 & 139.576 \\
185 & 15493 & & \\
\hline
\end{tabular}


TABLE 6.2

Infinitely Dilute

Gold Foil Cadmium Ratios and Thermal Flux

Configuration \#3

\begin{tabular}{|c|c|c|c|c|c|c|}
\hline \multirow[b]{2}{*}{$\begin{array}{l}\text { Radius } \\
(\mathrm{cm})\end{array}$} & \multicolumn{2}{|c|}{ Bare Foil } & \multicolumn{2}{|c|}{ Cad.Cov. Foil } & \multirow[b]{2}{*}{$\begin{array}{l}\text { Cadmium } \\
\text { Ratio }\end{array}$} & \multirow{2}{*}{$\begin{array}{l}\text { Thermal Flux } \\
\mathrm{n} / \mathrm{cm}^{2}-\mathrm{sec} / \text { watt } \\
\times 10^{-6} \\
\end{array}$} \\
\hline & $\begin{array}{l}\mathrm{d} / \mathrm{m} / \mathrm{gm}-\mathrm{watt} \\
\mathrm{x} 10^{-5} \\
\end{array}$ & wti & $\begin{array}{l}\mathrm{d} / \mathrm{m} / \mathrm{gm} \text {-watt } \\
\times 10^{-4}\end{array}$ & $\begin{array}{l}\text { wt. } \\
\text { (g) }\end{array}$ & & \\
\hline \multicolumn{7}{|c|}{ Sensor Well } \\
\hline 5 & 1.066 & .0385 & 8.038 & .0350 & 1.16 & 0.454 \\
\hline 25 & 1.147 & .0308 & 8.274 & .0363 & 1.14 & 0.409 \\
\hline 45 & 1.332 & .0363 & 8.399 & .0367 & 1.25 & 0.758 \\
\hline 75 & 2.538 & .0375 & 9.905 & .0351 & 1.69 & 2.440 \\
\hline 90 & 3.179 & .0356 & 9.509 & .0365 & 2.00 & 3.440 \\
\hline 105 & 4.250 & .0346 & 5.087 & .0363 & 4.16 & 5.790 \\
\hline 125 & 3.131 & .0358 & 0.743 & .0372 & 18.50 & 4.740 \\
\hline 145 & 1.817 & .0368 & 0.090 & .0356 & 84.40 & 2.800 \\
\hline 175 & 0.425 & .0355 & 0.005 & .0351 & 412.00 & 0.659 \\
\hline \multicolumn{7}{|c|}{ Guide Tube } \\
\hline 97.5 & 4.020 & .0363 & 9.006 & .0363 & 2.49 & 4.840 \\
\hline 115 & 3.971 & .0363 & 2.352 & .0363 & 7.84 & 5.790 \\
\hline 135 & 2.536 & .0364 & 0.215 & .0360 & 51.40 & 3.900 \\
\hline 155 & 1.340 & .0371 & 0.013 & .0362 & 459.00 & 2.080 \\
\hline 175 & 0.421 & .0376 & 0.005 & .0369 & 392.00 & 0.652 \\
\hline
\end{tabular}


TABIE 6.3

Infinitely Dilute

Indium Foil Cadmium Ratios and Thermal Flux

Configuration \#3

\begin{tabular}{|c|c|c|c|c|c|c|}
\hline $\begin{array}{l}\text { Radius } \\
(\mathrm{cm}) \\
\end{array}$ & $\begin{array}{c}\text { Bare Foil } \\
\mathrm{d} / \mathrm{m} / \text { gm-watt } \\
\times 10^{-7} \\
\end{array}$ & $\begin{array}{l}\overline{w t} \text {. } \\
(\mathrm{g})\end{array}$ & $\begin{array}{l}\mathrm{Cad} \text {. Cov. } \\
\begin{array}{l}\mathrm{d} / \mathrm{m} / \mathrm{gm}-\mathrm{watt} \\
\times 10^{-7} \\
\end{array}\end{array}$ & $\begin{array}{l}\frac{\text { goil }}{\text { wt }} \\
(\mathrm{g})\end{array}$ & $\begin{array}{l}\text { Cadmium } \\
\text { Ratio } \\
\end{array}$ & $\begin{array}{r}\text { Thermal Flux } \\
\mathrm{n} / \mathrm{cm}^{2}-\mathrm{sec} / \text { watt } \\
\times 10^{-6}\end{array}$ \\
\hline \multicolumn{7}{|c|}{ Sensor Well } \\
\hline 5 & 3.204 & .00584 & 2.368 & .00649 & 1.22 & 0.638 \\
\hline 35 & 3.665 & .00518 & 1.061 & .00516 & 2.75 & 2.160 \\
\hline 60 & 4.746 & .00512 & 2.635 & .00515 & 1.56 & 1.730 \\
\hline 90 & 7.738 & .00740 & 2.651 & .00515 & 2.43 & 4.430 \\
\hline 105 & 9.060 & .00584 & 1.426 & .00740 & 4.41 & 6.260 \\
\hline 120 & 7.596 & .00518 & 0.424 & .00518 & 13.00 & 5.960 \\
\hline 145 & 3.923 & .00512 & 0.137 & .00679 & 19.20 & 3.140 \\
\hline 170 & 1.166 & .00740 & 0.003 & .00519 & 248.00 & 0.966 \\
\hline 185 & 0.239 & .00510 & 0.0006 & .00679 & 283.00 & 0.198 \\
\hline \multicolumn{7}{|c|}{ Guide Tube } \\
\hline 135 & 2.399 & .00510 & 0.007 & .00562 & 52.60 & 4.420 \\
\hline 155 & 2.483 & .00649 & 0.0007 & .00516 & 261.00 & 2.060 \\
\hline
\end{tabular}


TABIE 6.4

Infinitely Dilute

Manganese Foil Cadmium Ratios and Thermal Flux

Configuration \#3

\begin{tabular}{|c|c|c|c|c|c|c|}
\hline \multirow[b]{2}{*}{$\begin{array}{l}\text { Radius } \\
(\mathrm{cm})\end{array}$} & \multicolumn{2}{|l|}{ Bare Foil } & \multicolumn{2}{|c|}{ Cad.Cov.Foil } & \multirow[b]{2}{*}{$\begin{array}{l}\text { Cadmium } \\
\text { Ratio } \\
\end{array}$} & \multirow{2}{*}{$\begin{array}{l}\text { Thermal Flux } \\
\mathrm{n} / \mathrm{cm}^{2}-\mathrm{sec} / \text { watt } \\
\mathrm{x} 10^{-6}\end{array}$} \\
\hline & $\begin{array}{c}\mathrm{d} / \mathrm{m} / \mathrm{gm-watt} \\
\mathrm{x} 10^{-5}\end{array}$ & $\begin{array}{l}\text { wt } \\
(\mathrm{g}) \\
\end{array}$ & $\begin{array}{c}\mathrm{d} / \mathrm{m} / \mathrm{gm} \text {-watt } \\
x \quad 10^{-4} \\
\end{array}$ & wt. & & \\
\hline Sensor h & & & & & & \\
\hline 5 & 4.368 & .0433 & 12.720 & .0460 & 2.15 & 0.692 \\
\hline 35 & 5.648 & .0437 & 13.180 & .0420 & 2.62 & 0.980 \\
\hline 60 & 5.262 & .0432 & 13.410 & .0410 & 2.46 & 0.889 \\
\hline 90 & 28.770 & .0415 & 13.580 & .0460 & 10.60 & 6.160 \\
\hline 105 & 44.950 & .0427 & 33.760 & .0433 & 6.96 & 9.360 \\
\hline 120 & 39.580 & .0426 & 1.845 & .0480 & 101.00 & 8.870 \\
\hline 145 & 21.920 & .0415 & 0.116 & .0440 & 909.00 & 4.930 \\
\hline 170 & 7.613 & .0430 & 0.049 & .0438 & 743.00 & 1.710 \\
\hline 175 & 4.972 & .0430 & 0.020 & .0423 & 1237.00 & 1.120 \\
\hline 185 & 1.168 & .0459 & 0.037 & .0430 & 152.00 & 0.212 \\
\hline \multicolumn{7}{|c|}{ Guide Tube } \\
\hline 97.5 & 9.740 & .0424 & 12.420 & .0468 & 8.00 & 4.160 \\
\hline 120 & 41.920 & .0480 & 0.826 & .0438 & 245.00 & 9.420 \\
\hline 135 & 1.465 & .0434 & 0.326 & .0423 & 22.40 & 0.323 \\
\hline 155 & 15.950 & .0456 & 0.035 & .0467 & 2160.00 & 3.590 \\
\hline 170 & 3.540 & .0439 & 0.051 & .0459 & 328.00 & 0.796 \\
\hline
\end{tabular}




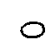

。

N $\omega$

○

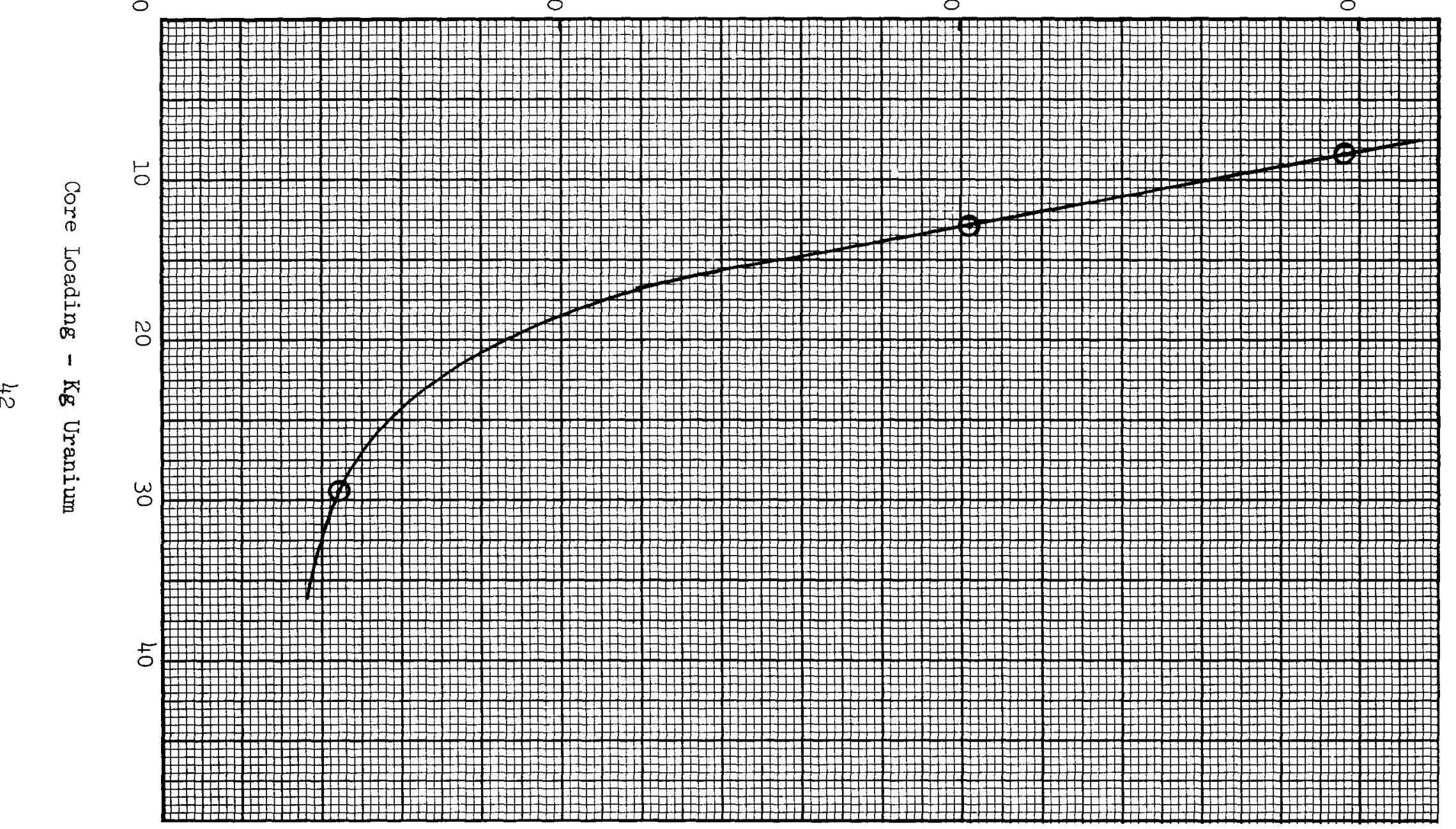

Fig. 6.1 Fuel Worth vs Core Loading 


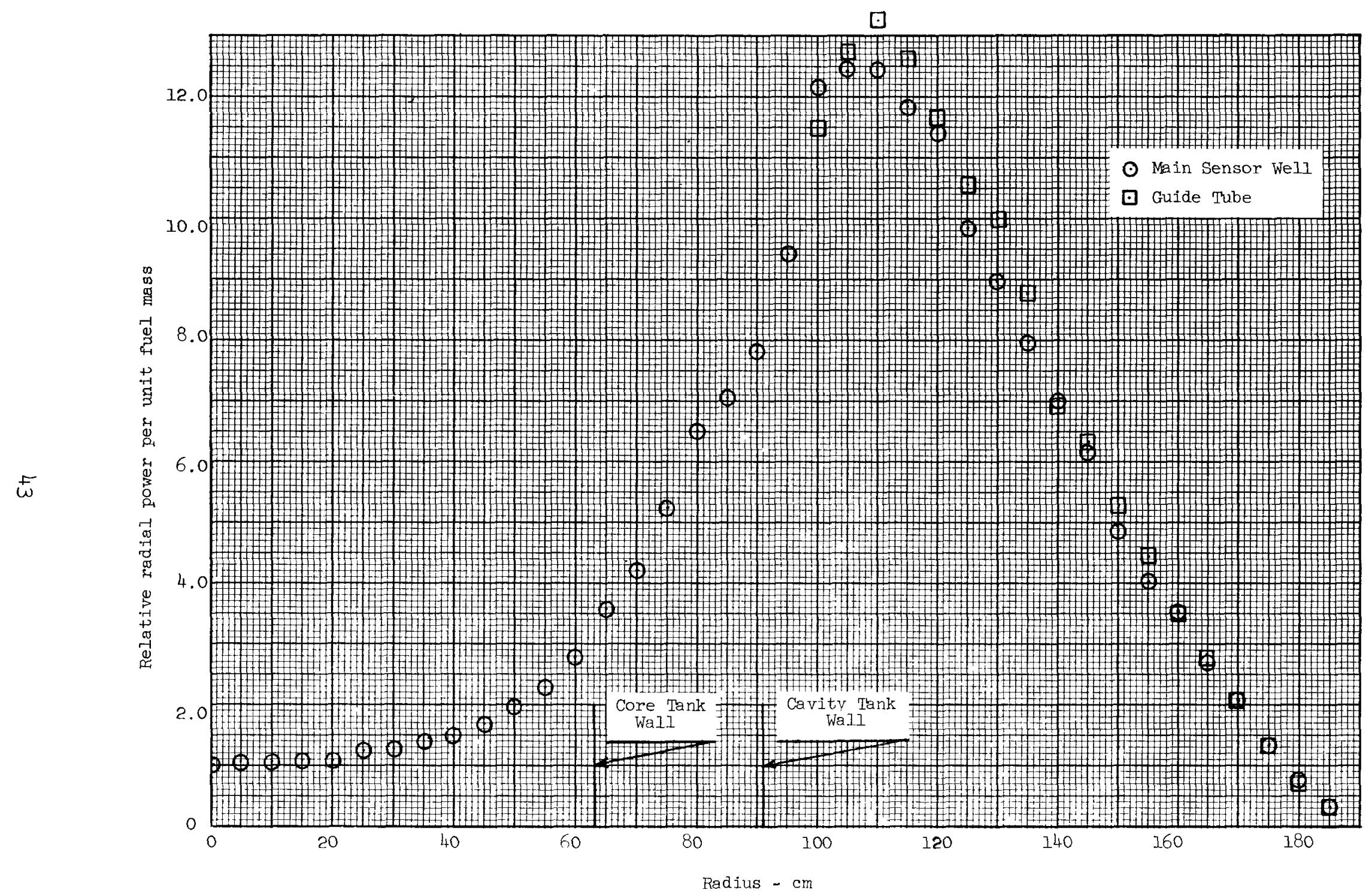

Fig. 6.2 Relative specific power (U-235 fission rate) Configuration \#3 


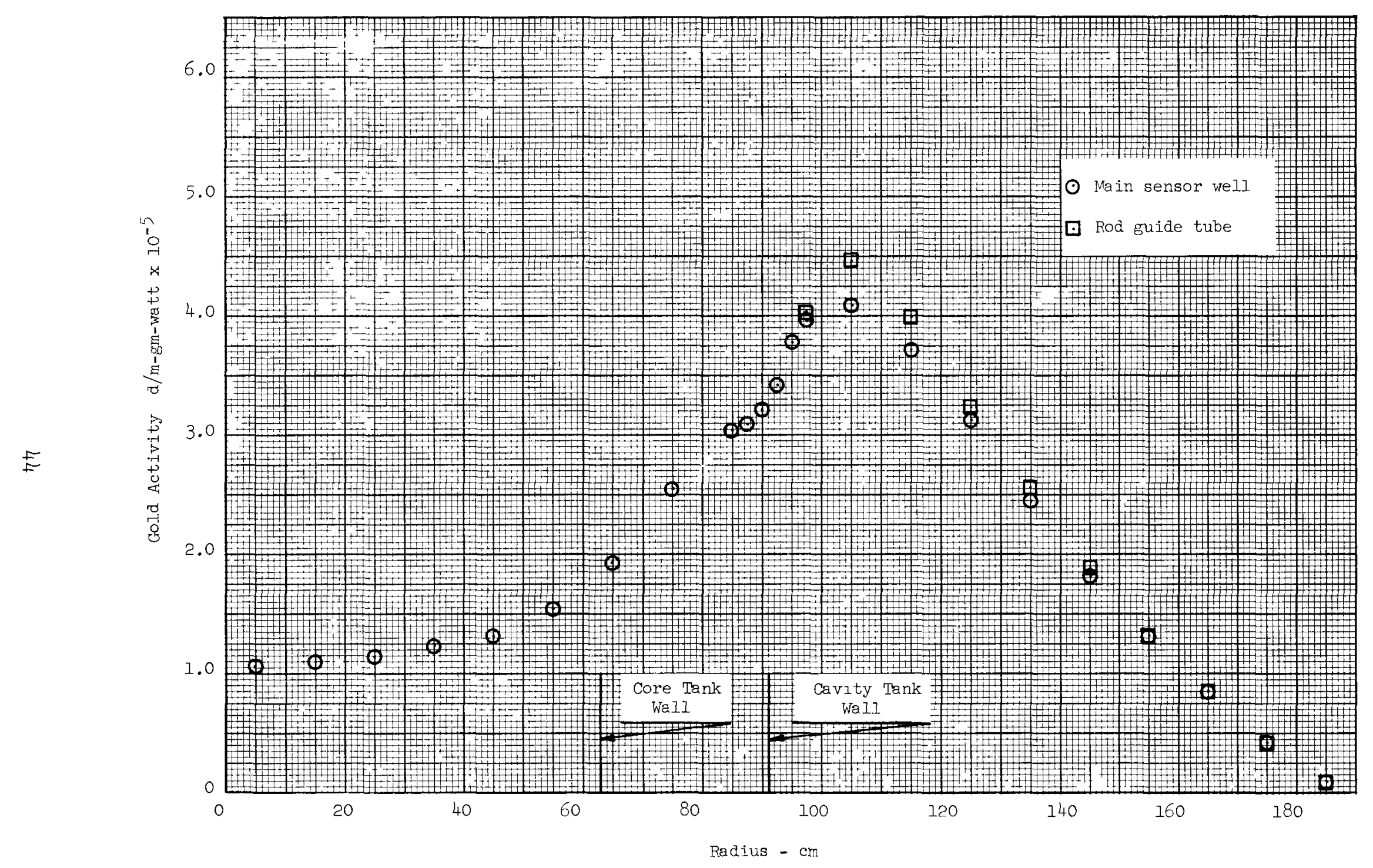

Fig. 6.3 Radial bare gold activity (d/m/gm-watt) Configuration \#3 


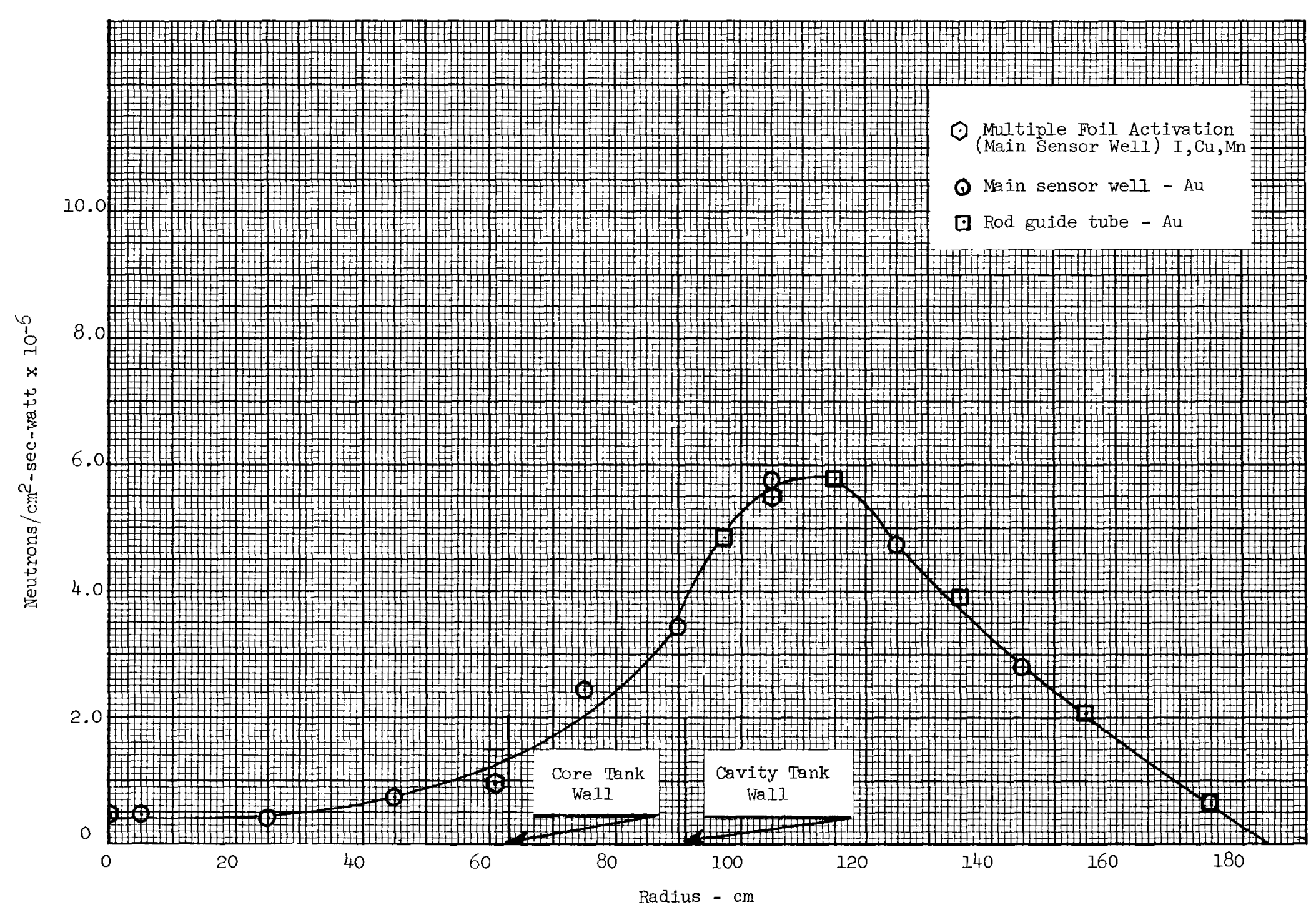

Fig. 6.4 Radial gold determined thermal flux - Configuration \#3 


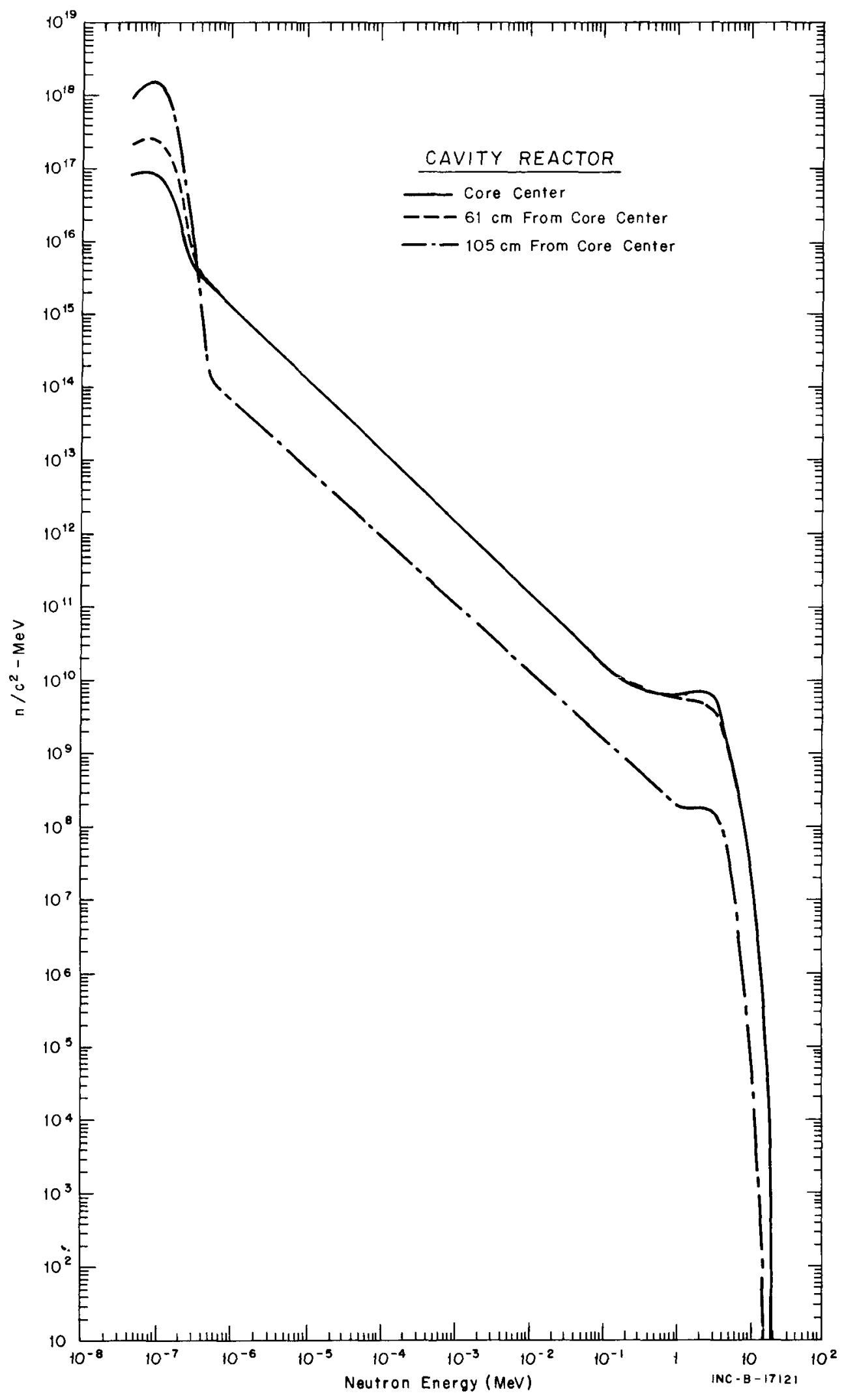

Fig. 6.5 Neutron spectrum determined from multiple foils activation 
The gas core will require substantial reactivity control to compensate for fluctuations in the reactivity created by shifts in the boundary between the hydrogen and uranium. Waves of the order of $2 \%$ to $3 \% \Delta \mathrm{k}$ might occur (Ref. 4). Therefore, an experjmental study of a number of control systems was performed on Configuration \#3.

\subsection{Designs}

The heavy water ( $D_{2} d$ reflector of the gas core (cavity) reactor offers an ideal Iocation for control devices. The commercial grade of $\mathrm{D}_{2} \mathrm{O}$ has a mean free absorption path length for thermal neutrons of about $12,000 \mathrm{~cm}$. Thus poison, even if placed only as discrete chunks in the reflector will substantially increase the absorption. Also, the average thermal flux in the reflector is 3 to 4 times what it is in the core, making absorption cross section added to the reflector particularly effective as a control method.

Several methods of moving poison control devices within the reflector can be envisioned. Four such devices measured with this reactor are shown schematically in Figure 7.1. The control rod method was utilized as the principal control device for operation of the critical. The control drum method has been used in some other reactor designs having cylindrical reactor boundaries. Control drums appear somewhat awkward when inserted in a spherical reflector, but nevertheless short drums can be fit into the system. The cap ("skull cap") and sleeve are schemes generally peculiar just to this type of reactor. They can very conveniently be designed into a spherical reflector. The dimensions of these control devices are shown in the sketches (Figure 7.1). Cadmium was the absorber material for all except the control rods, which contained boron carbide.

\subsection{Measurement Method}

Since all of the control devices considered must provide large amounts of reactivity control, evaluation of their worth requires techniques that can measure values of 2 to 20 dollars of reactivity. Operationally (and perhaps analytically) the prompt neutron decay via the pulsed neutron method is the most direct evaluation technique. Reference 12, for instance, is a relatively thorough article reviewing some of the now standard techniques, and it discusses their limitations and uncertainties. The reader is referred to this article and the subsequent article in the same issue for general background information.

In the case of the gas core cavity reactor, only the socalled Simmons-King (ref. 13) method of direct evaluation of reactivity from the decay rate of the pulse is generally applicable. The area-ratio methods of Sjostrand, Gozani, and Garelis and Russell can only be used for evaluating highly subcritical conditions of 5 dollars or more. This is because at lower levels of subcriticality the prompt neutron decay rate is of the same order of magnitude as that of the fastest delayed neutron group 
( $1 / 3$ second mean lifetime or $\lambda=3 \mathrm{sec}^{-1}$ ). Hence, only for total control system worth was an area-ravio method attempted. However, the timebudget limitations on the experiment generally left much to be desired in the accuracy and usefulness of this data.

The system was pulsed through a thimble-type tube extending into the reflector. The neutron producing target was approximately $2 \mathrm{~cm}$ from the cavity wall. The neutron decay was monitored with a small boron coated chamber inserted into an empty control rod guide tube until it nearly touched the cavity wall. Pulse widths were approximately one millisecond or less; repetition rates between 0.5 and 3 pulses per second, depending on the speed of the decay. Thus, even for the fastest repetition rate used the delayed neutron background was not constant (though the small correction for the fastest delayed groups could be made with little overall uncertainty fro the 3 pulse/second rate). All decay data was monitored with a 256 channel time analyzer. A typical plot is shown in Figure 7.2. The pulse "buildup" extends for a modal contamination, which is not unexpected unless the detector and source could both be placed near the reactor center.

7.3 Results of Pulsed Neutron Data

Because of the overlap of the faster delayed neutron decay rates with that of the prompt decay, the Simmons-King (ref. 13) (or $\alpha$-method) was the principal method used for converting $\alpha$ to reactivity. All of the data was analyzed by least squares fitting to a single exponential plus background, $\phi=A e^{-\alpha t}+B$, three parameters. Double exponential fits yielded nothing significant other than a long decay component approximately equal to the average delayed neutron decay constant. The results of the various measurements are show in Table 7.1. To apply the SimmonsKing $\alpha$-method, one must know the prompt neutron lifetime. Unfortunately, the lifetime varies with the amount of control inserted into the reactor. The I/v-lifetime was calculated, using a 19-group diffusion code, to be 2.4 milliseconds without control in the reflector. With all the control rods inserted (3.5\% subcritical), the calculated lifetime was 2.14 milliseconds. However, the measurements at or near critical vs those with the control rods inserted showed the reverse (and unexplainable) trend, 2.52 milliseconds near critical but 2.9 milliseconds with control rods in. A thorough experimental investigation of this anomaly was precluded by programmatic obligations. It is assumed that the location of the chamber, surrounded by control rods, involved long-lived higher order harmonics. These then influenced the apparent decay, giving a different result from the fundamental mode, uniformly poisoned reflector, which the calculation simulated for the control system worth. 
The results for the worths of the four main control systems measured were deduced from the calculated and measured lifetimes, and appropriately averaged.

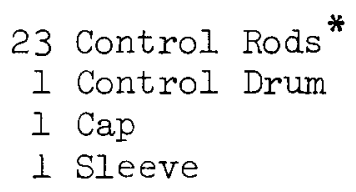

Total Worth $\% \Delta \mathrm{k} / \mathrm{k}$

$$
\begin{aligned}
& (3.8 \pm 0.4) \\
& (2.0 \pm 0.3) \\
& (3.9 \pm 0.5) \\
& (17 \pm 4.0)
\end{aligned}
$$

Worth $\frac{\% \Delta \mathrm{k} / \mathrm{k}}{\mathrm{cm}^{2}}$

$1.44 \times 10^{-3}$

$1.58 \times 10^{-3}$

$.96 \times 10^{-3}$

(Note: One dollar $=0.788 \% \Delta \mathrm{k}$ )

Figure 7.3 shows the worth shape curves of these four control methods.

All of these control methods provide large control margins, if one considers using a number of drums or caps (such as six). The worths of six will not be six times the worth of one. But the effect of interactions of the control elements is not sufficient to alter the conclusion that large amounts (order of $10 \% \Delta \mathrm{k}$ and above) can be achieved by reflector control schemes, despite the uncertainties in the experimental results.

*This value is that from the inverse kinetics analysis, and is about 12\% lower than the incremental summed rod worths. It does, however, give the best consistency with the overall pulsed neutron results. 
Control Rods
$0.55 \%$ subcritical ${ }^{*}$
$0.0054 \pm 0.0006$
$3.54 \%$ subcritical ${ }^{*}$
$0.0149 \pm 0.0002$

Single Drum

Position of Poison

$\begin{aligned} 0^{\circ} \text { (toward core) } & 0.01095 \pm 0.00004 \\ 45^{\circ} & 0.0062 \pm 0.0001 \\ 90^{\circ} & 0.0043 \pm 0.0001 \\ 135^{\circ} & 0.0032 \pm 0.0001 \\ 180^{\circ} \text { (pointing outward) } & 0.0034 \pm 0.0003\end{aligned}$

Cap

Cm from Cavity WaI1
2.5
$0.0163 \pm 0.0001$
12.5
$0.0125 \pm 0.0002$
30.5
$0.0075 \pm 0.0002$
61
$0.0046 \pm 0.0003$

Sleeve

Cm that Center is above Midplane

$\begin{array}{lll}18 & 0.077 & \pm 0.001 \\ 30 & 0.077 & \pm 0.001 \\ 45 & 0.0575 \pm 0.0004 \\ 76 & 0.0289 \pm 0.0004\end{array}$

'Lnown from previous control rod calibrations using inverse kinetics and bump period. 

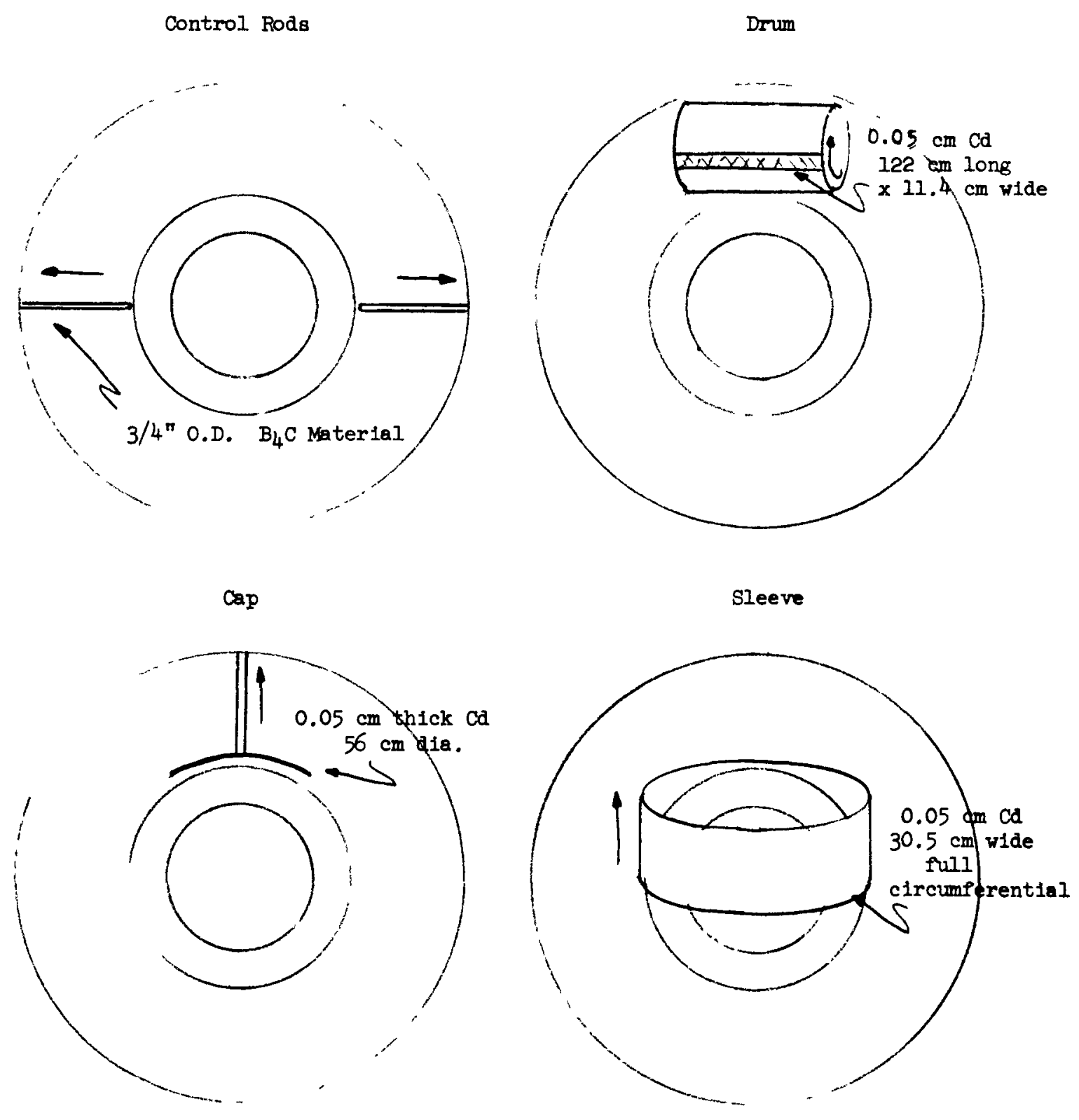

Figure 7.I Control Schemes 
LOG (Detector Response)

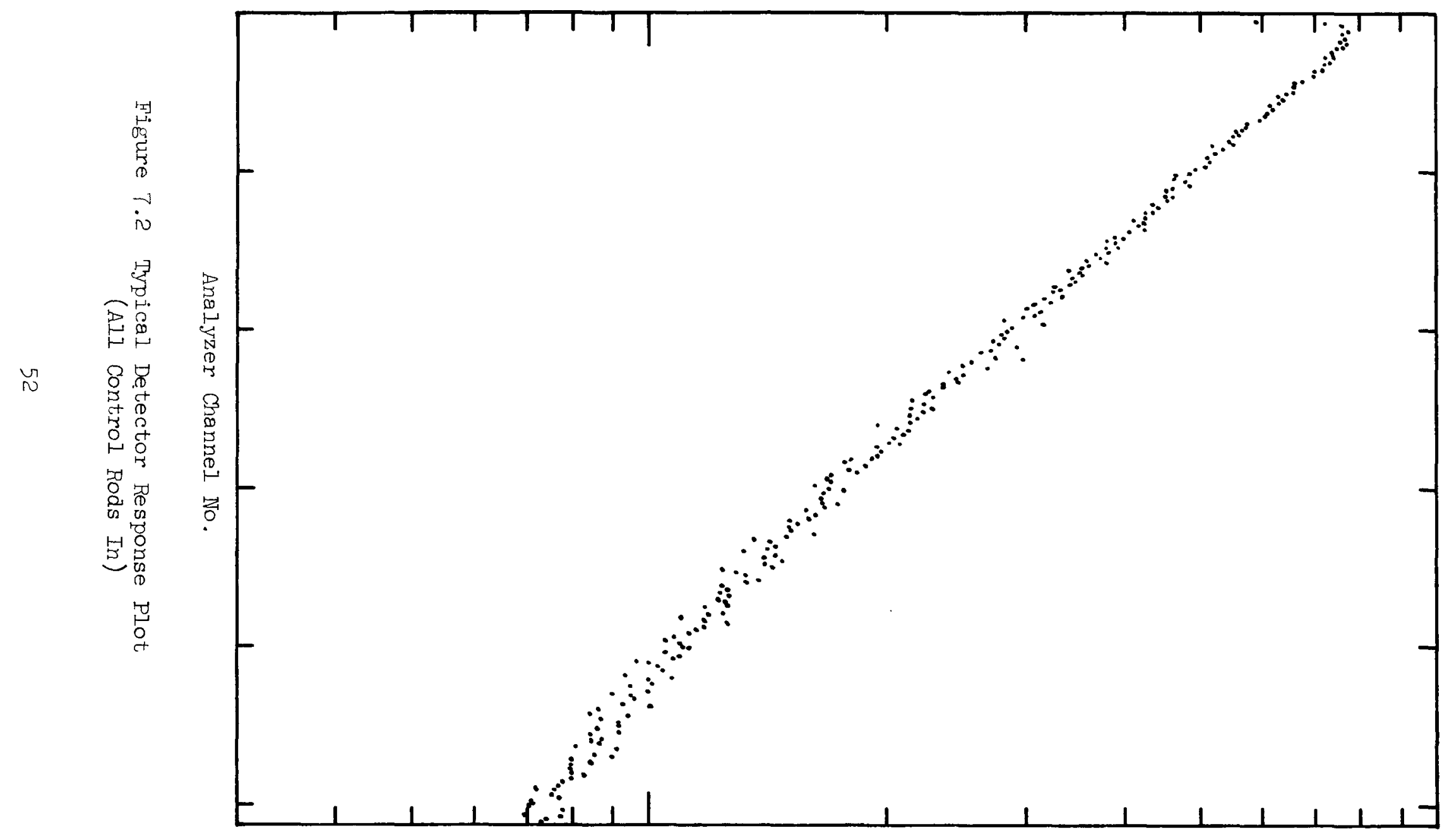



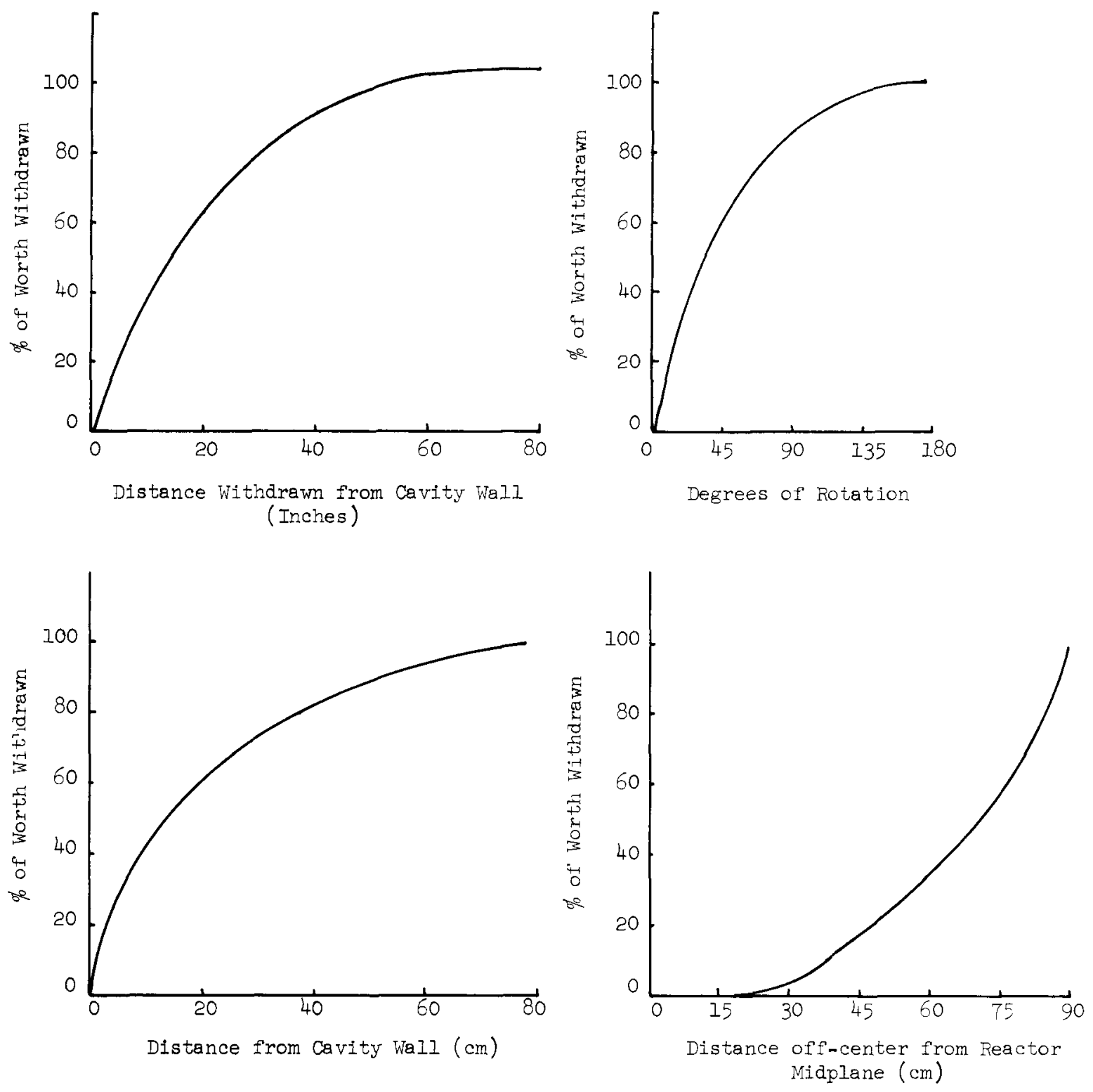

Figure 7.3 Control Worth Shape Curves 
Reactor physics calculations were performed on the three basic configurations using multi-energy-group computer codes. Because of the spherical symmetry of the configuration, all calculations were carried out in one-dimensional spherical geometry. A diffusion theory code using 19 energy groups with only one Maxwell-Boltzmann thermal group was used for routine operational predictions. For calculating absolute values of $\mathrm{k}$-effective this code gives a bias factor of about $3 \%$. However, for predicting $k$-excess differences for minor changes in a configuration, the code is a useful reactor operational tool.

The principal calculations to predict the initial fuel loadings for each configuration were performed with a $S_{n}$-transport theory code, SCAMP (ref. 14). The analyses were all done in $\mathrm{S}_{4}$ angular detail. Reference 6 discusses the sensitivity of gas-core reactor calculations to the space energy and angle parameters. The spatial detail with one dimensional calculations could use a much finer mesh than was used in the two dimensional calculations reported in Reference 6 . In this spherical geometry, 62 mesh points were usually employed. For energy group structure, 12 fast and slowing down groups and 7 thermal groups with up scatter were employed, for a total of 19 energy groups. The energy group structure is given in Table 8.1. The fast cross section were obtained from a 99-group GAM-II tape modified for use with the PHROG (ref. 15) (Phillips-Hanford Revision Of GAM) code. The thermal cross sections were obtained from the code INCITE (ref. 16), similar to GATHER. The cross sections obtained from the Idaho codes were compared to those obtained from GAM-GATHER codes at the Lewis Research Center, and appropriate corrections were made to obtain the ostensibly most satisfactory set possible from the two sets of codes.

With the detail specified above in angle, space, and energy, typically 120 to 150 outer iterations had to be run before k-effective was converged to within 0.0001 and the pointwise fluxes to within 0.0002 . The initial calculations were done with the support column aluminum and void homogenized throughout the $\mathrm{D}_{2} \mathrm{O}$ reflector. The predicted critical mass for the first configuration was $8.4 \mathrm{~kg}$. The actual measured mass turned out to be $8.434 \mathrm{~kg}$ after applying the various corrections for the support column. Strangely, the calculated fuel worth was 10 by $50 \%$ compared to the measured value of $2.96 \% \Delta \mathrm{k} / \mathrm{kg} \mathrm{U}$. Despite the good success on the critical loading prediction, success was not as good on the other two basic configurations. Initial calculations on these, grossly underpredicted the critical loading. Calculated k-effectives were high by as much as 10\%. One cause of this serious discrepancy was an incorrect scattering kernel for polyethylene in the low energy thermal groups. When the water kernel was used for hydrogen, the bias on k-effective was reduced to about $3 \% \Delta \mathrm{k}$ for these last two configurations. Most of this bias is attributed to the hydrogen in the form of $\mathrm{CH}$ and $\mathrm{CH}_{2}$. The absorption cross sections are probably correct, but the scattering is suspected as being the major calculational problem. The change from Configuration 2 to Configuration 3, which was the addition of $0.075 \mathrm{~cm}$ of stainless steel to the cavity was calculated to within $0.5 \% \Delta \mathrm{k}$. The total worth of the change was experimentally determined to be $-15.3 \% \Delta \mathrm{k} / \mathrm{k}$. Table 8.2 is a summary of the calculated eigenvalues for the three configurations measured in this experiment. 
There appear to be no other major problems with the analytical calculations except that with hydrogen worth and fuel worth. The calculated spectra were equivalent to the measured spectra, within the accuracy of the measurements (See Section 9.0). The inability to accurately predict fuel worth has been a general problem in previous work (ref. 6) and the reason for the discrepancy is not understood. This problem does lead to some concern for the ability to predict criticality accurately with other fuels (Pun239or U-233). However, the hydrogen discrepancy is far too severe, and deserves more immediate attention. The sensitivity of the calculation to the hydrogen scattering kernels needs to be evaluated, and then the correct kernels for the hydrogen in the experiment must be developed. Ironically, the operation of a gas core at high temperatures involves major changes in the hydrogen scattering properties and the absorption of uranium fuel. Since neither of these materials are ostensibly being handled correctly at present at "room" temperatures, the high temperature calculations are considerably in doubt. Some of the high temperature hydrogen effects are covered in Reference 17. 
TABLE 8.1

Cross Sections 19-Energy Group Format

\begin{tabular}{ccc}
\hline Group & $\begin{array}{c}\text { Lower } \\
\text { Lethargy }\end{array}$ & $\begin{array}{c}\text { Lower } \\
\text { Energy } \\
\text { (Mev) }\end{array}$ \\
\hline 1 & 1.0 & $3.7 \times 10^{0}$ \\
2 & 1.5 & $2.2 \times 10^{0}$ \\
3 & 2.0 & $1.4 \times 10^{-1}$ \\
4 & 3.0 & $5.0 \times 10^{-1}$ \\
5 & 4.0 & $1.8 \times 10^{-1}$ \\
6 & 5.0 & $6.7 \times 10^{-2}$ \\
7 & 6.0 & $3.5 \times 10^{-2}$ \\
8 & 8.0 & $4.5 \times 10^{-4}$ \\
9 & 10.0 & $6.1 \times 10^{-5}$ \\
10 & 12.0 & $8.3 \times 10^{-6}$ \\
11 & 14.0 & $2.4 \times 10^{-6}$ \\
12 & 15.25 & $4.1 \times 10^{-7}$ \\
13 & 17.0 & $2.0 \times 10^{-7}$ \\
14 & 17.7 & $1.2 \times 10^{-7}$ \\
15 & 18.24 & $8.0 \times 10^{-8}$ \\
16 & 18.65 & $2.5 \times 10^{-8}$ \\
17 & 19.80 & $5.0 \times 10^{-9}$ \\
18 & 21.41 & 0.0 \\
19 & -- & \\
\hline \hline
\end{tabular}

TABLE 8.2

Calculated Eigenvalues for Three Configurations

\begin{tabular}{|c|c|c|}
\hline $\begin{array}{c}\text { Nuclear Model of } \\
\text { Table } 4.1 \\
\end{array}$ & Fuel (kg U) & Calculated $\mathrm{k}$ \\
\hline Configuration \#l & 10.0 & $1.058^{*}$ \\
\hline Configuration \#2 & 13.3 & 1.180 \\
\hline Configuration \#3 & 29.2 & 1.175 \\
\hline
\end{tabular}

*

The $10 \mathrm{~kg} U$ loading was the smallest loading calculated. A correction was made, using a fuel worth value based on measurements in previous cylindrical geometry experiments (Ref. 3) of $0.32 \% \Delta \mathrm{k} / \mathrm{kg} \mathrm{U}$, which yield the predicted critical mass of $8.4 \mathrm{~kg} \mathrm{U}$. This prediction allows for the $0.70 \% \Delta \mathrm{k}$ net penalty of the support columns and fuel line, which are non-spherical perturbations (see p.14). 
This experiment represents the second all gas core reactor critical experiment. It is the first simple, clean, spherical geometry experiment of its type and hence should be quite useful as a benchmark exnerinent. The first all-gas-core experiment was operated in 1967 (ref. 2) without incident. In the spherical experiment just completed, one minor leak incident occurred when a UFG valve diaphragm ruptured during a heat-up operation A few grams (less than 10) of UF6 were lost from the system, insuf'f'icient to noticeably alter the apparent critical mass results. Otherwise, the operation of the experiment was without incident.

The approach to criticality as the reactor was heated and the converse cooldown provided some interesting effects. Selective evaporation and cooldown were observed, as shown in Fig. 9.1. In this figure, the indicated "average" core temperatures are merely the average of four thermocouples placed at the top, middle and bottom of the outside wall and at the center (through the flux monitor tube). As the core is being heated from a shutdown condition, the fuel is most likely being evaporated from a large solid and/or liquid pool at the bottom of the sphere (depending on the pressure). As the core cools, selective condensation occurs on the cool spots of the wall first, then on the entire wall as the wall temperature equalizes. As the layer on the wall thickens, it eventually drops off or runs off to the bottom of the sphere. There is probably an optimum thin thickness of condensed fuel on the wall that gives a peak in reactivity, but a very large spike was not observed in this experiment as had been observed in the first UFG gas core experiment (ref. 2).

The ostensible temperature-reactivity coefficient shown in Figure 9.1 is caused by evaporation or condensation of the last or initial, respectively, amounts of fuel, and is therefore not a true temperature coefficient, such as due to sphere expansion. This latter coefficient was, for all practical purposes quite small and essentially unmeasurable (less than $0.001 \% \mathrm{\Delta k} /{ }^{\circ} \mathrm{C}$ ).

Multiple foil packets for obtaining neutron spectral data were exposed for two hours during a reactor run at 500 watts power. During this run it was possible to maintain the UF6 gas core at a sufficient temperature from nuclear heating to keep the core above the UF6 vaporization temperature and the external electrical heat source normally used could be shut down. This is the first time that a gas core reactor has been operated at a power level sufficient to supply its own heat for maintaining the core in the vapor state. Operation in this mode was possible for only short periods of a few minutes duration. This was not because of any problem with heat removal from the core, but was due to the necessity of keeping the inlet fuel line hot to prevent fuel migration to the cooled line which is normally heated by the air circulated from the external heaters to the core heating plenum. 
A summary of critical masses and fuel worths is given in Table 9.1. The deduced penalties of hydrogen and stainless were $11.0 \% \mathrm{k}$ and $15.3 \% \mathrm{k}$ respectively, and these values probably will be generally applicable to any similar configuration regardless of the base fuel density. Figure 9.2 is a comparison of ruel worth results in this configuration vs that in the previous cylindrical configuration (Rcf. 1 through 5). As can be seen, the curve shapes are quite similar, indicating a rather general applicability of these results to any nominally similar reactor configuration. The penalty one must pay in fuel loading to overcome a negative reactivity effect (such as increased hydrogen or wall thickness) becomes quite severe as the loading density increases.

Fine radial power profiles were obtained, with catcher foils, on each of the three configurations tested. Figure 9.3 shows the relative radial power distribution in the sensor well for all three configurations plotted on the same scale for easy comparison. This data has been normalized to a relative power of one at the center of the core. Likewise, the thermal flux calculated from thin bare and cadmium covered gold foils exposed in the sensor well, and from which infinitely dilute cadmium ratios were calculated, are plotted on the same scale for each of the configurations, in Figure 9.4. No unexpected surprises or anomalies were encountered in the detail of these power and flux maps.

The neutron energy spectra as measured using a multiplicity of resonance and threshold detectors (See 6.2.2) are compared in Figures $9.5,9.6$, and 9.7 with the calculated spectra from the 19-energy group transport calculations. It should be re-iterated that the calculated result had about a 3\% positive bias in k-effective due ostensibly to the incorrectness of the hydrogen scattering kernel. However, the energy spectra should only be affected within or very near to this very dilute hydrogen region by the scattering kernel used. Comparison of these three figures shows that the slowing down flux is not flat in lethargy and differs in slope in various parts of the reactor. Thus the flux is generally not asymptotic, and this condition stresses the need for the relatively fine energy group detail needed within the slowing down region. The same comments can be applied to the thermal region even though such detail is not apparent in the figures.

The worth of polyethylene in the void has been measured ol a number of configurations, both in cylindrical and spherical geometries. Results have varied from $0.17 \% \Delta \mathrm{k} / \mathrm{kg}$ to $0.6 \% \Delta \mathrm{k} / \mathrm{kg}$ of $\mathrm{CH}_{2}$. On some configurations there was a strong worth dependence on radial position, with the higher worth being nearest the core. The reverse appears to be true on tris latest configuration, though the perturbing influence of the steel bolts on the upper core flange may have significantly influenced the measured results. Furthermore, the trend on the previous cylindrical configurations was for lower specific polyethylene worth as the core fuel loading increased. Again, on this recent spherical configuration, the reverse appears to be the case, though the conclusion must be labeled questionable because of the presence of the steel bolts. The overall penalty of the $1 \times \mathrm{O}^{2} \mathrm{l} \mathrm{H} / \mathrm{cc}$ in the form of both polyethylene and 
TABIE 9.1

Summary of Critical Masses and Fuel Worth

for Three Configurations

\begin{tabular}{|c|c|c|}
\hline Configuration & $\begin{array}{l}\text { Critical Core Ioading } \\
\text { (adjusted for K-excess } \\
\text { and inlet line worth) } \\
\end{array}$ & $\begin{array}{c}\text { Fuel Worth } \\
\% \mathrm{dk} / \mathrm{k} \text { per } \mathrm{kg} \\
93.2 \% \text { enriched U-235 }\end{array}$ \\
\hline $\begin{array}{l}\# 1 \\
\text { Clean spherical } \\
\text { Geometry }\end{array}$ & 8.43 & 2.96 \\
\hline $\begin{array}{l}\# 2 \\
1 \times 10^{21} \text { atoms } / c c \\
\text { hydrogen added to } \\
\text { cavity as } \mathrm{CH} \& \mathrm{CH}_{2}\end{array}$ & 12.9 & 2.02 \\
\hline $\begin{array}{l}\# 3 \\
0.0762 \mathrm{~cm} \text { of stain- } \\
\text { less steel added to } \\
\text { outer cavity wall }\end{array}$ & 29.2 & 0.437 \\
\hline
\end{tabular}

polystyrene was $11.0 \% \Delta \mathrm{k}$, which reduces to an equivalent polyethylene worth of $0.42 \% \Delta \mathrm{k} / \mathrm{kg}$ assuming only the hydrogen contributes. This further assumes equivalence of hydrogen worth in the $\mathrm{CH}$ and $\mathrm{CH}_{2}$ molecules, a fact found to be true in one configuration (Ref. 5, p. 38) but not in another (Ref. 3, p. 88). Hence, the worth of hydrogen in the void has given varied results, with ostensibly no uniform trend pertaining to other reactor parameters. The calculations of its effect have likewise not met with uniform success, particularly on calculating the penalty in fuel loading between Configurations 1 to 2 of this spherical experiment. Hydrogen thus seems to present the major difficulty for this benchmark experiment, and this likely will also apply to operating cavity reactor calculations where high hydrogen temperatures will further complicate the problem. 


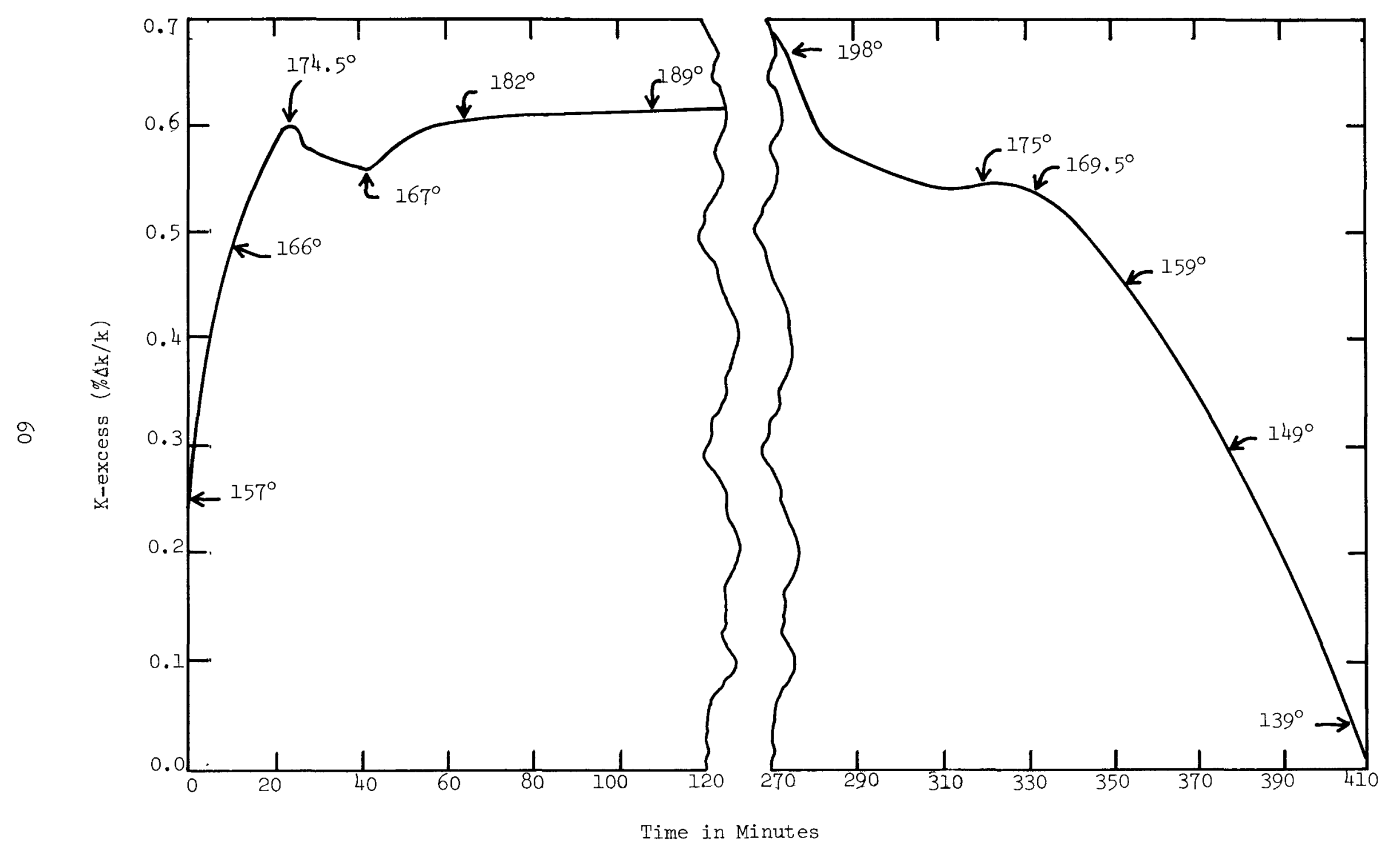

Figure 9.1 Reactivity changes during heatup and cooldown 


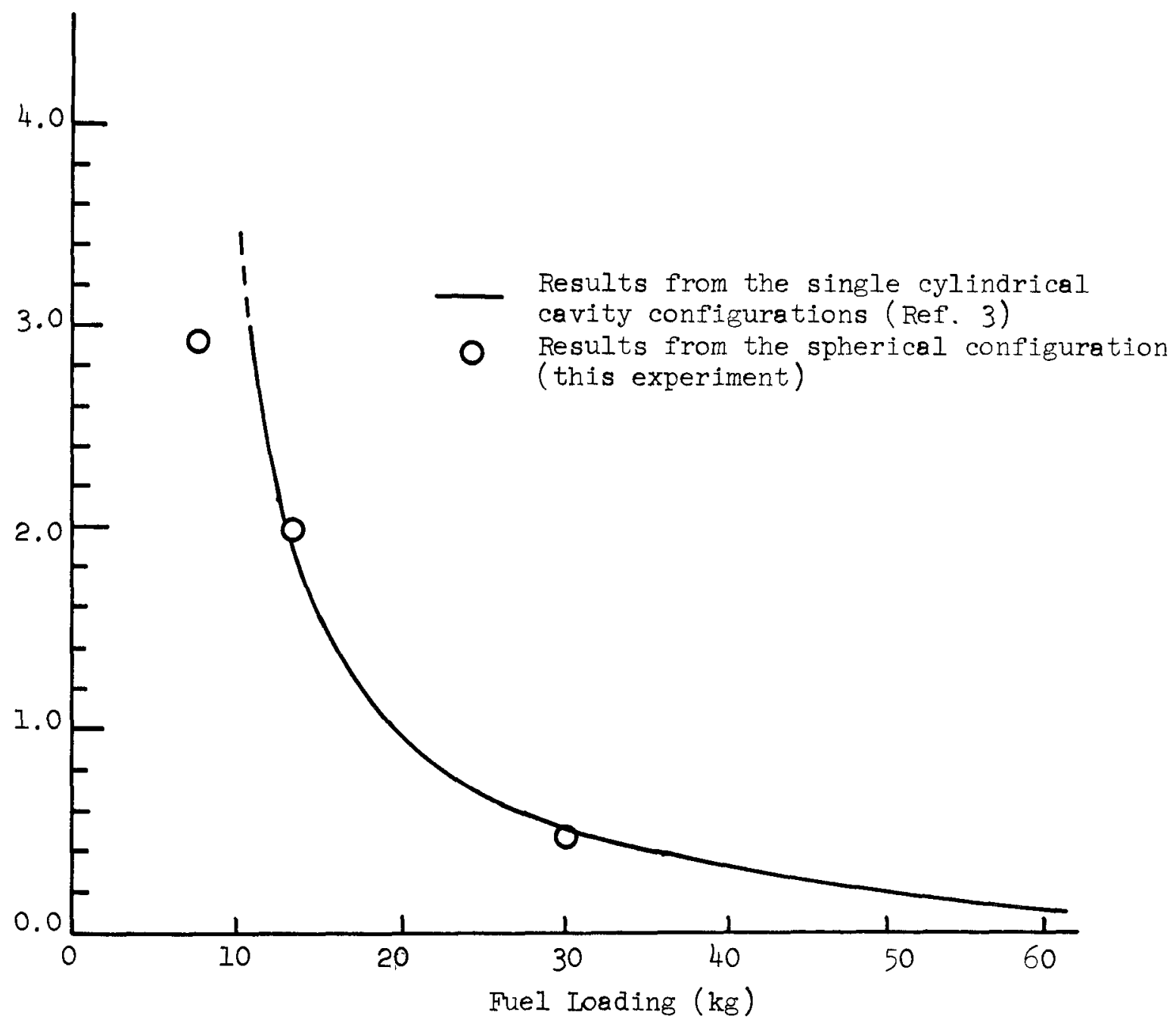

Figure 9.2 Comparison of Fuel Worth vs Fuel Iosding for Two Configurations 


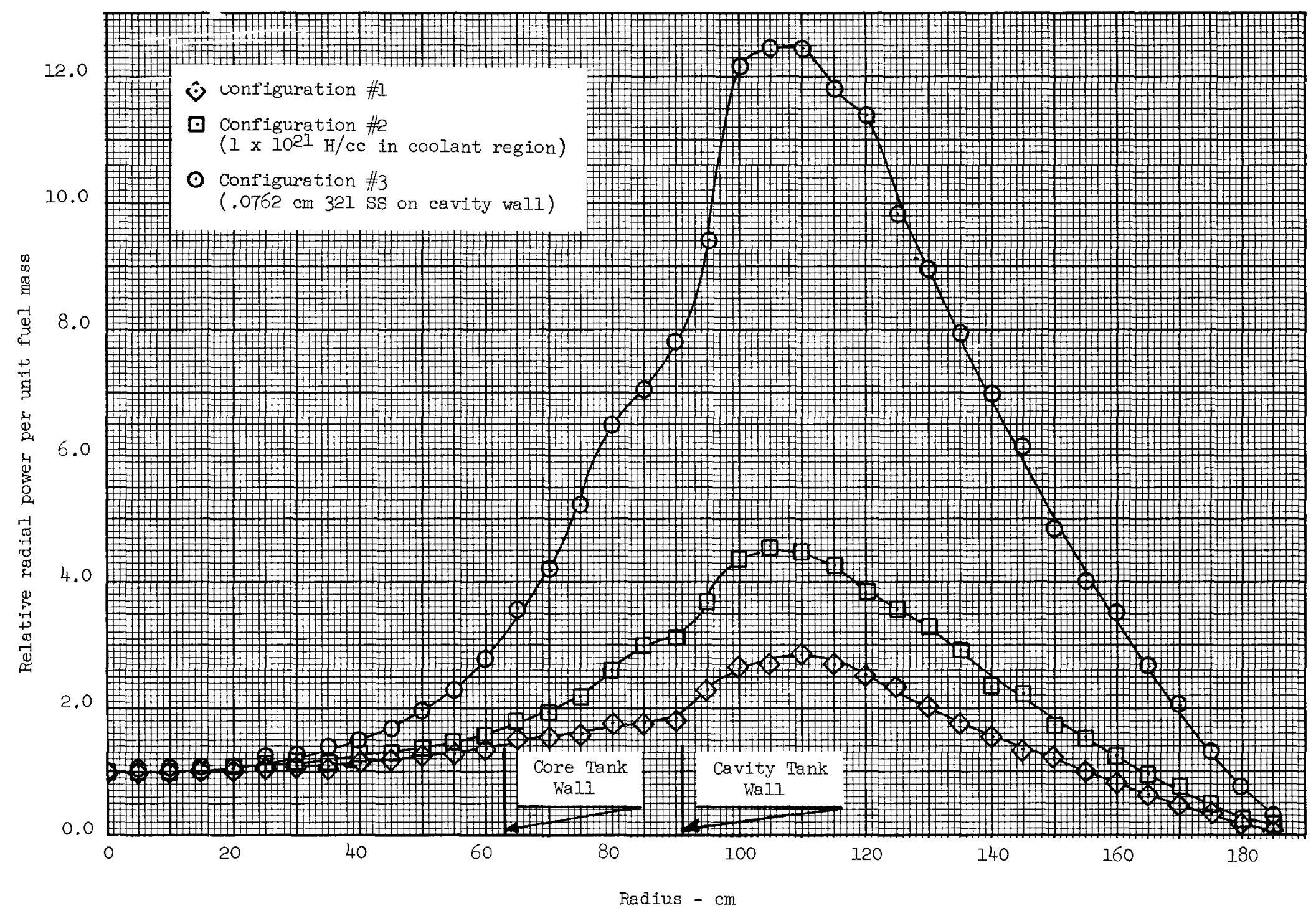

Fig. 9.3 Comparison of relative radial fission rate for three Spherical Cavity Reactor Configurations 


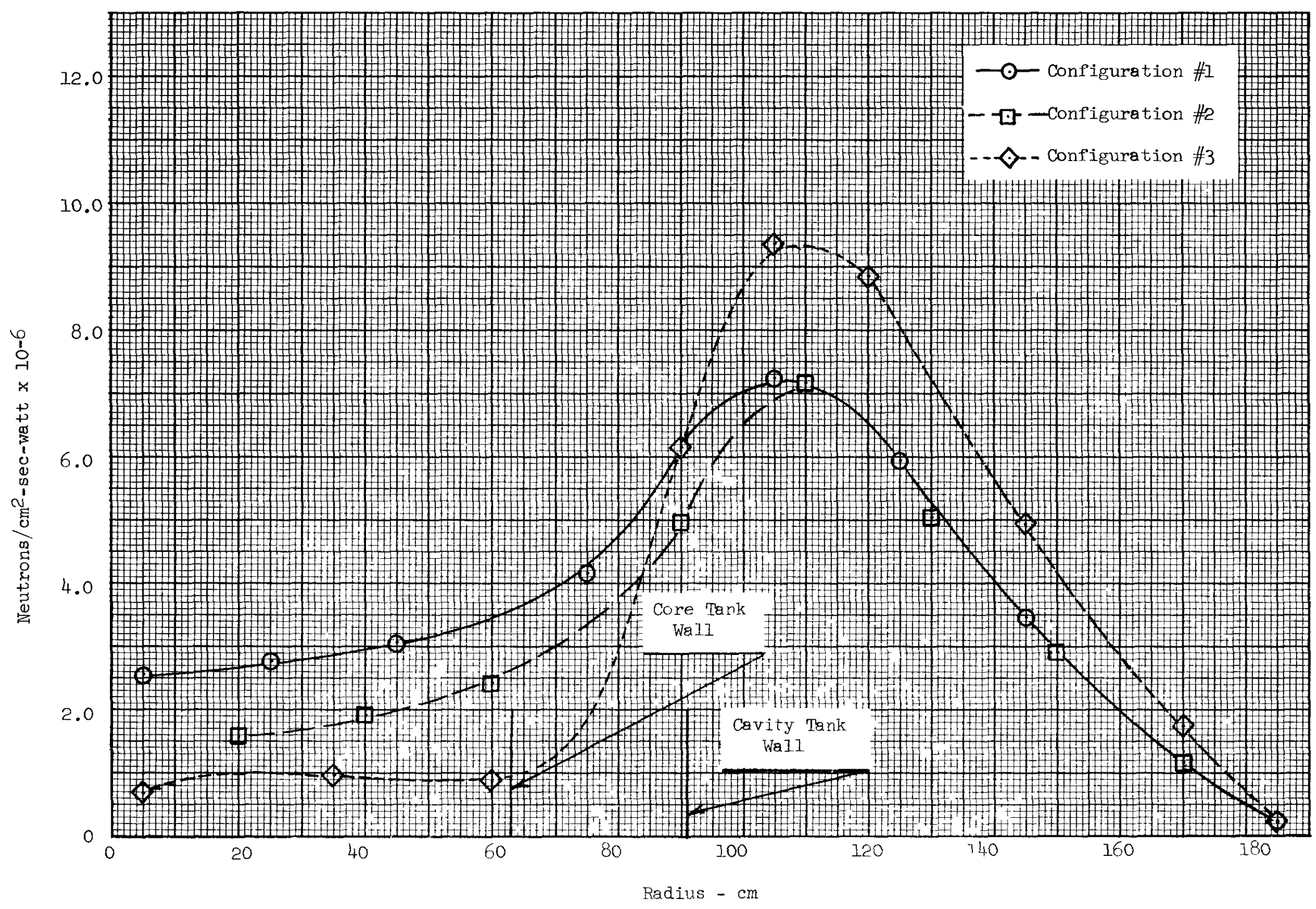

Figure 9.4 Thermal neutron flux determined from bare and cadmium covered gold foils in the sensor well for three configurations 


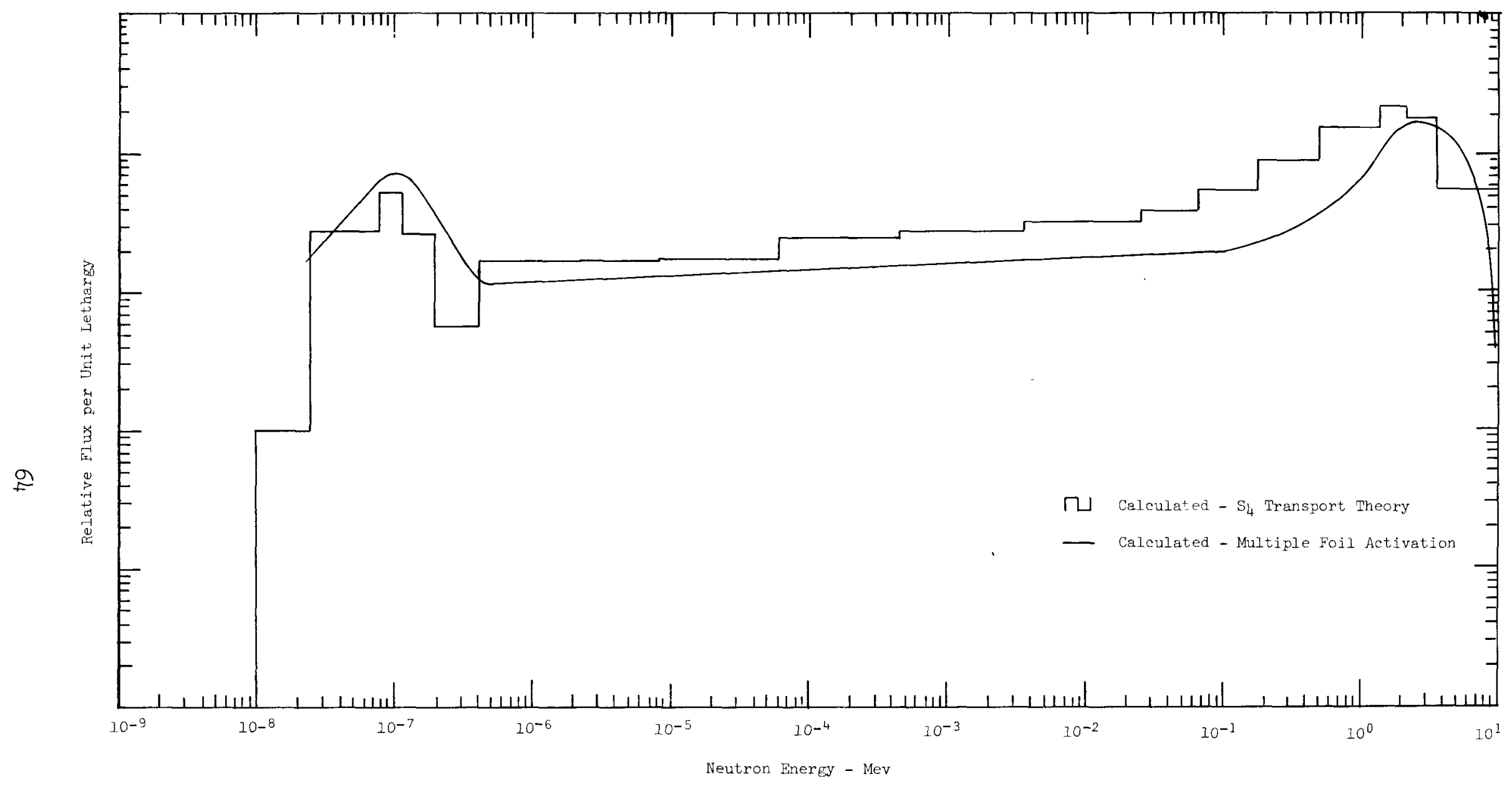

Fig. 9.5 Comparison of neutron spectra calculated from multiple foil exposure and calculated with $S_{4}, 19$ energy group, transport theory (SCAMP code) at a radial distance of $0.0 \mathrm{~cm}$. 


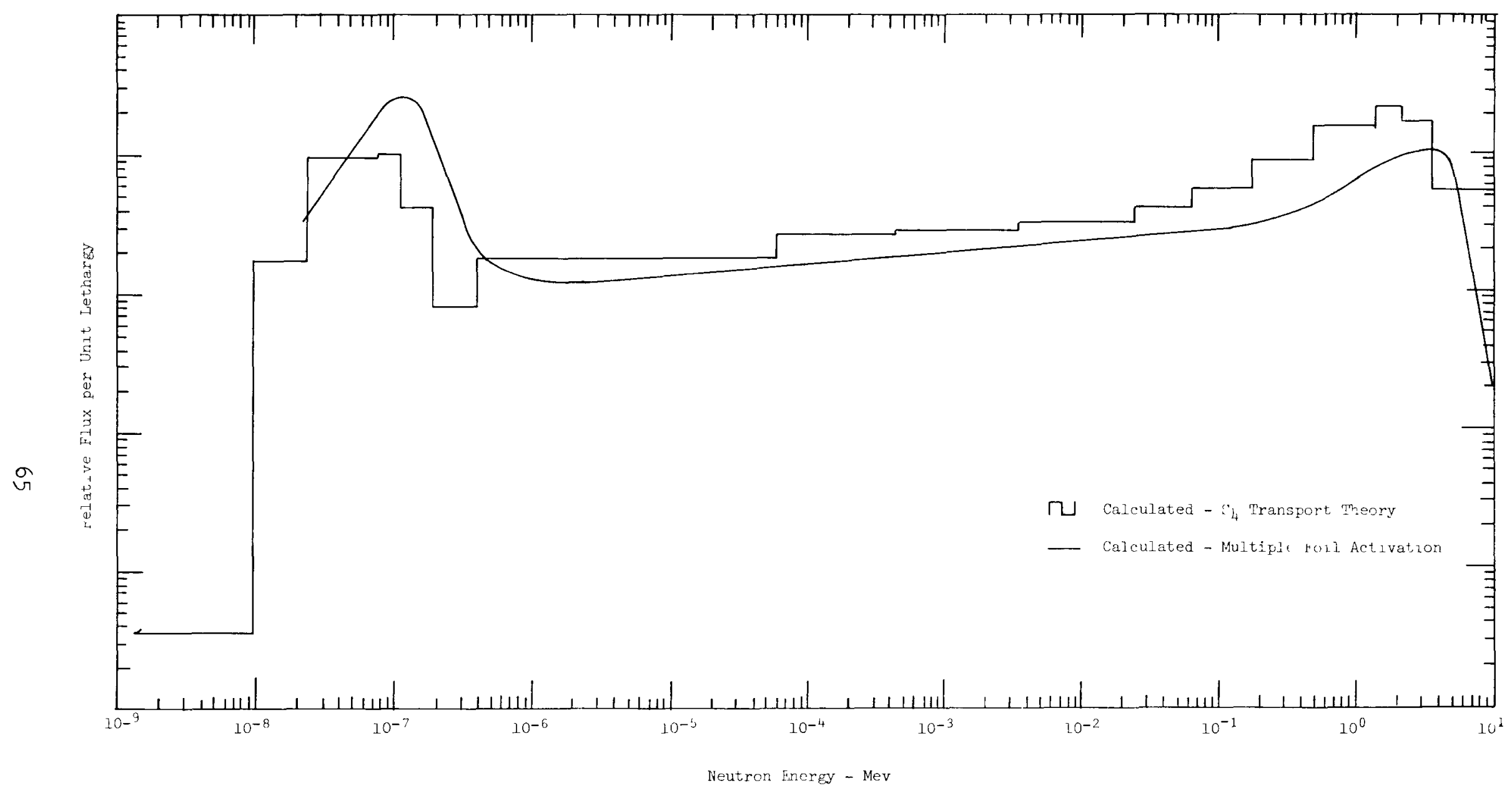

Fig. 9.6 Comparison of neutron spectra calculated from multiple foil exposure and calculated with $\mathrm{S}_{4}$, 19 energy group, transport theory (SCAMP code) at a radial distance of $61.0 \mathrm{~cm}$. 


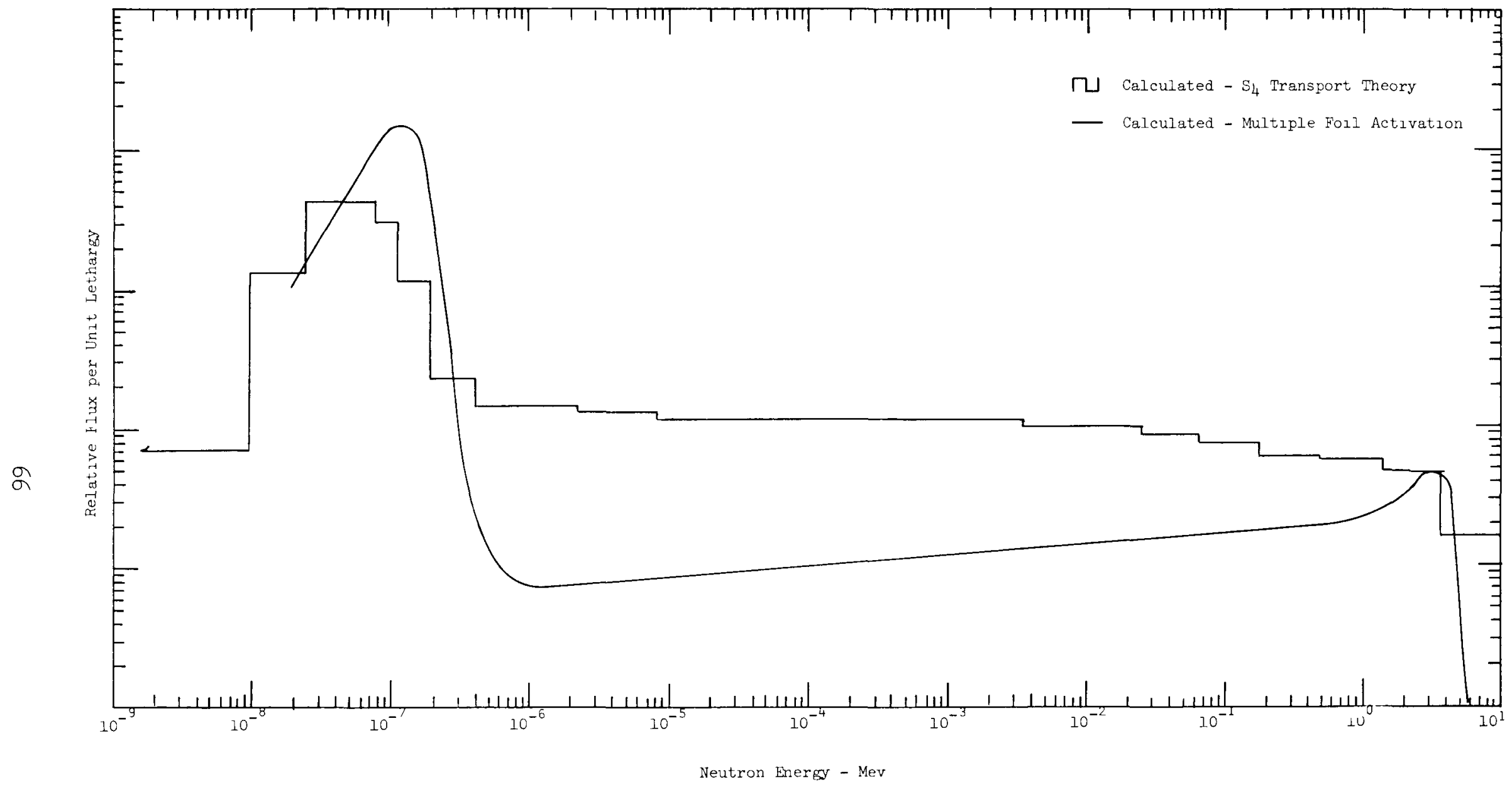

Fig. 9.7 Comparison of neutron spectra calculated from multiple foil exposure and calculated with $\mathrm{S}_{4}$, 19 energy group, transport theory (SCAMP code) at a radial distance of $105.0 \mathrm{~cm}$. 
1. The spherical symmetry with non-spherical perturbations being worth less than $1 \% \Delta \mathrm{k}$ makes this an ideal benchmark experiment for comparison with one dimensional spherical calculations.

2. The penalty for hydrogen and neutron absorbing cavity walls is just as severe as in previous experiments, despite the relatively clean reflector in these latter configurations. Hydrogen with a density of $1 \times 10^{21} / \mathrm{cc}$ in the "void" raised the critical mass from 8.43 to $12.9 \mathrm{~kg}$. Then $0.076 \mathrm{~cm}$ extra thickness of stainless steel on the cavity wall ( 0.019 mean free absorption paths) raised the critical mass to $29.2 \mathrm{~kg}$.

3. Calculational difficulties exist with hydrogen (appears as a major effect on k-effective) and with the fuel (fuel worth incorrectly predicted). Since the temperature of these materials will change drastically between this cold experiment and operating gas-core reactor conditions, these two materials represent major reactor physics problems.

4. Control methods and control adequacy for system reactivity does not appear to be a problem. Very large amounts of reactivity can be controlled with several different schemes.

5. As a result of these experiments, it appears that the next appropriate developmental step, that of a flowing gas critical experiment can be undertaken safely with respect to criticality control. 


\section{APPENDIX A}

\section{Calculation of Infinitely Dilute Cadmium Ratios from Resonance Foil Activities}

The following procedure was used to correct bare and cadmium covered resonance foil activities for self shielding and give cadmium ratios and thermal flux based on infinitely dilute foils. A single level resonance formula was employed as follows:

$$
\left.A=B\left(\frac{I_{\infty}}{I_{\text {eff }}}\right) \text { where } \frac{I_{\infty}}{I_{\text {eff }}}\right)=\frac{1}{\sqrt{S / 4 n v+\sigma_{0}(\Gamma \gamma / \Gamma)}}
$$

In terms of the foil radius and weight this reduces to

$$
A=\frac{B}{\sqrt{\frac{\pi R^{2} \rho}{\pi R^{2} \rho+2 N W \sigma_{0}(\Gamma \gamma / \Gamma)}}}
$$

where:

$A=$ Infinitely dilute cadmium covered foil activity per gram

$B=$ Uncorrected cadmium covered foil activity in activity per gram

$\mathrm{R}^{2}=$ Foil radius in $\mathrm{cm}$

$\rho=$ Foil density in grams $/ \mathrm{cm}^{3}$

$\mathrm{N}=$ Number of absorbing atoms $/ \mathrm{cm}^{3}$

$W=$ Cadmium covered foil weight

$\sigma_{O}=$ Theoretical peak cross section of resonance

$\Gamma \gamma=$ Gamma width

$\Gamma=$ Total width $(\Gamma \gamma+\Gamma n)$

$I_{\infty}=$ Infinitely dilute resonance integral

Ieff= Effective resonance integral

$\mathrm{S}=$ Foil surface area

$\mathrm{V}=$ Foil volume 
The sub-cadmium foil activity was determined as follows:

$$
S_{a}=C-A / \frac{I_{\infty}}{I_{\text {eff }}(\text { bare foil })}
$$

where:

$\mathrm{S}_{\mathrm{a}}=\mathrm{Subcadmium}$ foil activity per gram at reactor shutdown $C=$ Bare foil activity per gram at reactor shutdown $A, I_{\infty}$ and $I_{e f f}$ are defined for the previous equation

This expression reduces to the following equation:

$$
S_{a}=C-A \sqrt{\frac{\pi R^{2} p}{\pi R^{2} p=2 N W}}
$$

bare foil.

where the expression under the square root sign is for the

The thermal flux is then calculated from:

$$
S_{a}=\Sigma_{a} \phi V\left(1-e^{-\lambda t}\right)
$$

where:

$\Sigma_{a}=$ Macroscopic absorption cross section

$\phi=$ Neutron flux

$\mathrm{V}=$ Volume of 1 gram foil weight

$\lambda=$ Radioactive decay constant

$t=$ Foil exposure time in the reactor 
1. Pincock, G. D., Kunze, J. F., "Cavity Reactor Critical Fxperiment, Volume I," General Electric Company, NMPO-ITS, September 6, 1967 (NASA-CR-72234).

2. Pincock, G. D., Kunze, J. F., "Cavity Reactor Critical Fxperiment, Volume II," General Electric Company, INSP-ITS, May 3I, 1968, (NASA-CR-72415).

3. Pincock, G. D., Kunze, J. F., "Cavity Reactor Critical Experiment, Volume III," General Electric Company, NSP-ITS, September, 1968, (NASA-CR-72384).

4. Pincock, G. D., Kunze, J. F., "Cavity Reactor Critical Experiment, Volume IV," Idaho Nuclear Corporation, October, 1969, IN-1336 (NASA-CR-72550).

5. Pincock, G. D., Chase, P. I., "Cavity Reactor Critical Experiment, Volume V," Idaho Nuclear Corporation, November, 1969, IN-1340 (NASA-CR-72577).

6. Henderson, W. B., Kunze, J. F., "Analysis of Cavity Reactor Experiments, "Ceneral Electric Company, NSP-ITS, January, 1969 (NASA-CR-72484).

7. Ianzo, D. C., "A Flow Experiment on a Curved-Porous-Wall GasCore Reactor Geometry," Nuclear Applications and Technology, Vol. 8, No. 1, page 6, January 1970

8. Kelber, C. N., "Resonance Integrals for Gold and Indium Foils", Nucleonics, August, 1962, p. 162.

9. Dalton, G. R. and Osborne, R. K., "Flux Perturbations by Thermal Neutron Detectors", Nuclear Science and Engineering, Vol. 2, p. 198 February, 1961.

10. Brown, H. L. and Connolly, T. J., "Cadmium Cutoff Energies", Nuclear Science and Engineering, Volume 24, p. 6, January, 1966.

11. Private Communication, Letter C. L. Beck to R. S. Marsden "Input Description of SCAMP Codes ( $S_{\mathrm{n}}$ Codes for the Analysis of Multigroup Problems)" January 19, 1968.

12. Masters, C. F., Cady, K. B., "A Procedure for Evaluating Modif'ied Pulsed-Neutron-Source Experiments in Subcritical Nuclear Reactors," Nuclear Science and Engineering, Volume 29, No. 2, August, 1967.

13. Simmons, B. E., King, J. S., "A Pulsed Neutron Technique for Reactivity Determination," Nuclear Science and Engineering, Volume 3, page 595,1958 . 
14. Idaho Nuclear Corporation Computer Code, Author G. E. Putnam. Reference letter Put-5-70, Aug. 7, 1970, SCAMP Consolidation and Modification.

15. "PHROG - a Fortran IV program to Generate Fast Neutron Spectra and Average Multigroup Constants" by R. L. Curtis, F. J. Wheeler, R. A. Grimesey, G. L. Singer. (to be published).

16. "INCITE - A Fortran IV program to Generate Thermal Neutron Spectra and Multigroup Constants Using Arbitrary Scattering Kernels" by R. I. Curtis and R. A. Grimesey, November, 1967.

17. Herwig, L. O. and Latham, T. S., "Nuclear Characteristics of Large Reflector-Moderated Gaseous-Fueled Cavity Reactors Containing Hot Hydrogen", American Institute of Aeronautics and Astronautics, Volume 5, No. 5, pp 930-937, May 1967. 
Aluminum, worth - 13, 14

Analytical, Correlation - 54, 55

Benchmark - 1, 67

Catcher foils - 5, 14, 20,30,36, 38, 58

Cavity $\operatorname{tank}-3,6,7$

Configurations -

$\# 1-1,2,12,62,63$

$\# 2-1,2,28,62,63$

$\# 3-1,2,35,62,63$

Control -

systems - 3, 12, 47

methods - 1, 47, 48, 49,67

rod worth, curves, worth - 12, 19, 24, 53

Core tank - 3, 6, 7

Critical mass - 1, 59

Delayed neutrons -

parameters $-4,5,9$

Dimensions -

reactor $-1,3,7,8,11$

Deuterium $\left(\mathrm{D}_{2} \mathrm{O}\right)-3,5,47$

Fuel $\left(\mathrm{UF}_{6}\right)-2,4,5,14,28,35,42,55,57,59,61$

Hydrogen, propellant - 1, 2, 35, 58, 67

Inverse multiplication - 17, 23

Mean Free Path (see stainless steel)

Multiplication factor, calculated - 1

Nuclear model - 16

Perturbations -

from spherical - 1, 67

Polyethelene $\left(\mathrm{CH}_{2}\right)$ see configuration $\# 2$

mass in cavity - 28

worth - 14, 28

Polystyrene (see configuration \#2)

mass in cavity -28

worth $-4,28$ 
Power distribution

$$
\begin{aligned}
& \text { configuration } \# 1-25 \\
& \text { configuration } \# 2-29 \\
& \text { configuration } \# 3-36
\end{aligned}
$$

Pulsed neutron

$$
\text { methods - 1, 47, 48, } 49
$$

Reactivity worths

see aluminum

see stainless steel

see polyethelene

see polystyrene

References - 70,71

Reflector-moderator 3, (see Deuterium)

Resonance foils

Gold - 5, 15, 21, 26, 29, 31, 33, 36, 39, 44

Indium - 15, 22, 36, 40

Manganese - 15, 22, 36, 41

Sensor well - 3, 14

Spectrum - 37, 46, 58, 64, 65, 66

Stainless steel

mass on cavity wall - I, 2

reactivity worth $-13,35,58$

Temperature coefficient - 5, 57

Thermal absorber

$$
\text { (see stainless steel) }
$$

Thermal neutron flux - 5, 21, 22, 27, 31, 34, 39, 40, 41, 45

Transport theory $-1,2,54,58,64,65,66$ 